

\title{
NOTICE
}

This report was prepared as an account of work sponsored by the United States Government. Neither the United States nor the United States Nuclear Regulatory Commission, nor any of their employees, nor any of their contractors, subcontractors, or their employees, makes any warranty, express or implied, or assumes any legal liability or responsibility for the accuracy, completeness or usefulness of any information, apparatus, product or process disclosed, or represents that its use would not infringe privately owned rights.

\author{
PACIFIC NORTHWEST LABORATORY \\ operated by \\ BATTELLE \\ for the \\ UNITED STATES DEPARTMENT OF ENERGY \\ Under Contract EY-76-C-06-1830
}

Printed in the United States of America
Available from
National Technical Information Service
United States Department of Commerce
5285 Port Royal Road
Springfield, Virginia 22151
Price: Printed Copy \$_" Microfiche $\$ 3.00$

*Pages




\title{
INTERIM REPORT
}

\section{A FIELD AND MODELING STUDY OF WINDBLOWN PARTICLES FROM A URANIUM MILI. TAILINGS PILE.}

\author{
L. C. Schwendiman \\ G. A. Sehme 1 \\ T. W. Horst \\ C. W. Thomas \\ R. W. Perkins
}

Apri1 1979

Prepared for the

Office of Nuclear Regulatory Research

Division of Safeguards, Fuel Cycle and

Environmenta? Research

U.S. Nuclear Regulatory Commission

Washington, DC 20555

under a Related Services Agreement

with the U.S. Department of Energy

Contract EY-76-C-05-1830

FIN No. B2095-9

NOTICE

This document was prepared primarily for preliminary or internal use. It has not received full review and approval. Since there may be substantive chenges, this document should not be considered final.

Pac if ic Northwest Laboratory

Richland, Washington 99352 
-

, 


\section{ABSTRACT}

Progress on a research study sponsored by the U.S. Nuclear Regulatory Comassion is presented. The objective of this study is to develop an understanding of the nature and transport of solid particles from a uranium mill tailings pile. The intent is to develop and verify suspension and transport models that may be useful when applied more genericaliy to similar spoil piles of uranium extraction tailings. A field study is reported, showing that for a carbonate-leach-process mill tailings pile in the Grants, New Mexico region much of the residual radioactive constituents in the tailings is found associated with particles $7 \mathrm{\mu m}$ in diameter and smaller. As the tailings material dries, particle attachment and aggregation occurs with the result that radioactive constituents become associated more with larger particles. Soil samples taken at surface and subsurface on radial lines extending from the tajlings pile for 5 miles showed the distribution of radium-226 and other radionuclides in the soil. After corrections for background were made, it was shown that the ${ }^{226} \mathrm{Ra}$ deposited on the soil was distributed in such a manner that about $1.6 \mathrm{Cj}$ of radon-222 per day enters the atmosphere from this secondary source.

The suspension and transport of particles were studied using an array of sampling towers and wind speed and velocity instrumentation that signaled designated samplers at upwind and downwind locations to operate when wind direction and speed criteria were satisfied. Flux of particles in various size ranges was determined as a function of wind speed. The radionuclide content of airborne particles as a function of particle size was measured for some samplers. A general conclusion was reached that a significant fraction of airborne radioactive material is associated with respirable particles. Additional field experiments are continuing.

Suspension and transport models and their application to this problem are under investigation. Several curves are presented to show how deposition and downwind concentration are related to wind speed, distance downwind, and particle mass or size. Continuing study will apply site 
meteorology to estimate airborne concentrations downwind, using pile release fluxes as the primary source data. An attempt will be made to reconcile field data and transport models. 


\section{CONTENTS}

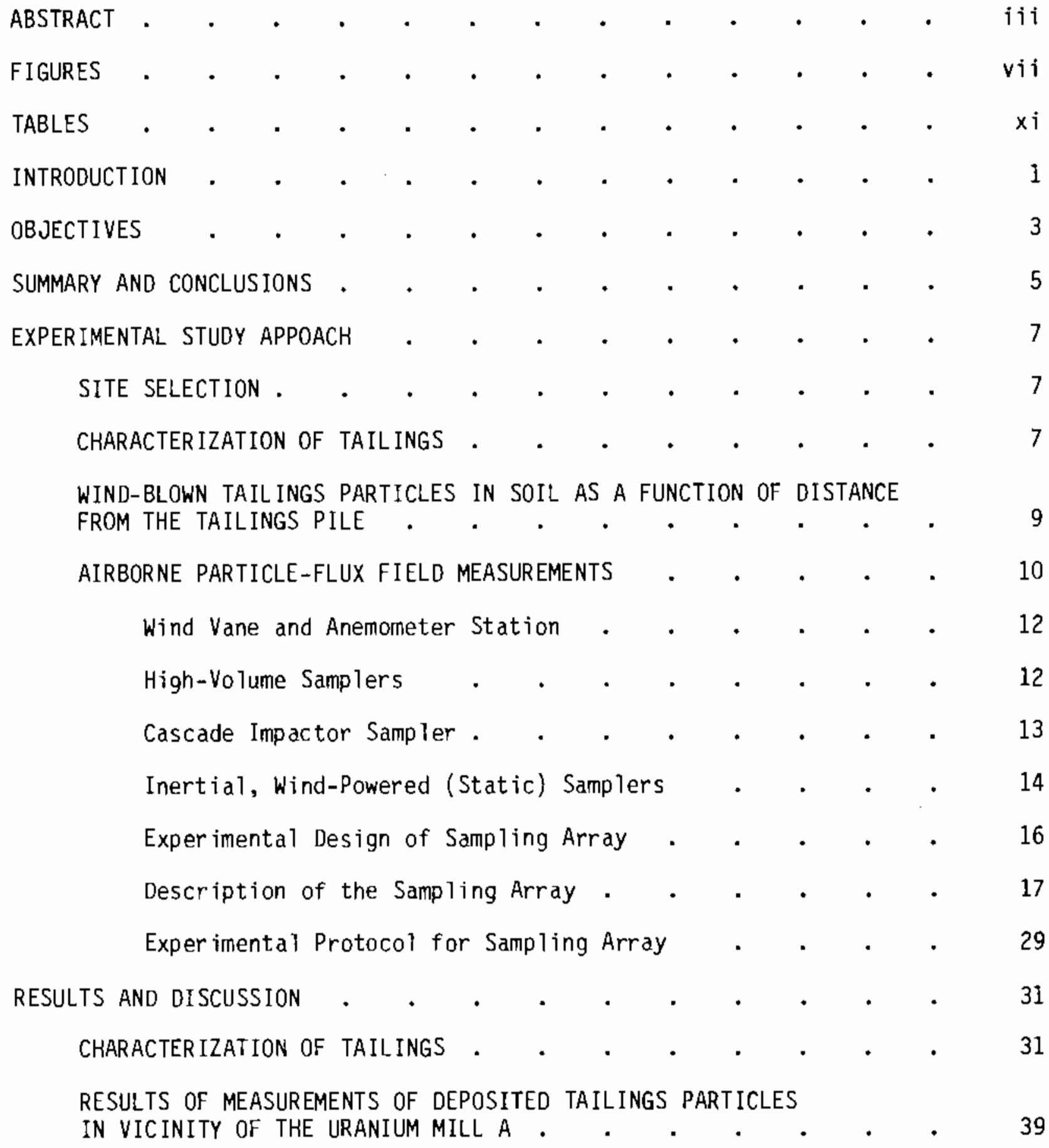




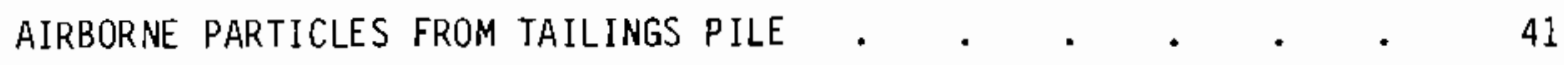

Radionuclide Concentrations . . . . . . . . . . 41

Radionuclide Concentration (Activity Density) $\mathrm{dpm} / \mathrm{g}$ of

Airborne Particles . . . . . . . . . . . 49

Airborne Particle Concentrations . . . . . . . 56

Estimation of Mass Fluxes for Selected Particle

Diameters. . . . . . . . . . . . 64

Short-Term Mass Flux Variations . . . . . . . . . 70

Mass Fluxes--Air Impact Collectors . . . . . . . . 71

Particle Fractionation Between Inlet and Filter-Isokinetic

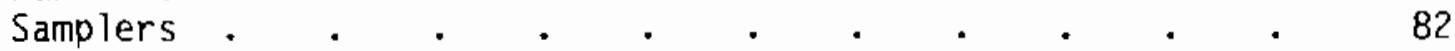

AIRBORNE PARTICLE DATA-ODISCUSSION AND INTERPRETATION . • . . 86

ATMOSPHERIC TRANSPORT PREDICTION

INTRODUCTION

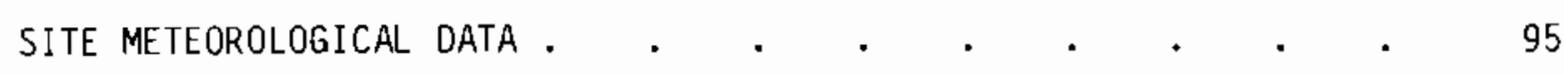

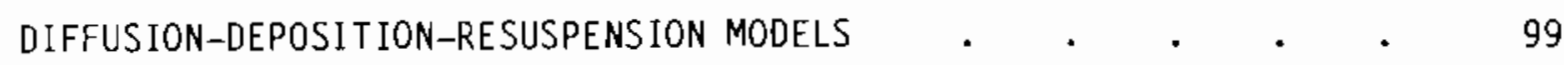

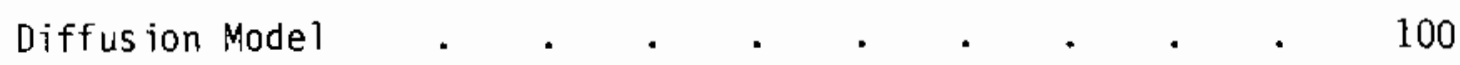

Deposition Model for Nonsettling Particles . . . . 101

Deposition Model for Settling Particles . . . . . . 104

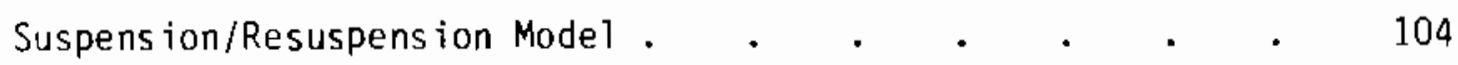

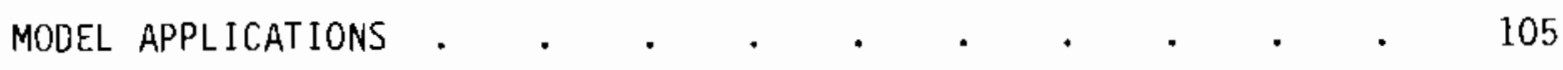

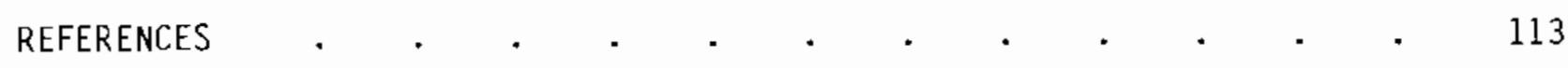

APPENDIX A - METHODS OF SAMPLING AND INSTRUMENTAL TECHNIQUE FOR THE
MEASUREMENT OF URANIUM AND URANIUM DAUGHTERS $\bullet \quad \cdot \quad \cdot \quad \cdot \quad \cdot \quad \cdot \quad$ A-1

APPENDIX B - BRIEF CHRONOLOGY OF FIELD STUDY . 


\section{FIGURES}

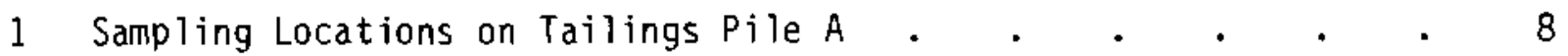

2 Soil Sampling Locations Around Tailings Pile A . . . . . 11

3 High-Volume Isokinetic Sampler - Inlet Closed . . . . . 13

4 High-Volume Isokinetic Sampler - Inlet Open . . . . . . . 14

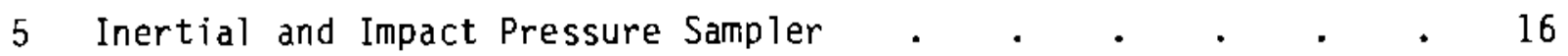

6 Air Sampling Arrays . . . . . . . . . . . . . . . . . 18

7 Background Site A, with View Towards Southwest Away from Uranium Mill Tailings Pile $. \quad . \quad . \quad . \quad . \quad . \quad . \quad . \quad . \quad . \quad 20$

8 Background Site A, with View North Towards Pile . . . . . 21

9 Site Bl with View Towards Northwest . . . . . . . . . 22

10 Site $B 2$ with View Towards Northwest. Note at B2 Cascade Impactors with Cyc lone Preseparators are on Dike. In This View, Lowest Isokinetic Samplers on B2 tower are Just Below Top of Dike . . . . . . . . . . . . . $\quad$. 23

11 Site B2 with View Towards Southwest. At B2 Cascade Particle Impactors with Cyclone Preseparators are on Dike, Whereas Tower is Located on Flat Fines Surfaces of Pile $\quad$. $\quad$. $\quad$. 24

12 Site $\mathrm{C}$ with View Towards Southwest. At Site C Sampling Tower is Centrally Located Between Virtual Impactor on Left and Particle Cascade Impactors with Cyclone Preseparators on Right. Site Bl is in Background Between Virtual Impactor and Sampling Tower. . .

13 A North Fence Samping Site with View Towards Northwest Showing Isokinetic Sampler and South- and North-Facing Air Impact Flow

Particle Collectors . . . . . . . . . . . . . 27

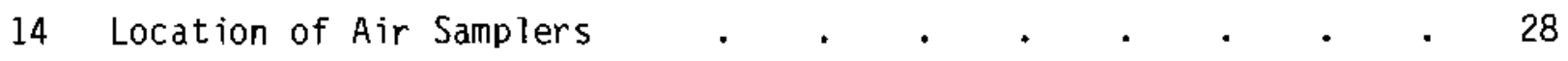

15 Electrically-Powered Downwind Air Samplers . . . . . . 28

16 X-Ray Fluorescence Spectrum of Soil Taken Five Miles from Tailings Pile A at a Depth of One Foot . . . . . . . . . . 35 
17 X-Ray Fluorescence Spectrum of Tailings Material from Tailings

Pile A . . . . • . . • . • . 36

18 Isopleths of Radium Concentrations in Environs of Tailings

Pile A . . . . . . . . . . . 40

19 Depth Distribution of $210 \mathrm{~Pb}$ in the Environs of Tailings

pile A . . . . . . . . . . . . 41

20 Airborne ${ }^{238} \mathrm{U}$ Concentrations at $1.5 \mathrm{~m}$ as a Function of Particle Diameter During August 10 to September 8, 1977 - Sampling All Winds with Direction $211^{\circ} \pm 30^{\circ}$ at Site A . . . . . . 44

21 Airborne ${ }^{230} \mathrm{Th}$ Concentrations at $1.5 \mathrm{~m}$ as a Function of Particle Diameter During August 10 to September 8, 1977 - Sampling All Winds with Direction $211^{8} \pm 30^{\circ}$ at Site A . . . . . .

22 Airborne ${ }^{226} \mathrm{Ra}$ Concentrations at $1.5 \mathrm{~m}$ as a Function of Particle Diameter During August 10 to September 8, 1977 - Sampling All Winds with Direction $211^{8} \pm 30^{\circ}$ at Site A . . . . . 46

23 Airborne $210 \mathrm{~Pb}$ Concentrations at $1.5 \mathrm{~m}$ as a Function of Particle Diameter During August 10 to September 8, 1977 - Sampling A11 Winds with Direction $211^{\circ} \pm 30^{\circ}$ at Site A . . . . . .

$24238 \mathrm{U}$ Concentration on Airborne Solids as a Function of Particle Diameter . . . . . . . . . . 50

$25 \quad 230$ Th Concentration on Airborne Solids as a Function of Particle Diameter . . . . . . . . . . 51

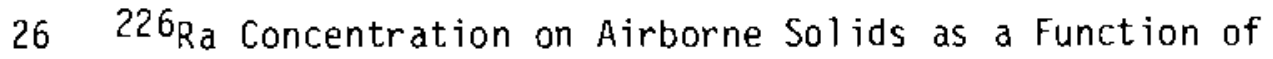
Particle Diameter. . . . . . . . . . 52

$27 \quad 210 \mathrm{pb}$ Concentration on Airborne Solids as a Function of Particle Diameter . . . . . . . . . . 53

$28238 \mathrm{U}$ Concentration on Airborne Solids as a Function of Particle Diameter . . . . . . . . . . . 54

29230 Th Concentration on Airborne Solids as a Function of Particle Diameter

$30 \quad{ }^{22} 6_{\mathrm{Ra}}$ Concentration on Airborne Solids as a Function of Particle Diameter . . . . . . . . . . 
$31210 \mathrm{~Pb}$ Concentration on Airborne Solids as a Function of

32 Average Airborne Fluxes and Concentrations During August 10 to

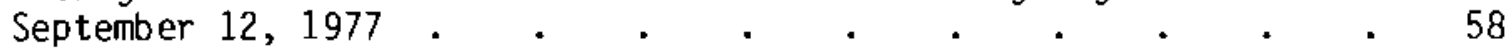

33 Airborne Solid Concentrations at Each Site During November 19 to December 8, 1977 . . . . . . . . .

34 Airborne Solid Concentrations at Each Site During February 21 to March 27, 1978 . . . . • • . . • . . 62

35 Airborne Solid Concentrations at Each Site During March 30 to April 17, 1978 . . . . . . . . . .

36 Airborne Solid Concentrations at Each Site During May 26 to

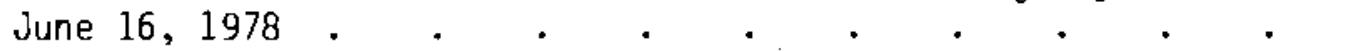

37 Airborne Sol id Concentrations at Each Site During June 16 to June 26,1978 .

38 Airborne Mass Flux as a Function of Particle Diameter at Site B2 During November 19 to December 8, 1977 . . . . .

39 Airborne Mass Flux as a Function of Particle Diameter at Site $C$ During November 19 to December 8, 1977 . . . . . . 68

40 Airborne Mass Flux as a Function of Particle Diameter at Site B1 During November 19 to December 8, 1977 ..$\quad$. . . . 70

41 Average Airborne Fluxes Toward North . . . . . . 71

42 Airborne Mass Flux from Air Impact Flow Particle Collectors November 19 to December 8,1977 . . . . . . . 72

43 Total Airborne Mass Flux From Air Impact Flow Particle Collectors During March 30 to April 17, 1978 . . . . . 73

44 Total Airborne Mass From Air Impact Flow Particle Collectors During April 8 to May 29, 1978 . . . • . . . 74

45 Total Airborne Mass Flux From Air Impact Flow Particle Collectors During May 26 to June 26, 1978 . • • • . 75

46 Total Airborne Mass Flux From Air Impact Flow Particle Collectors During June 28 to August 9, 1978 . . . . . 76 
47 Percent Airborne Solids Collected on Filter at Each Site During November 19 to December 8, 1977 . . . . . .

48 Percent Airborne Solids Collected on Filter at Each Site During February 21 to March 27, 1978 . . . . . .

49 Percent Airborne Solids Collected on Filter at Each Site During March 30 to April 17, 1978 . . . . . .

50 Annual Distribution of Wind Direction At Two Sites in New Mexico

51 Annual Distribution of Wind Direction for High Wind Speeds at Two Sites in New Mexico. . . . . . . . . .

52 The Dependence of Airborne Contamination on Particle Size . . 106

53 The Dependence of Airborne Contamination on Source Height . . 108

54 The Dependence of Airborne Contamination on Friction Velocity . . . . . . . . . . . . . 109

55 The Dependence of the Azimuthal Distribution of Airborne Contamination on Resuspension Rate . $. \quad . \quad . \quad . \quad . \quad . \quad 110$

A.1 Coring Device for Five-Centimeter Core Samples . . . . . A-2 


\section{TABLES}

1 Variation of Radionuclide Concentration with Increased Depth in Core Samples from Tailings Pile A.$\quad$..$\quad$. 32

2 Radionuclide Concentration in Tailings Pile B $B \quad$. . . . 33

3 Radionuclides in and Around Tailings Pile C . . . . . . . 33

4 Uranium and Selenium Concentration on Sediment Core from

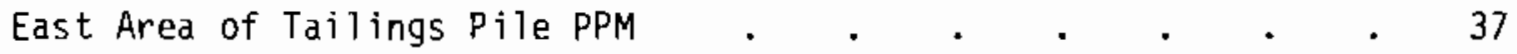

5 Particle Size versus Radionuclide Composition of Tailings from

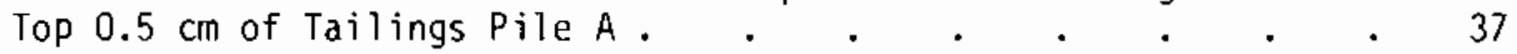

6 Particle Size versus Radionuclide Composition of Tailings in

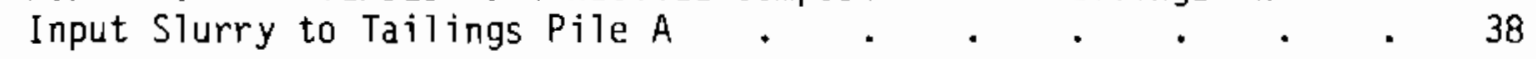

7 Radon Emission Rate from Tailings, Secondary Sources and Background Areas . . . . . . . . . . . 42

8 Particle-Size Distributions and $210 \mathrm{~Pb}$ Concentrations in
Surface Soil Near Tailings Pile B. . . . . . . 42

9 Average Airborne Mass Flux Per M Width During February 21 to

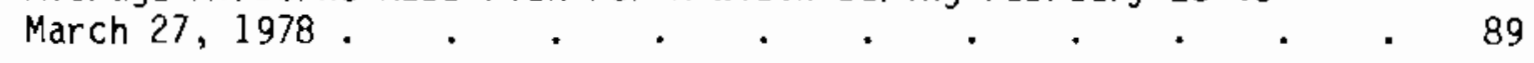

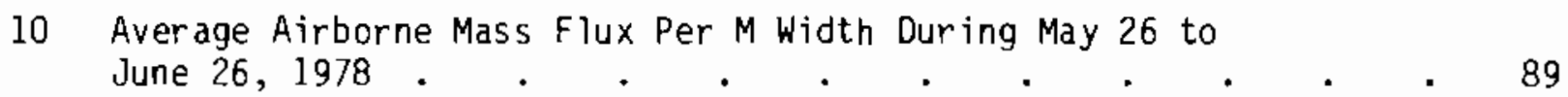

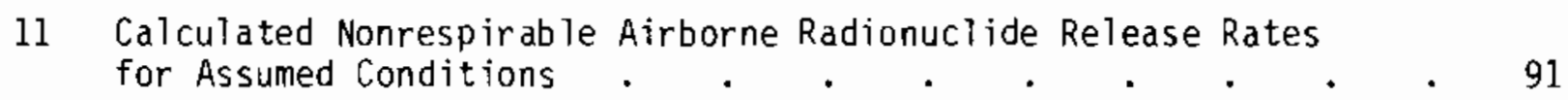

12 Calculated Respirabie Airborne Redionuclide Concentrations and

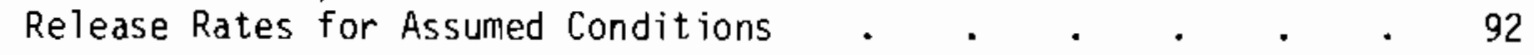

A.1 Radionuclides, Photon Energies, and Abundance of Photons . . A-1 


\section{INTRODUCTION}

One of the potential environmental impacts of uranium extraction from the ore is the windblown particles from the uranium mill tailings disposal sites. These tailings are the fine "sand" that is produced when the ore is crushed and then rod-milled. The resulting fine, ground sand is subsequently leached either with dilute sulfuric acid or alkaline carbonate that dissolves any uranium present on the grains. Since virtually all the uranium and daughter products are associated with a thin coating on the sand grains, the ore mi1ling process is designed to break up and remove this coating, thus permitting ready access of the leach chemicals. For efficient dissolution of uranium, the alkaline leach process requires a finer breakup of the particles than does the acid leach process.

Following uranium extraction, the sand and very fine particles from the breakup of the active coating is slurried to a disposal site--the tailings pile--where carrying water is allowed to form a pond over some portion of the tailings area. The very fine particle fraction is called "slimes." Evaporation and infiltration are the principal modes of water disposal. Some water may be recirculated as process water.

Each uranium mill has a more or less unique method for tailings disposal, but as all tailing piles dry out, they produce windblown particles under some conditions. The particles blown from the piles are of concern because of the presence of long-1ived thorium-230, uranium-238, and radium-226 and its daughter products on particles of respirable size. Moveover, the suspension into the air and deposition of radium-containing particles over a long period of time produce a secondary source of radon which could be significant.

Estimates have been made of airborne release of particles from a tailings pile (Sears et al. 1975; Mills, Dahlman and 01son 1974); however, these estimates have required use of theoretical principles and models of aerodynamic behavior of particles, as well as greatly simplified assumptions about the nature of the surface. Because of meager theoretical and experimental 
information relating to airborne movement of particles from an operational tailings pile, the Office of Nuclear Regulatory Research, U.S. Nuclear Regulatory Commission, sponsored the study described here. The principal objective of the study is to develop methods for evaluating airborne particle releases, taking into account wind speed and the characteristics of the tai1ings particles. Whereas the authors anticipated that much information would be developed about airborne release of particles from the particular tailings pile(s) chosen for the field portion of the study, the "monitoring" of the particles airborne from a given tailings pile was not a primary objective. 


\section{OBJECTIVES}

A prime objective of this study is to determine the flux of airborne particles from an operating tailings pile as a function of wind speed. Supplemental objectives that relate closely to the principal objective are also identified:

- Characterize the particulate material on and near the surface of the tailings pile.

- Determine the transport of particulate materials from the tailings pile that have been deposited on the soil surfaces surrounding the mill during the operating life of the mill chosen for the study. This information will hopefully support conclusions concerning the nature and flux of particles suspended from the tailings pile and the meteorology of the site.

- Explore transport and deposition models that, when applied to the problem at hand, will prove useful in predicting the fate of airborne particles from any tailings pile that can be characterized according to important parameter 5 .

- In relation to the preceding, apply the data to estimate radiological dose commitment to individuals who may be living in the vicinity of such a mill tailings pile. (This segment of the study is not discussed in this interim report.)

Progress made to date toward reaching these objectives is reported here. 
, 


\section{SUMMARY AND CONCLUSIONS}

This report describes progress on the characterization of particulate materials discharged on a uranium mill tailings pile and reports on the determination of the quantity, nature, and fate of material transported by the wind into the environment as a function of wind speed and other variables. Data developed are to be used to validate suspension, dispersion, and deposition models. Data have been obtained from extensive field measurements on and in the vicinity of the tailings pile. Important observations from these studies to data are the following:

- Residual radioactivity in the tailings slurried from the mill is asso-' ciated with particles of all sizes, but about $60 \%$ of the active material is found with the $<20 \mu \mathrm{m}$ fraction, which represents roughly $15 \mathrm{w} / 0$. As the sand is dewatered by infiltration and evaporation, a much higher fraction is associated with the larger particles by cementation and physical attachment.

- Core samples taken from the tailings pile show wide variability of radionuclide content with depth.

- Selenium was found in tailings at levels of 70 to $>200 \mathrm{ppm}$.

- Radium-226 and lead-210 could be distinguished from background out to a distance of about 5 miles in soil taken on radial lines from the tailings pile. Much of the active material was found in the first four cm depth. The ${ }^{226} \mathrm{Ra}$ present in the soil is estimated to generate about $1.6 \mathrm{Ci}$ per day above the natural background from soil.

- The concentration of radionuclides carried from the tailings pile was measured in several samples for various particle sizes, both in terms of $\mu \mathrm{Ci}$ per gram of soil and also $\mu \mathrm{Ci} / \mathrm{cm}^{3}$. These values were compared with samples obtained at a site upwind of the tailings pile. Concentrations of the order of $10^{-13}$ to $10^{-14} \mu \mathrm{Ci} / \mathrm{cm}^{3}$ were found compared to background of the order of $10^{-14}$ to $10^{-15} \mu \mathrm{Ci} / \mathrm{cm}^{3}$. 
- Data relating to radioactivity on airborne particles of various sizes show that the active material is distributed among all particle sizes, but a consistent relationship with particle sizes emerges for particles larger than about $100 \mu \mathrm{m}$, suggesting strongly that larger particles are carrying a "coating" of small particles.

- Estimates were made of average airborne mass flux and radioactive material flux over some periods of sampling for the background location and various downwind locations. Fluxes of larger particles ranged from 10 to several thousand grams per square meter per day depending on sampling height.

- There appears to be no consistent pattern emerging from these studies of wind pickup of particies as a function of wind speed. In some cases concentrations have increased with wind speed. In other instances, this has not occurred.

- Cross-wind variability was demonstrated and showed that a factor of 10 variability over distances of several hundred meters could be expected.

- Site meteorology was obtained and models for transport, deposition, and entrainment were developed, and some cases were calculated to show the relative importance of assumptions. These models are to be applied to current and future data to determine the applicability of the models to the mill tailings particles.

The work undertaken has illuminated the multidimensional features of the problem of windblown particles from uranium mill tailings piles. A considerable effort will be undertaken in an attempt to find conformance to models or to generate empirical relationships useful in determining the environmental consequences of uranium and its daughter products in blowing dust. 


\section{EXPERIMENTAL STUDY APPROACH}

\section{SITE SELECTION}

The Ambrosia Lake District in New Mexico was visited in the fall of 1976 and three tailings piles considered for the study. Mill A was using the carbonate leach process, whereas mills $B$ and $C$ were using the acid leach process. Samples of tailings materials from all three sites were obtained and taken to the laboratory for preliminary analysis and characterization.

Since an extensive air sampling network was required, available electrical power was needed within a reasonable distance to operate a widespread array of air samplers. The study was aimed at obtaining particle behavior data as a function of atmospheric and other physical parameters, rather than just finding out what a given tailings pile was delivering to the atmosphere. Therefore, the principal site for the study was selected not only on the basis of available power but also on the desirability of a relatively unobstructed, flat terrain in all directions from the tailings pile. Ideal conditions were not met by any of the three mill tailings piles, but Site A was judged to have the most advantages for the objectives of the study. The tailings pile and topographic features of the region are described in more detail in a later section of this report.

\section{CHARACTERIZATION OF TAILINGS}

An essential part of the study was to characterize the particle size distribution versus radiochemical composition of material on the tailings pile and of material that had been transported various distances from the pile by the prevailing winds. In designing this portion of the study, it was recognized that by determining the downwind distribution of tailings material, it might be possible to verify resuspension models being developed to predict this transport. The radial distribution of tailings material as a function of distance from the tailings pile could also serve as a basis for estimating secondary radon emission from this transported material. 
For the tailings pile, the sampling strategy was aimed at determining the particle size versus radiochemical composition of the pile. The tailings pile is continuously growing by addition of the slurry of tailings material that arrives from the mill via slurry lines. This slurry enters a truck-mounted centrifugal separator located on a top edge of the pile. This separator moves around the perimeter of one-half of the pile during about a six-month period. The coarse material from the separator forms the brim of the pile, whereas the fine material that remains in suspension in the centrifugal separator flows toward the center of the pile. The tailings pile at Mill $\mathrm{A}$ is schematically represented in Figure 1.

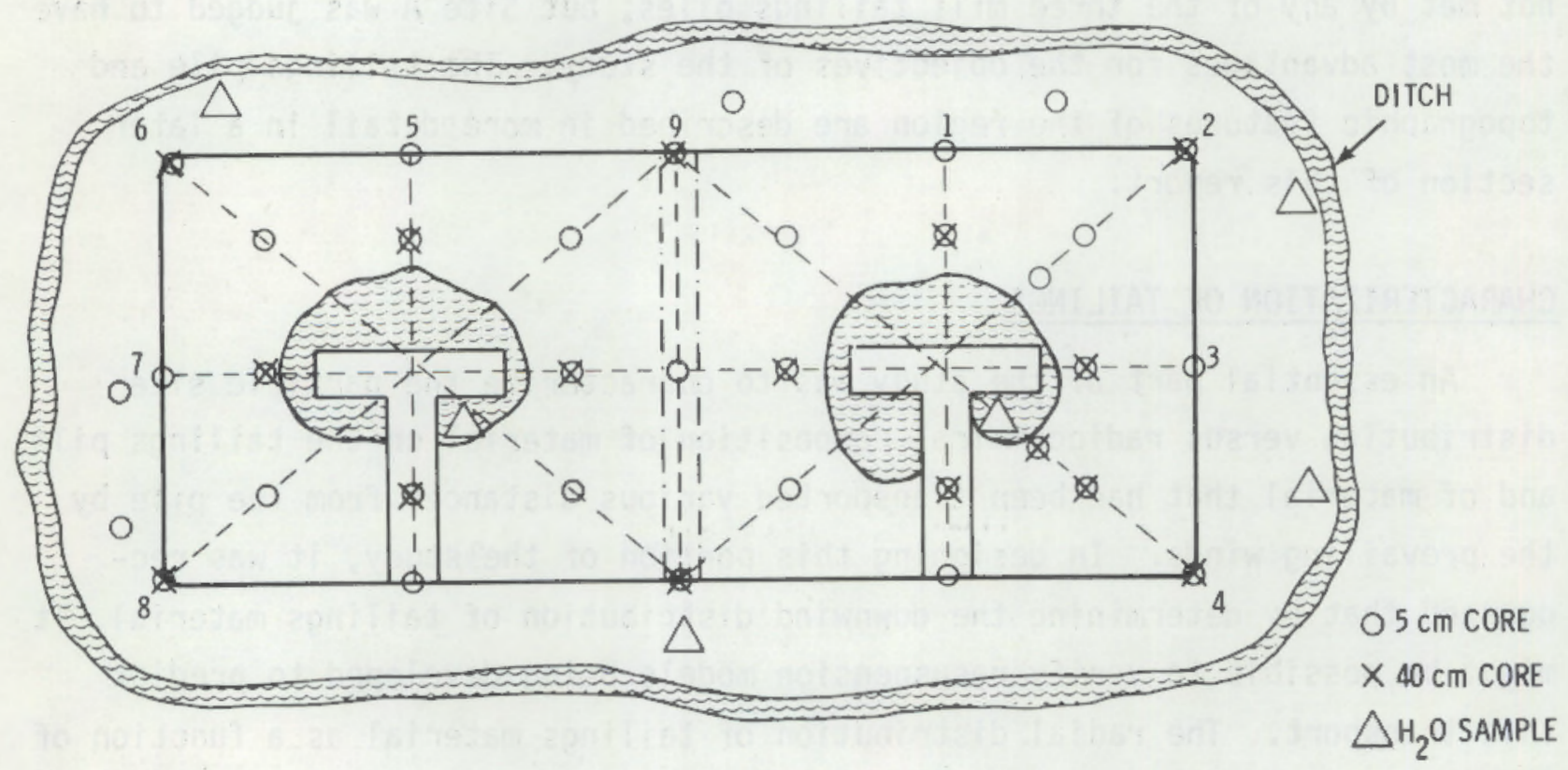

FIGURE 1. Sampling Locations on Tailings Pile A 
When the tailings pond formed by the slurry of fine material becomes relatively large, the tailings are deposited in the second half of the tailings pile for approximately a six-month period. This allows water in the first half of the tailings pile to either evaporate or be removed by seepage. A ditch surrounding the tailings pile collects water that seeps through the pile, and this water is recirculated into the plant as a vehicle for transporting additional tailings material to the tailings pile.

Sampling locations for the two halves of the tailings pile are shown in Figure 1. Here cores $5 \mathrm{~cm}$ and $40 \mathrm{~cm}$ in depth were collected. Analysis of sections of these cores indicated the degree of stratification of radioactivity as a function of depth. Analysis of water from the tailings pond and in the slurry indicated the degree to which various uranium daughters remained in solution.

The radionuclides of principal concern in the tailings material included uranium-234 and 238, thorium-230, radium-226, and lead-210. There was also interest in the trace element concentrations in the tailings material. Some samples were analyzed for potentially toxic materials, and results were compared with ambient soils in the area. All the measurements were made by nondestructive analyses; the techniques employed for these analyses are described in Appendix A.

In addition to the sampling and analysis at tailings pile $A$ and its environs, some initial measurements of the material from tailings piles $B$ and $C$ and also of soils from the environs of $C$ were made. These acid leach tailings were expected to be different in the uranium daughter ratios that reflect the chemical extraction process differences.

\section{WINDBLOWN TAILINGS PARTICLES IN SOIL AS A FUNCTION OF DISTANCE}

\section{FROM THE TAILINGS PILE}

In order to estimate the amount of tailings material that has been carried by the prevailing winds to the tailings pile $A$ environs, samples have been analyzed over the sample network (shown in Figure 2). 
The sampling strategy used for determining the amounts of tailings transported by the wind and redeposited included the collection of soil samples along the 16 compass directions extending outward from the pile up to distances of five miles. The sampling points and the type of sample collected at each of these points are shown in Figure 2. The primary sample collected consisted of a 5 -cm-deep core that was subsequently sectioned into $0.5-, 1.0-$, and 3.0-cm-deep layers for analysis. As indicated in Figure 2, 24-cm-deep cores were taken in some areas to determine the downward migration of deposited material. A few one-square centimeter surface samples were also taken to provide sufficient material for determining radioactivity as a function of particle size. Radionuclide measurements included the analys is of surface samples for uranium and its daughters, the analysis of core samples to determine the depth distribution of radioactivity, and the analysis of particle size to obtain some estimate of the material that had been transported.

\section{AIRBORNE PARTICLE-FLUX FIELD MEASUREMENTS}

In developing the design of the field experiment for flux measurement and characterization of airborne particles downwind of the tailings pile, consideration was given to characteristics of the tailings pile and the general distribution pattern of fine and coarser sand on the tailings pile. The geometry of the pile would determine the wind erosion characteristics, and the particle size of the sand would determine suspension and transport characteristics.

The tailings pile under investigation is built up gradually by slurrying the fine residues into a cyclone-type separator that delivers the water and slimes to the relatively flat area partially covered with water. The coarser sands are deposited wet in the perimeter dike surrounding the tailings. The more bluff, sloping sides present erodable surfaces, whereas the fines deposited across the more level surface of the tailings pile provide sources of finer resuspendable particles. Airborne particle samplers were selected and placed in an array to permit the particle concentration to be measured as a function of wind speed and height. Locations were chosen to permit 


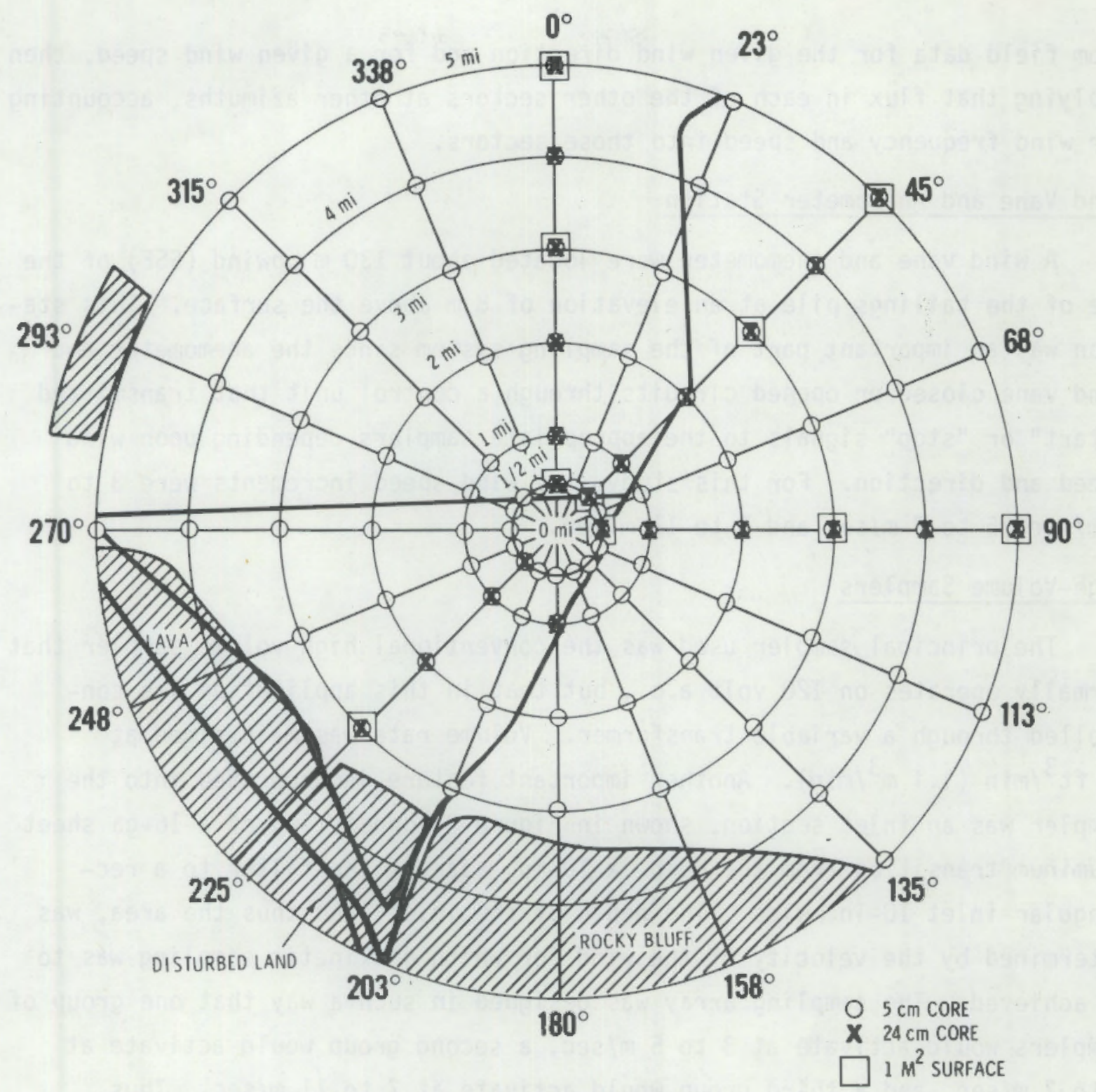

FIGURE 2. Soil Sampling Locations Around Tailings Pile A

reasonable representation of the blowing fine and coarse particles. At selected locations, particles were to be sampled with size-classification samplers that separate particles in several size ranges.

The prevailing wind direction is from SSW; hence, much of the sampling array was designed to operate only when the wind was from a sector of $60^{\circ}$ whose center was at $211^{\circ}$ (clockwise from north). To determine the flux in other sectors would merely require calculating the flux per unit sector 
from field data for the given wind direction and for a given wind speed, then applying that flux in each of the other sectors at other azimuths, accounting for wind frequency and speed into those sectors.

\section{Wind Vane and Anemometer Station}

A wind vane and anemometer were located about $130 \mathrm{~m}$ upwind (SSE) of the toe of the tailings pile at an elevation of $8 \mathrm{~m}$ above the surface. This station was an important part of the sampling system since the anemometer and wind vane closed or opened circuits through a control unit that transmitted "start" or "stop" signals to the appropriate samplers depending upon wind speed and direction. For this study, the wind speed increments were 3 to $5 \mathrm{~m} / \mathrm{sec}, 5$ to $7 \mathrm{~m} / \mathrm{sec}$ and 7 to $11 \mathrm{~m} / \mathrm{sec}$.

\section{High-Volume Samplers}

The principal sampler used was the conventional high-volume sampler that normally operates on 120 volt a.c., but that in this application was controlled through a variable transformer. Volume rate was maintained at $40 \mathrm{ft}^{3} / \mathrm{min}\left(1.1 \mathrm{~m}^{3} / \mathrm{min}\right)$. Another important feature incorporated into the sampler was an inlet section, shown in Figure 3, consisting of a 16-ga sheet aluminum transition from the 8 -in. $\times 10-i n$. size of the filter to a rectangular inlet 10-in. wide. The depth of the inlet, and thus the area, was determined by the velocity of the wind for which isokinetic sampling was to be achieved. The sampling array was designed in such a way that one group of samplers would activate at 3 to $5 \mathrm{~m} / \mathrm{sec}$, a second group would activate at 5 to $7 \mathrm{~m} / \mathrm{sec}$, and a third group would activate at 7 to $11 \mathrm{~m} / \mathrm{sec}$. Thus, samplers of each group would have an inlet section whose area for a sampling rate of $40 \mathrm{ft}^{3} / \mathrm{min}\left(1.1 \mathrm{~m}^{3} / \mathrm{min}\right)$ would be such that the inlet velocity would be nearly the same as the mid-velocity of the activated range. The inlet cross-sectional area was held constant for the first $7.5 \mathrm{~cm}$ towards the filter, after which the top of the 16-ga aluminum inlet was angled upward to fit over the filter holder. The distance between the inlet and the filter was $25 \mathrm{~cm}$.

An important feature of the high-volume isokinetic samplers was a solenoid-activated, hinged closure over the inlet that prevented wind-blown 


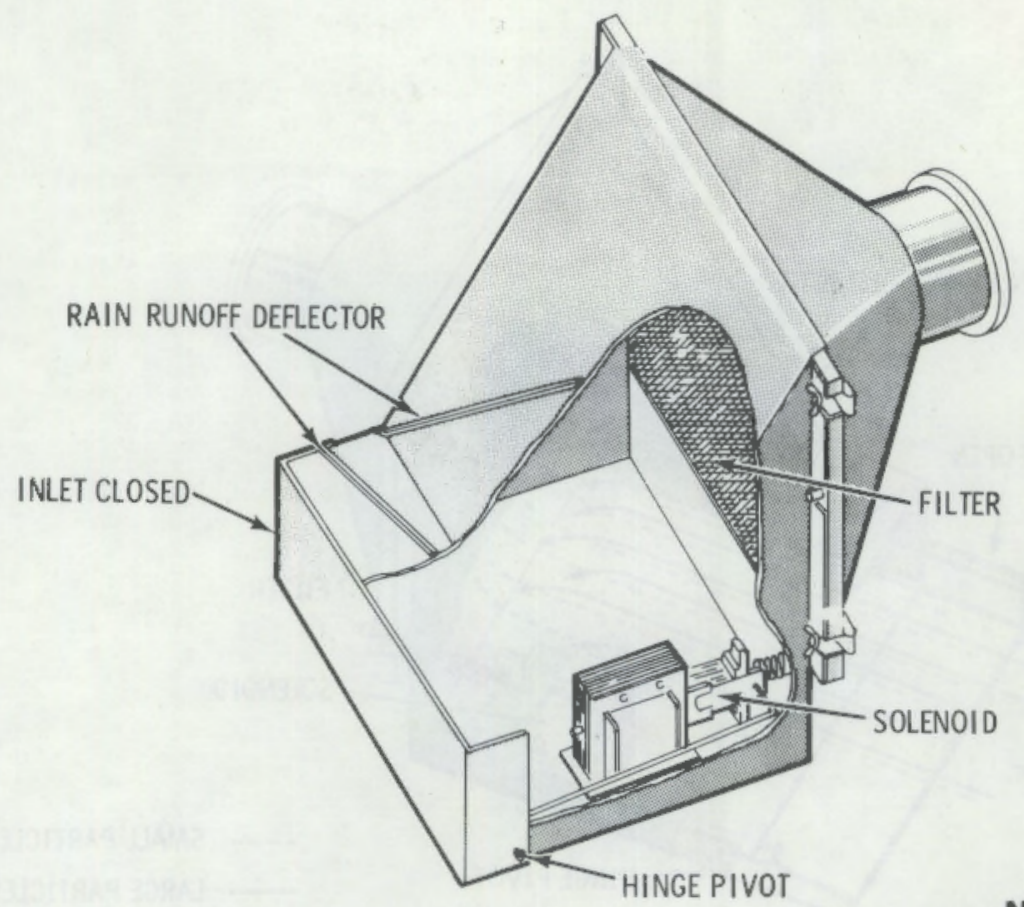

NEG. 7711495-10

FIGURE 3. High-Volume Isokinetic Sampler - Inlet Closed

particles from entering the sampler when the sampler was not operating. The solenoid was energized by the same signal that turned on the sampler. This closure was not provided during the initial sampling runs, but was later added to avoid possible entry by wind-driven particles.

The sampler inlet-transition ahead of the filter provided a nominal discriminator for "large" particles. Figure 4 shows the paths of motion for "large" and "sma11" particles. There is not a clean separation of sizes between those on the filter and those left in the inlet section, but these two fractions have been separated in this study by naming the particles collected in the inlet "large" and the particles collected on the filter "small."

\section{Cascade Impactor Sampler}

A second powered sampler for collecting airborne particulates was a particle cascade impactor (Sierra Instrument Company ${ }^{\circledR}$ ) sampling at $1.13 \mathrm{~m}^{3} / \mathrm{min}(40 \mathrm{cfm})$. A cyclone preseparator on the particle cascade

\footnotetext{
Use of brand name does not imply Battelle endorsement.
} 


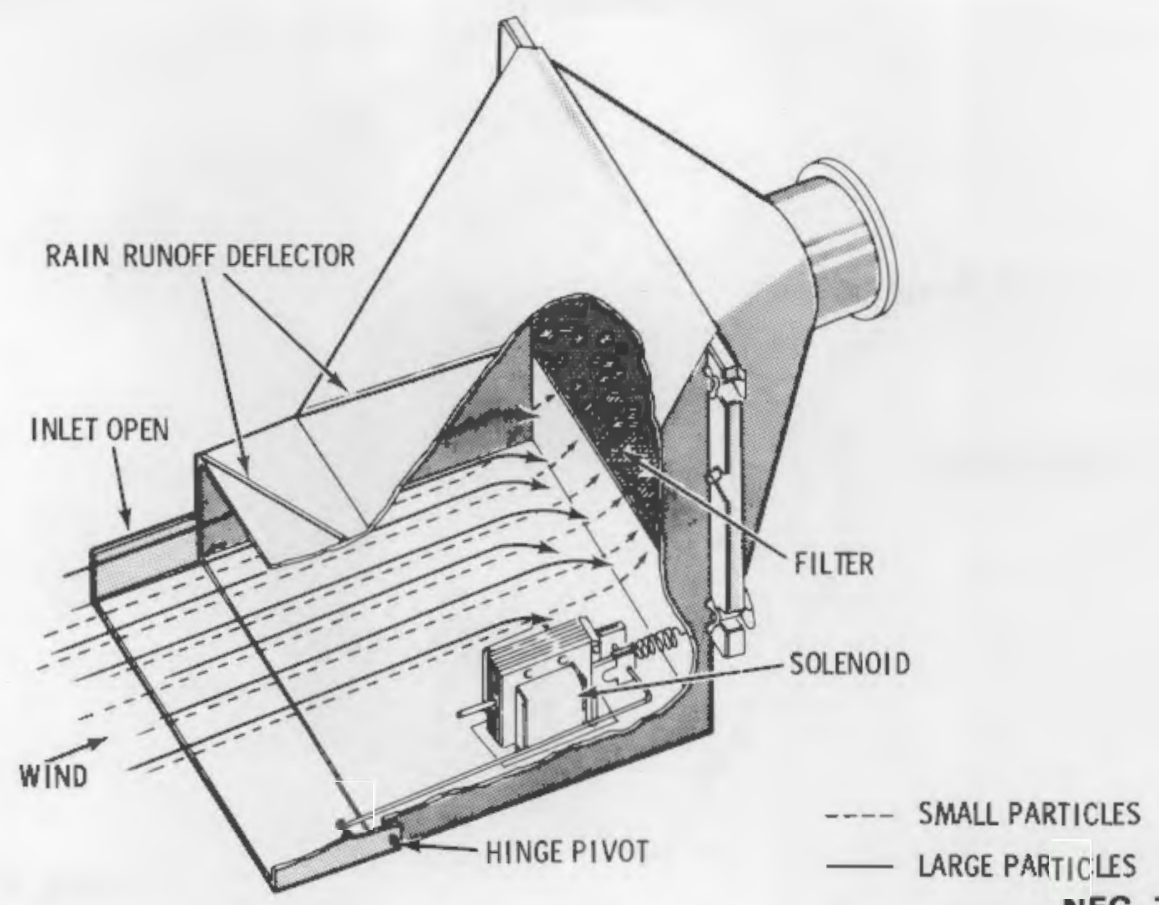

FIGURE 4. High-Volume Isokinetic Sampler - Inlet Open

NEG. 7711495-9

impactor was designed to prevent larger than respirable particles from entering the particle cascade impactor. Although large particle collection was minimized, some large particles did pass through the cyclone preseparator and were collected on the stages and filter of the cascade impactor.

Particle-size data were thus qualified, a rather universal feature of cascade impactors.

Inertial, Wind-Powered (Static) Samplers

A sampler was designed to supplement the electrically-powered samplers. In principal, the static sampler collects particles that are carried by inertia and are impacted into a thin-walled, cylindrical tube. If the tube were very short and open, the airflow rate through the tube would be isokinetic, corresponding to the undisturbed air blowing towards the sampler. In actuality, there is frictional air resistance in any such system, and any collector, such as a filter, would further reduce the inlet flow. A highly efficient filter would permit little air to pass. For the same air-impact pressure, the airflow rate through the tube can be increased by increasing 
the available area over which the impact pressure acts. Consequently, the outlet of the tube sampler was expanded to increase the airflow through the tube.

In designing the final sampler, dimensions were selected to match the availability of inexpensive component parts, and a low pressure-drop collector was selected. The inlet of the sampler consisted of a 7.6-cm (3-in.) diameter, thin-wall aluminum tube, cut off at an angle at the inlet to reduce the possibility of rain entering. Attached to the back end of the tube was a 23-cm-long cone made from a gasoline funnel. The cone terminated in a right, circular, metal-shell cylinder $25 \mathrm{~cm}$ in diameter and $7.6 \mathrm{~cm}$ long. Within the cylinder, two friction-fit, rubber-band tensioned embroidery hoops supported a monofilament nylon screen. The spacing and filament diameter were such that the hole size was very nearly $25 \mu \mathrm{m}$.

This filter assembly, with a sponge gasket cemented to the outer embroidery hoop, was pressed into the cylindrical shell until it contacted the cone where the circular metal shell joined the cone. The circular metal shell was closed with a sheet of thin plastic held in place with a rubber stretch cord. Air entering the inlet spilled out of a large slot in the lower half of the 8-cm-long cylindrical shell.

The static sampler is shown in Figure 5. Shown also are the nominal paths of motion of small and large particles, as well as the bulk of airflow through the collector and the outlet provided. Large particles do tend to collect at points ahead of the filter, demonstrating that air is slowed down in passing through the sampler. Because of their lower inertia, some small particles will be diverted with the air diverted around the sampler. Particles larger than $25 \mu \mathrm{m}$ are collected efficiently; smaller particles will be collected, but less efficiently.

Static samplers are fixed in direction--they do not turn into the wind. For this study, all samplers of this kind were faced into the prevailing wind direction $\left(225^{\circ}\right.$ ), yet wind approaching from up to $90^{\circ}$ in either direction from this prevailing wind direction carried some particles into the inlet with varying efficiency. In interpreting data from these samplers, it was assumed 


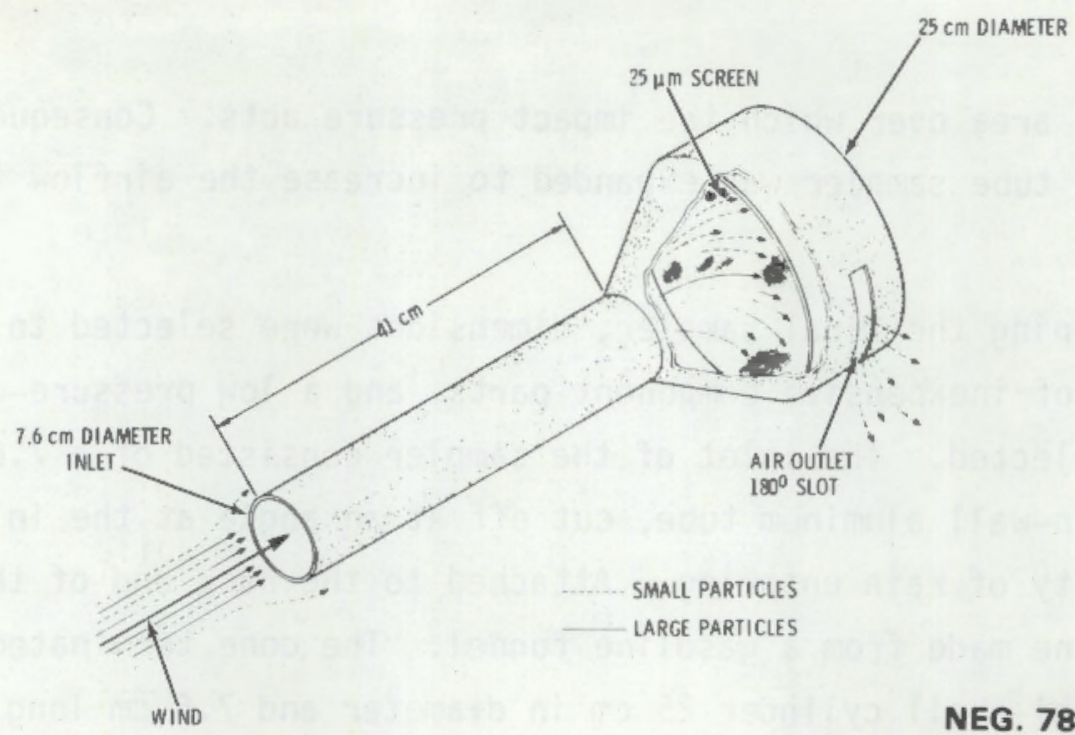

NEG. 7807917-3

FIGURE 5. Inertial and Impact Pressure Sampler

that nonisokinetic errors were minimal and that the wind speed was the average during the sampling period.

The sampling efficiency was investigated in a wind tunnel and found to be 70 to $80 \%$ for a wind of $4.5 \mathrm{~m} / \mathrm{sec}$ and for soil particles less than $44 \mu \mathrm{m}$ in diameter. (a) Presumably, efficiency would be as great or greater for larger particles. Complete data on the efficiency, under widely varying conditions, are not available. The samplers were used primarily to determine relative air loadings from point to point, and it was anticipated that these loadings could be normalized through comparison at a few locations by comparison with results from high-volume samplers alongside.

\section{Experimental Design of Sampling Array}

Samplers of the type described were deployed at an upwind station, on the tailings pile, at points a short distance downwind from the pile, and at sites a mile or more downwind. Some samplers were turned on selectively when the wind direction and wind speed were in the proper direction and speed. The running time of each sampler activated by the wind speed and direction sensor controller was taken at the end of the run. Samplers at considerable

(a) Particles used were fine road dust passing a 325 mesh screen. 
distances were to operate all the time when the wind was from the sector whose angle was the arc subtended by the tailings pile and were inactive at all other times.

Particle-size samplers at selected locations were also activated when wind direction and speed were satisfied.

Several static samplers were also set up at many locations to provide cross-wind variation and to yield data to supplement and to support particle flux measurements with the other sampling systems.

An experiment commenced by activating the system for an operation time believed to be long enough to obtain significant particulate material on each collector. Collectors were carefully removed, logged, and the collectors reweighed to obtain the net loading. Besides determining the gross weight of particles for a given time at a given height and for a given wind speed, data on particle size as a function of wind speed were determined. The change in airborne concentration with distance from the tailings pile was also determined.

During a rain the system was made inoperative by a moisture-activated sensor. Activation occurred when the sensor was dry. Description of the Sampling Array

The relative locations of airborne particle sampler equipment on and around the active mill tailings site are shown in Figure 6 --an aerial view of the tailings pile with symbols showing sampling locations and kinds of sampler. At the location illustrated, prevailing winds are from the southwest, whereas the secondary principal wind direction is from the northwest.

Three sampler types are shown in the symbol key. The high-volume isokinetic samplers are shown by triangles; particle cascade impactors are shown by squares; and air impact flow particle collectors are shown by circles. These air samplers were located at sampling tower heights from 0.3 to $15 \mathrm{~m}$ above the tower base, as shown alongside the line representing the tower at each site. 


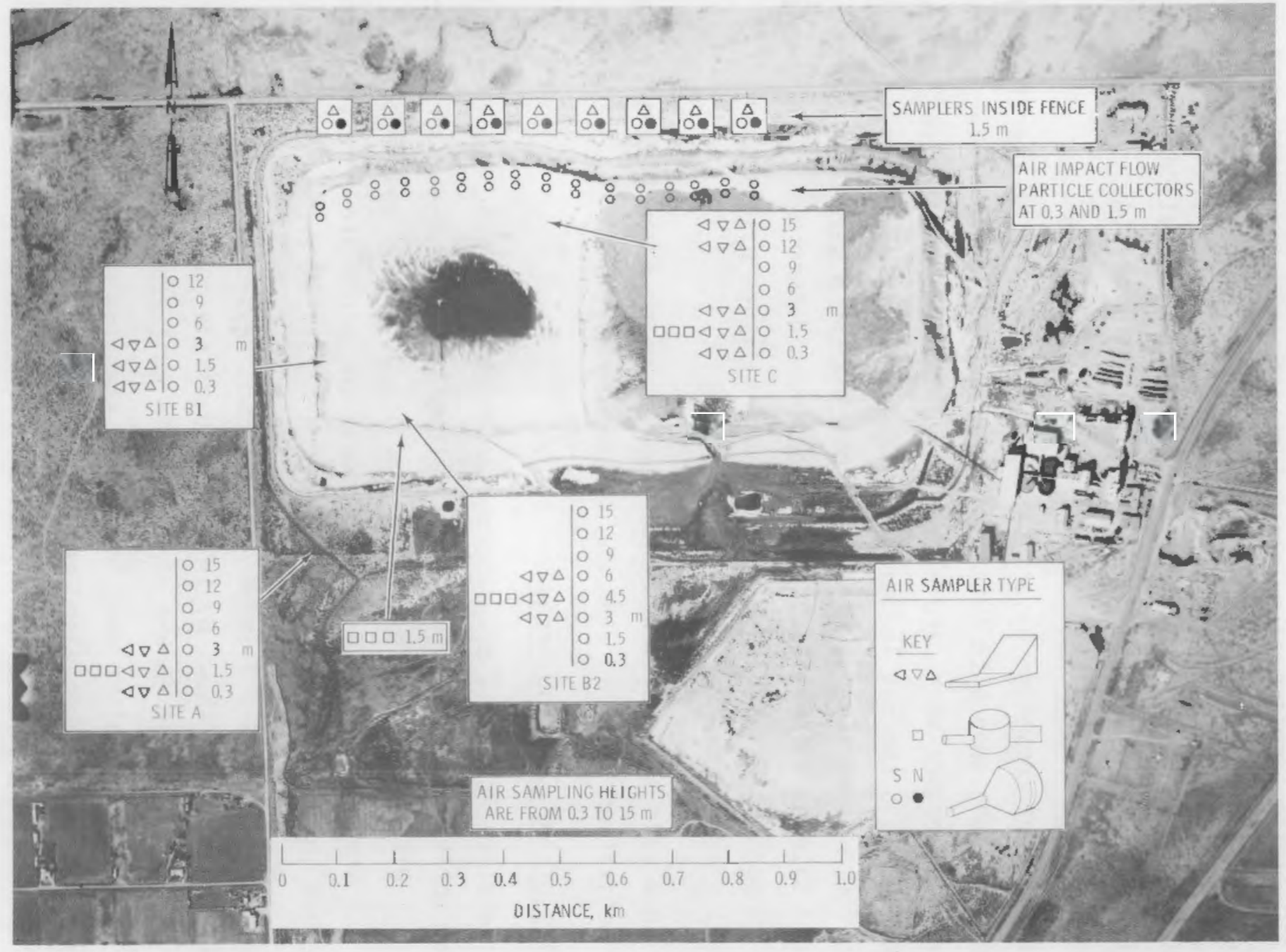

FIGURE 6. Air Sampling Arrays

NEG. 7808002-1 
There are six principal on-site sampling areas shown in this figure. These are Site $A$ (with two views 'shown in Figures 7 and 8 ); Site B1 (shown in Figure 9); Site B2 (with two views shown in Figures 10 and 11); and Site $C$ (shown in Figure 12), with the air impact flow collectors along the northern retaining dike and the samplers inside the north fence. Sites $\mathrm{B} 1$ and $\mathrm{B} 2$ were chosen to determine increased airborne concentrations caused by wind erosion from the sloping sides of the pile. Samplers on the tower at Site $C$ were to determine the suspension of mill tailings from the relatively flat surface between Sites $B$ and $C$. Between Site $C$ and the north fence, decreased airborne concentration with distance was studied.

Site $A$ was a background site at which wind speed and direction instrumentation was located. When wind was blowing from the southwest, selected air samplers on the 15-m tower were activated automatically to determine airborne solid concentrations in background air approaching the pile. There were three sets of isokinetic air samplers at the site, shown by the three orientations of the triangle symbol. One set of airborne particle collectors (triangles) was activated for wind speeds between 3 and $5 \mathrm{~m} / \mathrm{sec}$, the second between 5 and $7 \mathrm{~m} / \mathrm{sec}$, and the third between 7 and $11 \mathrm{~m} / \mathrm{sec}$ for the selected wind direction, which was centered around $225^{\circ}$. (a) Three cascade impactors are shown by the three square symbols. One cascade impactor was turned on for each of the three wind-speed increments.

Control signals for activating samplers at Site A were transmitted to Sites $B 1, B 2$, and $C$ for sampling at those sites for the three wind speed conditions at Site $A$. Wind-speed increment control signals were coordinated for all samplers inside the north fence in order that the north-fence air samplers operated when the wind direction requirement was satisfied, but when sampled winds were between 3 and $11 \mathrm{~m} / \mathrm{sec}$. A typical north-fence sampling station is shown in Figure 13.

These four sites, A, B1, B2, and C, were designed to permit measurement of airborne concentrations below $15 \mathrm{~m}$ and would give little information about

(a) The first three runs were made with direction controlled by $211^{\circ}$ with an activation range of $+35^{\circ}$ and $-35^{\circ}$. 


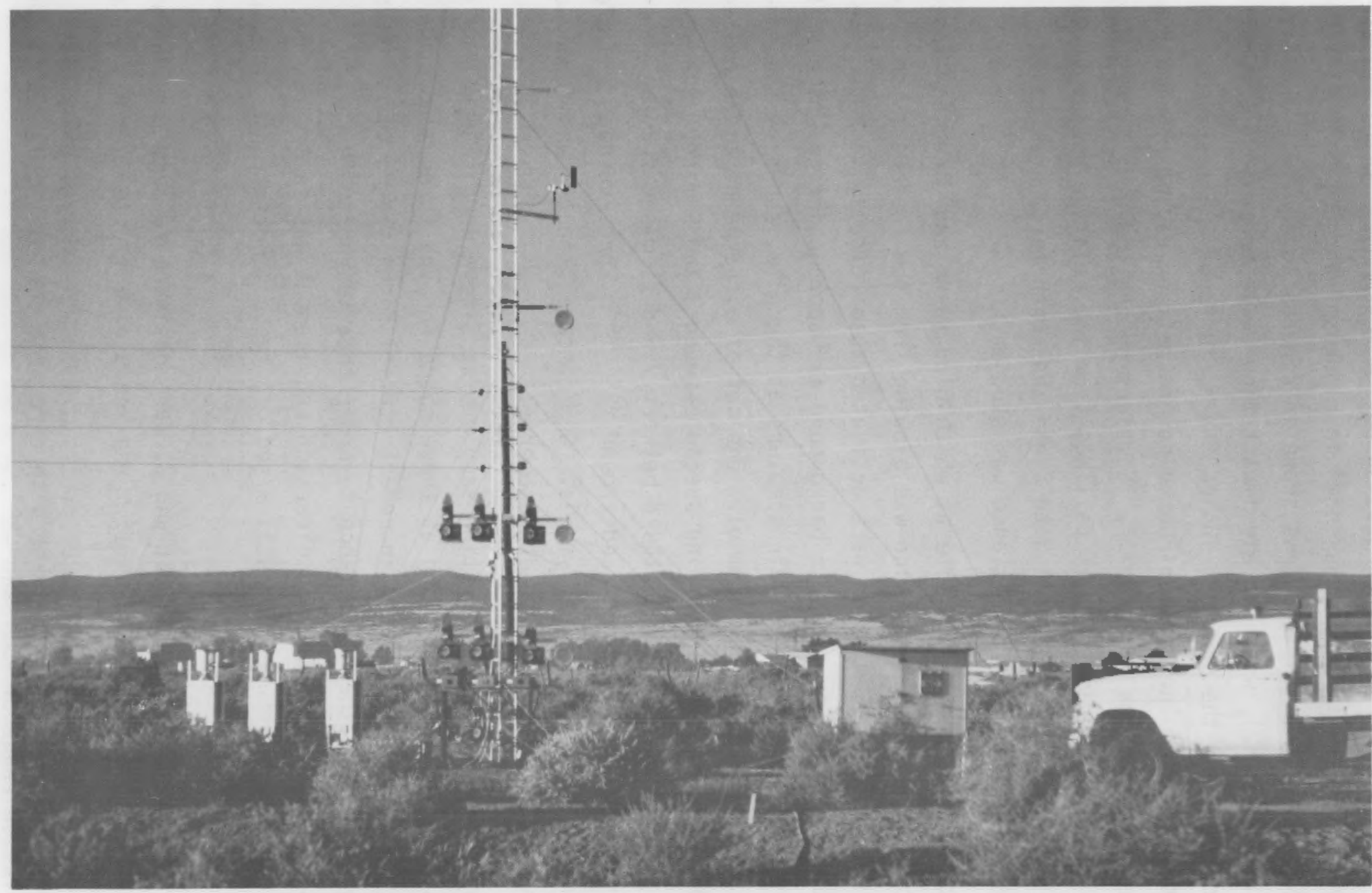

FIGURE 7. Background Site A, with View Towards Southwest Away from

NEG. 7900253-2

Uranium Mill Tailings Pile 


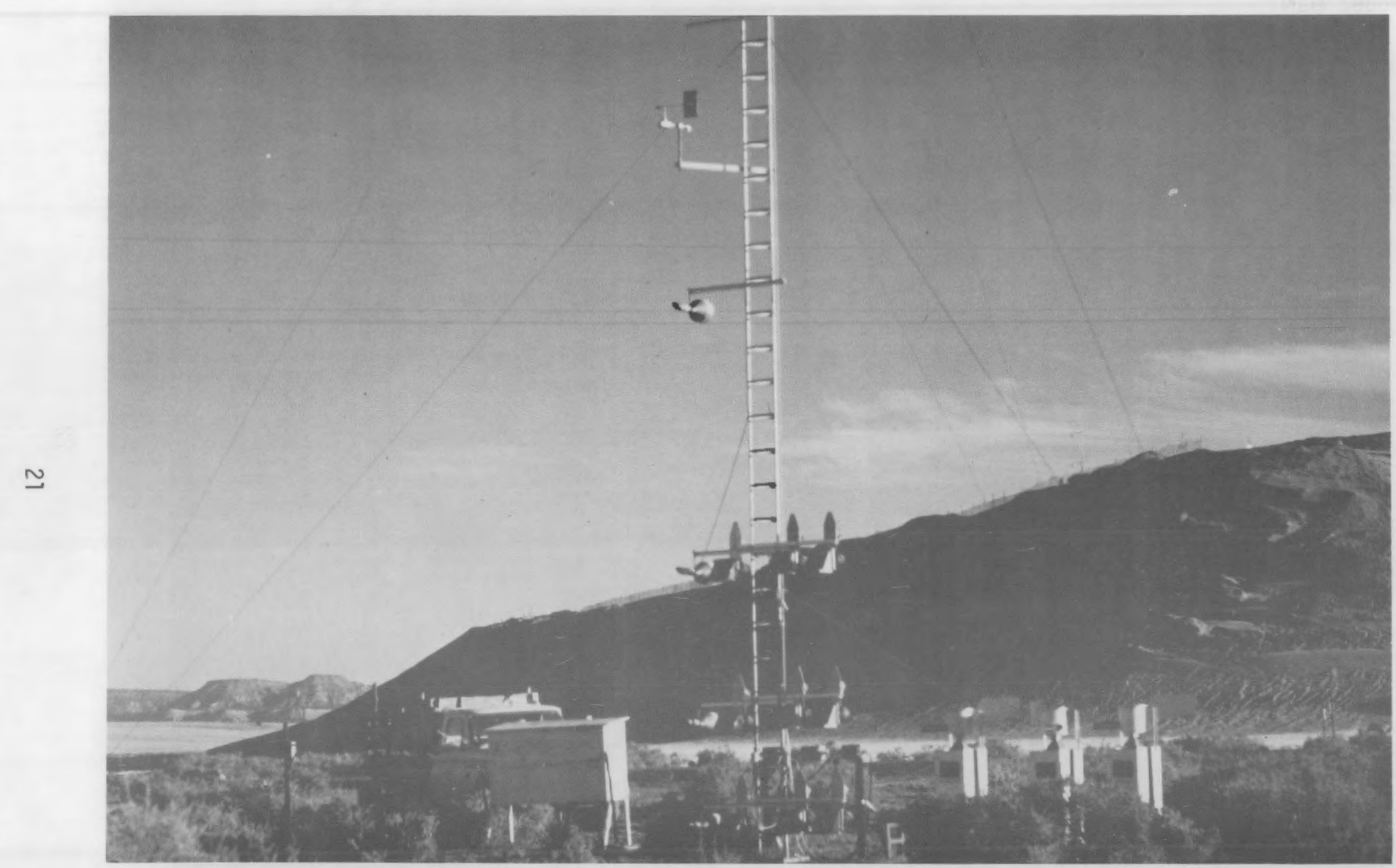

FIGURE 8. Background Site A, with View North Towards Pile

NEG. 7900253-3 


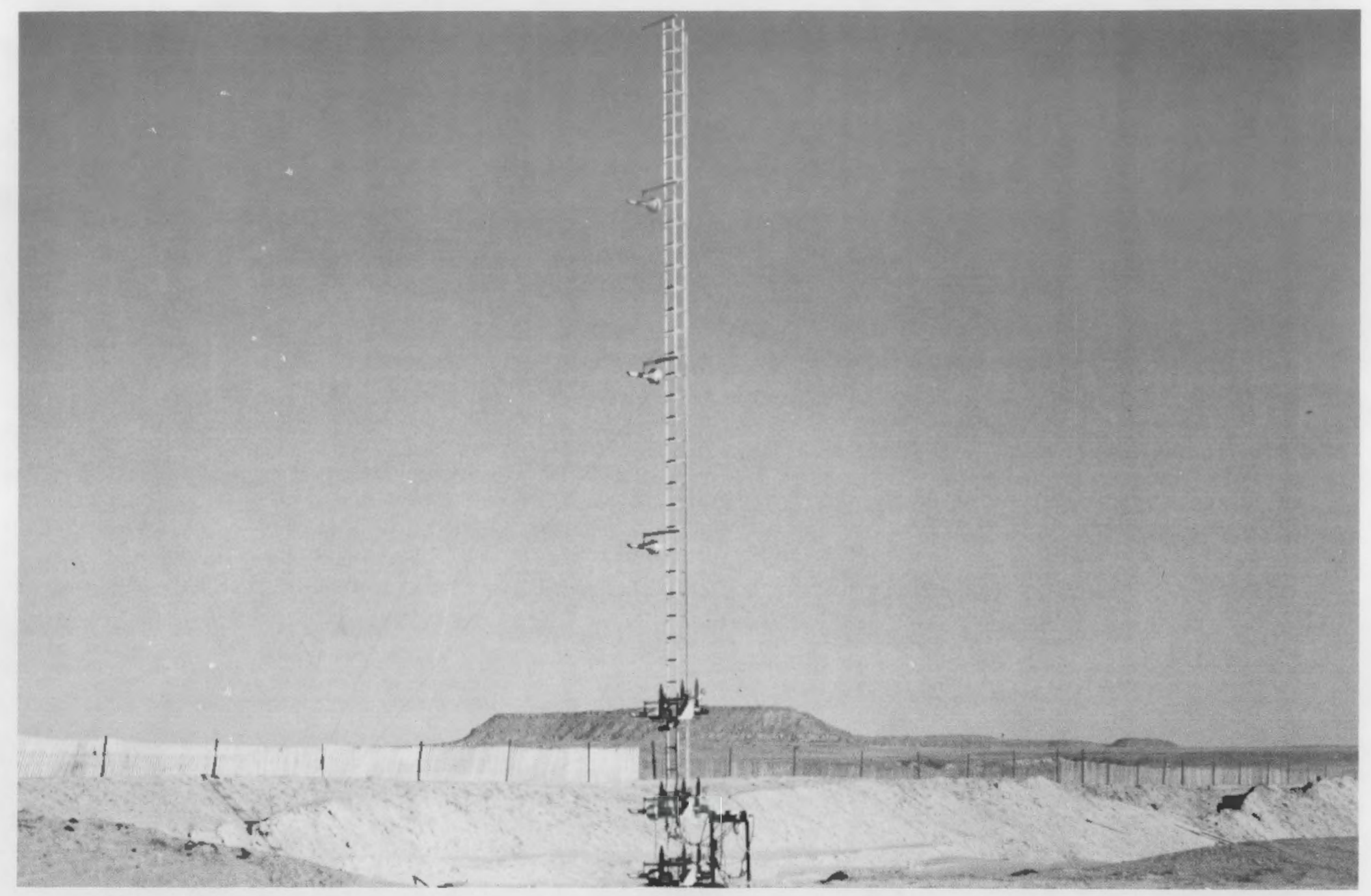

FIGURE 9. Site BI with View Towards Northwest (to the left Background

NEG. $7900253-4$ Site $A$, Out of View) 


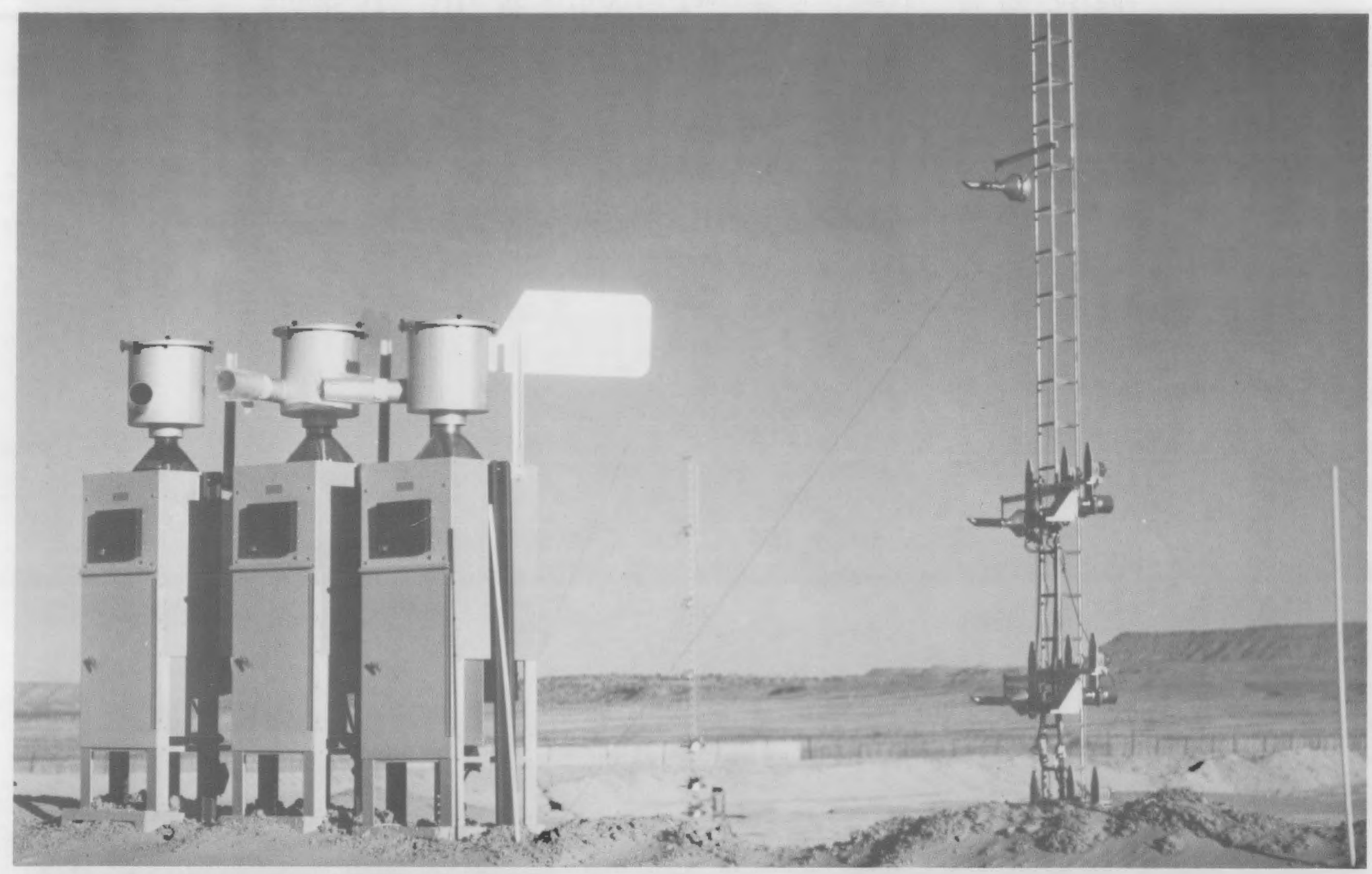

NEG. 7900253-6

FIGURE 10. Site B2 with View Towards Northwest (Site B1 in Central Background) Note at B2 Cascade Impactors with Cyclone Preseparators are on Dike. In this View, Lowest Isokinetic Samplers on B2 Tower Are Just Below Top of Dike 


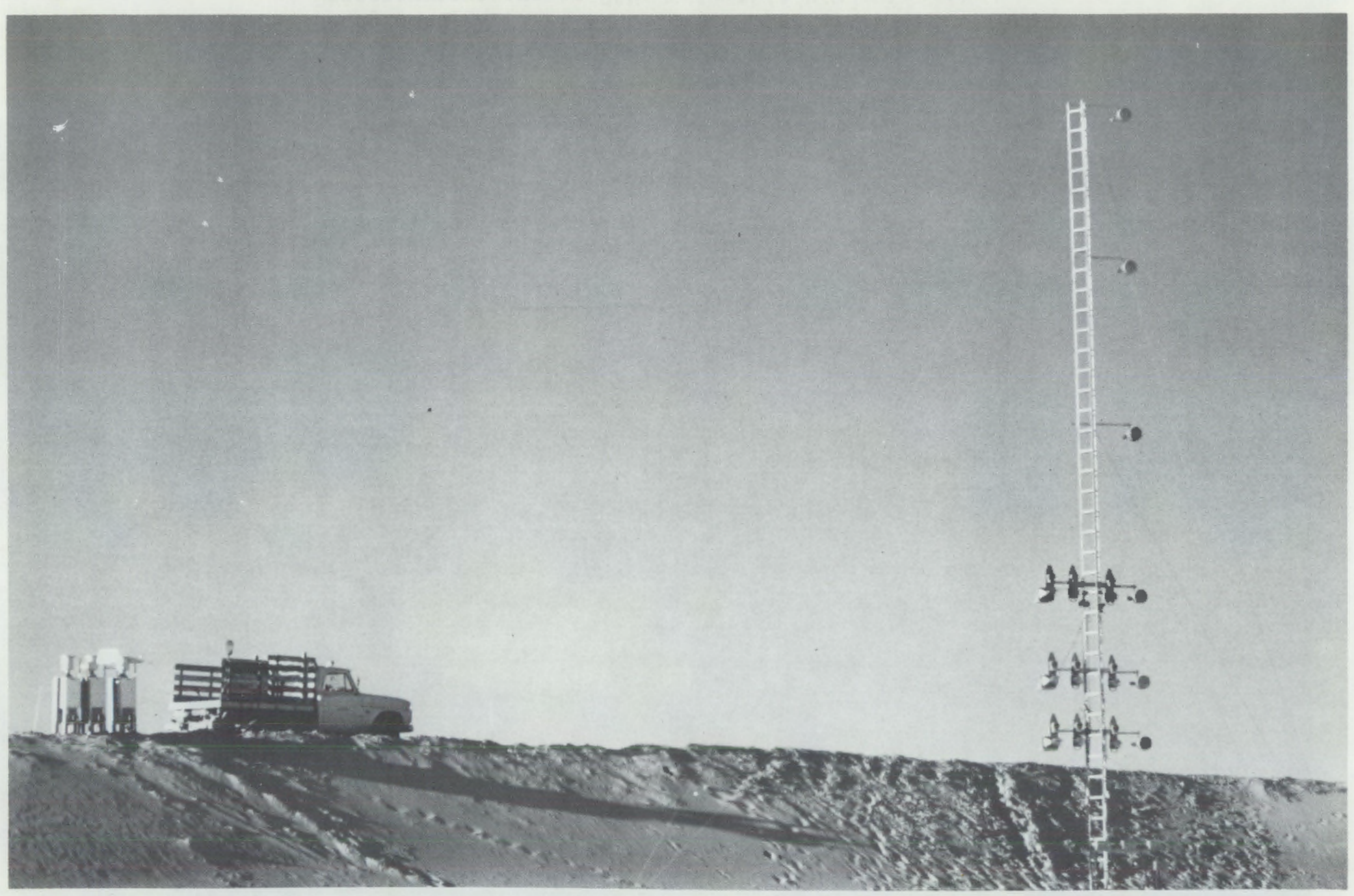

FIGURE 11. Site B2 with-View Towards Southwest. At B2 Cascade Particle Impactors with Cyclone Preseparators are on Dike, Whereas Tower is Located on Flat Fines Surfaces of Pile

NEG. 7900253-5 


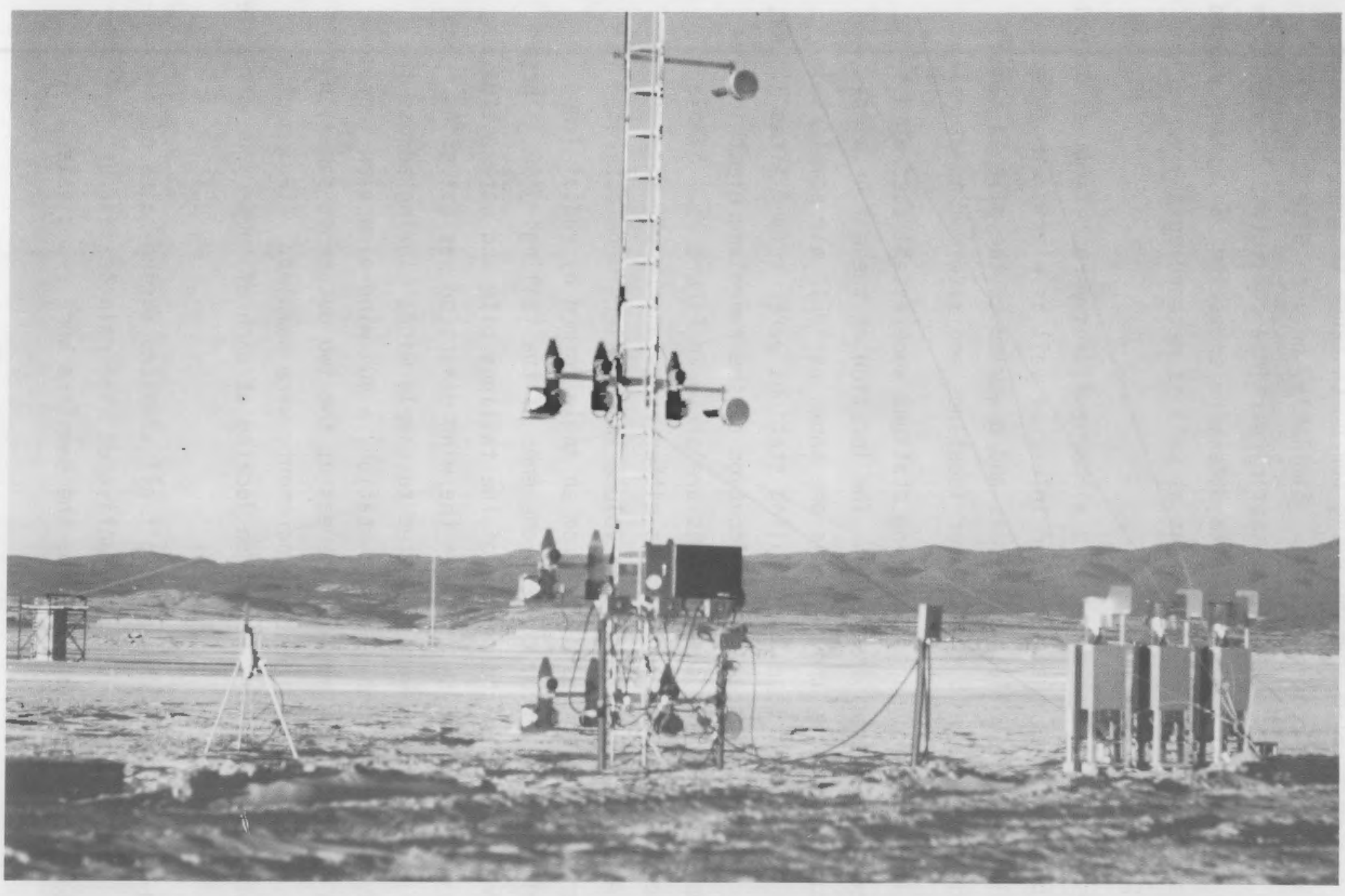

FIGURE 12. Site $\mathrm{C}$ with View Towards Southwest. At Site $\mathrm{C}$ Sampling Tower is Centrally Located Between Virtual Impactor on Left and Particle Cascade Impactors with Cyclone Preseparators on Right. Site B1 is in Background Between Virtual Impactor and Sampling Tower.

NEG. 7900253-7 
the crosswind airborne concentration variation due to wind erosion. Nine sites were located at $91-\mathrm{m}$ spacing along the north fence to show crosswind variations in airborne concentrations. Similarly, between Site $C$ and the north fence, there were impact flow (static) particle collectors located $52 \mathrm{~m}$ apart along the retaining dike ridge to determine crosswind variations caused by both local terrain (pile) variations as well as meteorological variations across the pile.

Changes in nonrespirable particle airborne fluxes were determined by collection on both isokinetic air-sampler inlets as well as within air impact flow particle (static) collectors across and downwind of the pile in rangeland (see Figures 14 and 15 for sampler locations and site nomenclature).

Four electrically-powered sampling stations were established at distances downwind of the tailings pile. The location of these four winddirection controlled sampling stations are shown as "MET" air samplers in Figure 14. These four rangeland sampling stations were termed Sites R1, R2, R3, and R4. A scale diagram of the location of the rangeland electricallypowered samplers and their descriptions are shown in Figure 15. Samplers north of the E-W road are described as either rangeland or off-site samplers. At these four sites, high-volume air samplers were activated for all winds arriving at the samplers from an angle formed by radial lines approximately extending from the extreme ends of the tailings pile. These samplers were "aimed" at the center of the tailings pile and were activated by a wind vane-controlled switch when the wind direction was satisfied. The wind-direction increments were selected to sample winds blowing across the pile. Thus, at the closest sampling station, a $90^{\circ}$ wind-direction increment centered on the pile was sampled, whereas at the two outermost sampling locations, on $1 y 15^{\circ}$ wind-direction increments were sampled. Air impact particle (static) collectors were also located at each of these four off-site locations.

A rain-activated switch turned off all samplers during rains of any consequence. Sampling arrays could be activated when rain ceased, but the ground could still be wet at the time the samplers were reactivated. A 


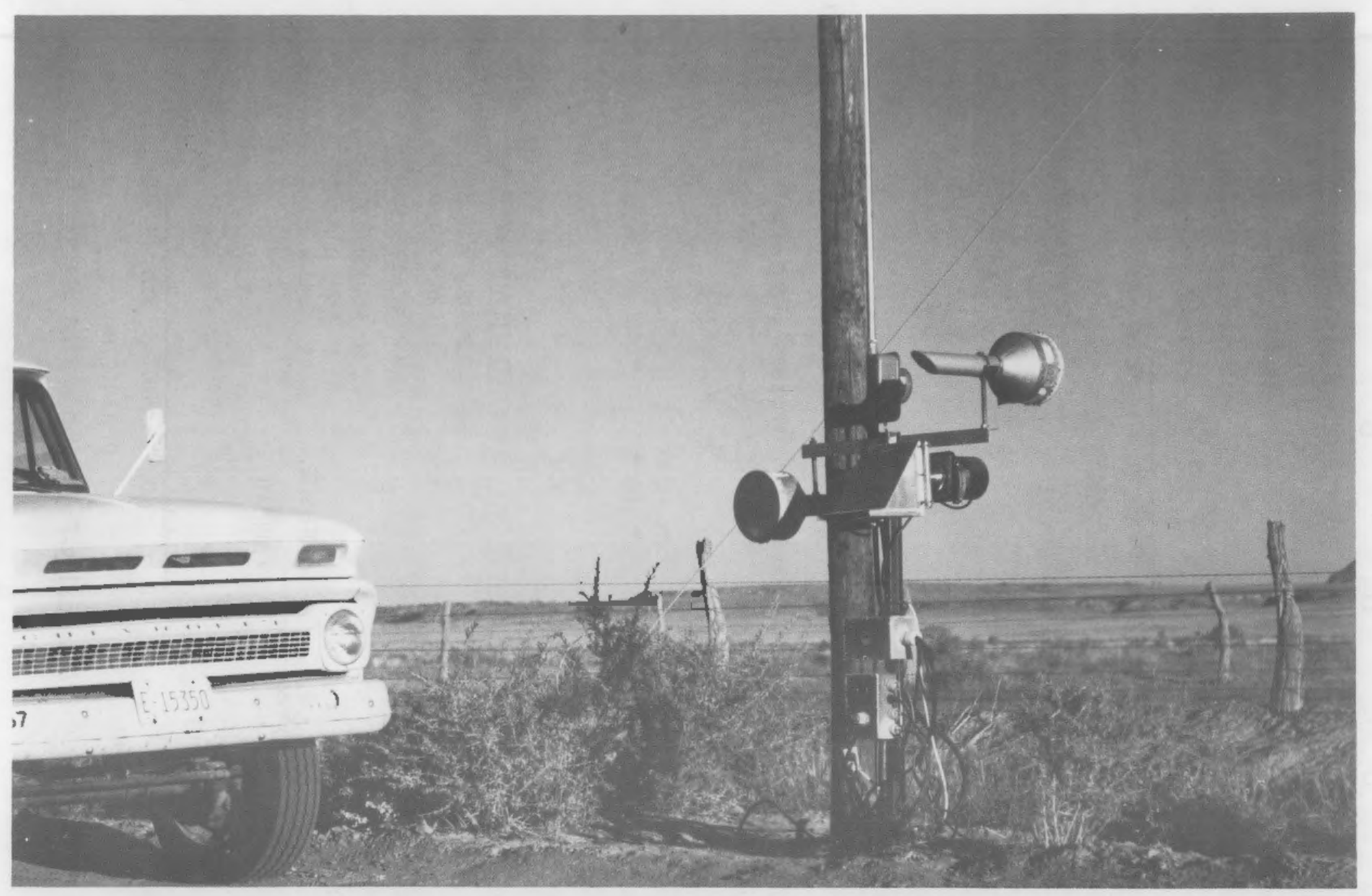

NEG. 7900253-1

FIGURE 13. A North Fence Sampling Site with View Towards Northwest Showing Isokinetic Sampler and South- and North-Facing Air Impact Flow Particle Collectors 


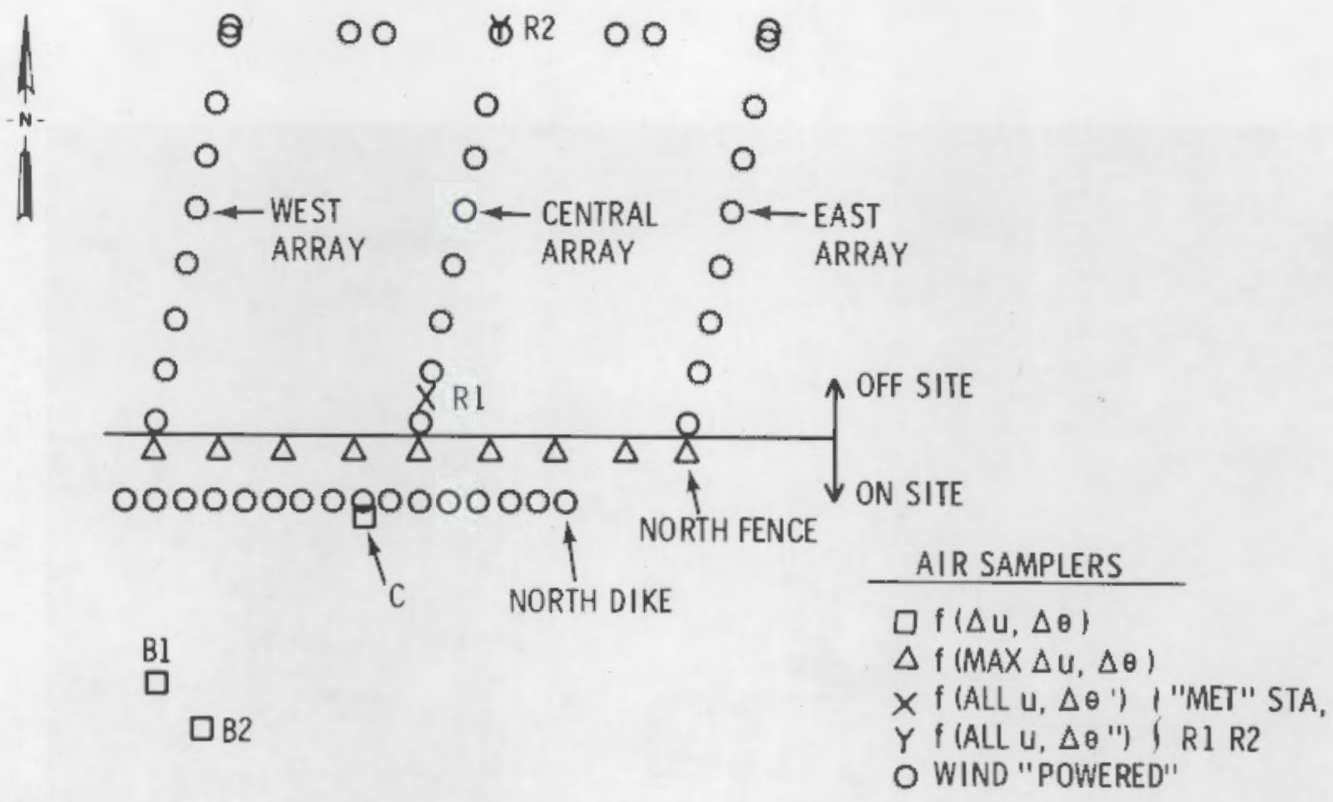

$\square \mathrm{A}$

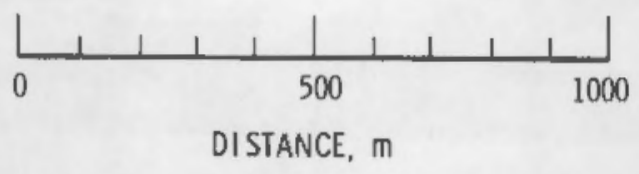

NEG. 7900381-1

FIGURE 14. Location of Air Samplers (Downwind)

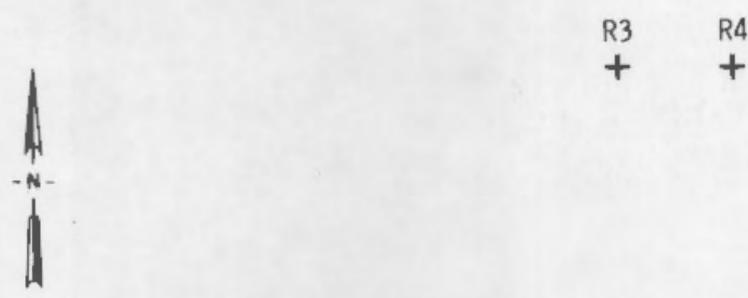

ON SITE AIR SAMPLERS

$\square \mathrm{f}(\Delta \mathrm{u}, \Delta \theta)$

$\Delta f(\operatorname{MAX} \Delta \mathrm{u}, \Delta \theta)$

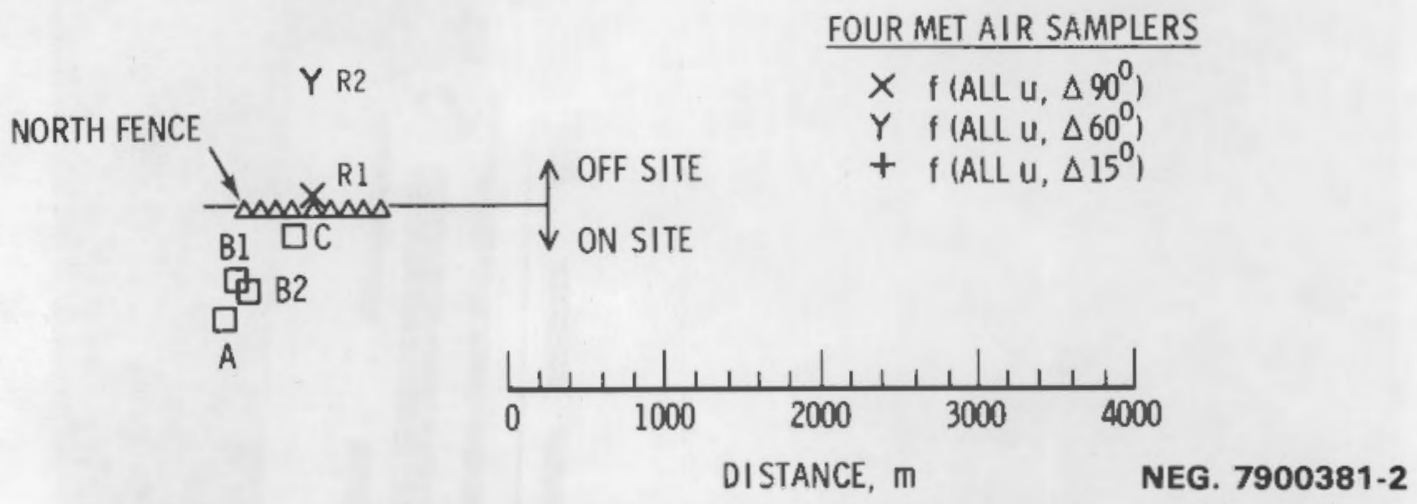

FIGURE 15. Electrically-Powered Downwind Air Samplers 
running time meter for each sampler was read each day, and the accumulated time at the end of run for each sampler was recorded and used in the analysis of the data.

\section{Experimental Protocol for Sampling Array}

The sampling array operated for a period long enough that sufficient but not excessive quantities of airborne particles could be collected. Filters were removed and the weight of collected "sand" determined. On the basis of the operating time of each sampler, the volume of air sampled for the increment of wind speed was determined. The concentrations and flux at the sampling height were then determined. The highest sampler was at $15 \mathrm{~m}$, and it was anticipated that extrapolation above this height could be performed if a reasonably consistent gradient were found. From these data, supplemented by observations from the air impact flow samplers and particle-size measurements of both surface and airborne sand, it was also anticipated that the resuspension flux of particles at the perimeter of the tailings pile could be calculated as a function of wind speed.

Some samples were analyzed for radioactive constituents as a function of particle size in order that not only the mass removal rate as a function of particle size and wind speed could be estimated but also so that the radionuclides associated with the particle-size mass flux could be determined.

Airborne concentrations and mass fluxes of particles in various size fractions were used in dispersion and deposition models. The site meteorology was used in estimating downwind concentrations and deposition as a function of distance. The distant air sampler results and the cumulative surfacedeposited radionuclides were to be compared with predictions from the dispersion deposition models.

The usual difficulties in setting up such a complex sampling array were encountered, and the equipment required much attention to achieve the desired performance. Several improvements were made during operations, and these improvements helped prevent some of the problems faced in earlier experiments.

The chronology of the sampling periods and notes concerning operational conditions are given in Appendix B. 


\section{RESULTS AND DISCUSSION}

\section{CHARACTERIZATION OF TAILINGS}

The majority of the work considered in this section was based on studies performed on the tailings materials from Mill A and on soil from its environs. This mill employed the alkaline carbonate leach process. Some analyses on tailings from Mills $B$ and $C$, which employed sulfuric acid leaching for the uranium extraction, were performed. There were some very significant differences in the radiochemical composition of tailings material from the alkaline and acid leach tailings piles. In the alkaline leach tailings material, the ratios of the uranium daughter radionuclides are near unity. In the case of the acid leach processes, this is not true. Because of the high solubility of ${ }^{230}$ Th in the sulfuric acid leach solution and the fact that ${ }^{226} \mathrm{Ra}$ is forced to remain on the particles by virtue of the very low solubility of radium sulfate, there is a considerable disequilibrium of ${ }^{230}$ Th relative to ${ }^{226} \mathrm{Ra}$ and ${ }^{210} \mathrm{~Pb}$ in most areas of the tailings materials.

Table 1 shows the radionuclide composition as a function of depth at two locations on tailings pile $A$. These data show that the ratios of uranium daughters are relatively close to unity but that their absolute concentrations as a function of depth vary considerably. These data seem to indicate, therefore, that there is a considerable degree of stratification in the interior of the tailings pile that apparently results as different fractions of the fine slurry material are deposited from the tailings pond water.

Table 2 shows the radionuclide concentrations in material from tailings pile $B$. In this case, materials from the tailings pile that were obviously fine, obviously coarse, or about average were collected. It is evident that there is a very much higher concentration of uranium daughters in the fine material and that this concentration is an order of magnitude higher than that of the coarse material for most of the radionuclides. In addition, the ${ }^{230} \mathrm{Th}$ is not present in as high a concentration as either ${ }^{226} \mathrm{Ra}$ or ${ }^{210} \mathrm{~Pb}$ in both the fine and coarse material. 
TABLE 1. Variation of Radionuclide Concentration with Increased Depth in Core Samples from Tailings Pile A

\begin{tabular}{|c|c|c|c|c|c|}
\hline \multirow[b]{2}{*}{$\begin{array}{l}\text { Samp } \\
\text { No. } \\
\text { a })\end{array}$} & \multirow[b]{2}{*}{$\begin{array}{l}\text { Depth } \\
\text { cm }\end{array}$} & \multicolumn{4}{|c|}{ Concentration, $\mathrm{dpm} / \mathrm{g}$} \\
\hline & & $210 \mathrm{~Pb}$ & $238 \mathrm{U}$ & ${ }^{230} \mathrm{Th}$ & ${ }^{226} \mathrm{Ra}$ \\
\hline A-1 & 4 & 493 & 78.3 & 294 & 435 \\
\hline 2 & 8 & 568 & 38.8 & 363 & 512 \\
\hline 3 & 12 & 466 & 39.8 & 344 & 494 \\
\hline 4 & 16 & 571 & 52.2 & 581 & 649 \\
\hline 5 & 20 & 491 & 57.4 & 540 & 602 \\
\hline 6 & 24 & 449 & 47.6 & 452 & 508 \\
\hline 7 & 28 & 462 & 37.0 & 352 & 461 \\
\hline 8 & 32 & 512 & 50.9 & 373 & 473 \\
\hline 9 & 36 & 902 & 28.8 & 746 & 941 \\
\hline 10 & 40 & 623 & 59.1 & 597 & 677 \\
\hline B-1 & 4 & 1149 & 103.0 & 1204 & 1387 \\
\hline 2 & 8 & 987 & 53.0 & 1167 & 1215 \\
\hline 3 & 12 & 686 & 37.0 & 637 & 745 \\
\hline 4 & 16 & 3305 & 129.0 & 3182 & 4044 \\
\hline 5 & 20 & 604 & 60.4 & 552 & 646 \\
\hline 6 & 24 & 506 & 28.0 & 349 & 499 \\
\hline 7 & 28 & 446 & 34.0 & 324 & 451 \\
\hline 8 & 32 & 581 & 38.0 & 449 & 576 \\
\hline 9 & 36 & 440 & 30.0 & 318 & 578 \\
\hline 10 & 40 & 428 & 27.0 & 333 & 493 \\
\hline
\end{tabular}

(a) Core A from north edge of evaporation pond shoreline in west half of tailings pile

Core B from $100 \mathrm{~m}$ southeast of evaporation pond in eastern half of evaporation pond 
TABLE 2. Radionuclide Concentration in Tailings Pile B (dpm/g)

\begin{tabular}{|c|c|c|c|}
\hline pe of Tailings & ${ }^{226} \mathrm{Ra}$ & ${ }^{230} \mathrm{Th}$ & ${ }^{210} \mathrm{~Pb}$ \\
\hline Fines & 5500 & 2400 & $\overline{6300}$ \\
\hline Coarse Material & 600 & 400 & 700 \\
\hline From Pond Edge & 700 & 500 & 800 \\
\hline
\end{tabular}

Table 3 illustrates the radionuclides in tailings material, in tailings pond water, in ore, and in soil about one mile from the tailings pile. Here again there is considerable disequilibrium between ${ }^{230} \mathrm{Th},{ }^{226} \mathrm{Ra}$, and ${ }^{210} \mathrm{~Pb}$, both in tailings material and in water from the evaporation ponds on this tailings material. The tailings material associated with soil at a mile from the tailings pile contained uranium daughter concentrations that were up to $10 \%$ of those in some areas of the tailings pile.

It was possible in the characterization of tailings material to establish whether there were concentrations of trace elements in tailings material significantly above those in ambient soil. To confirm this possibility, samples were collected of ambient soil at a distance of five miles from the tailings pile and at a depth of one foot to ensure that no windblown tailings were present. The X-ray fluorescence spectra of this sample and of samples taken directly from the tailings pile are shown in Figures 16 and 17 ,

TABLE 3. Radionuclides in and Around Tailings Pile C (dpm/g)

\begin{tabular}{|c|c|c|c|c|}
\hline Sample Type & ${ }^{226} \mathrm{Ra}$ & ${ }^{230} \mathrm{Th}$ & ${ }^{210} \mathrm{~Pb}$ & $234 / 238 U$ \\
\hline Main Tailings Area & 350 & 300 & 550 & 70 \\
\hline Main Tailings Area & 350 & 3300 & 500 & 175 \\
\hline Main Tailings Area & 300 & 450 & 400 & 50 \\
\hline Water on Tailings & $<1$ & 1100 & 120 & 75 \\
\hline Water Evaporation Pond & $<1$ & 1050 & 60 & 15 \\
\hline Ore & 1100 & 1000 & 1300 & 1100 \\
\hline 1 Mile East of Tailings & 35 & 50 & 45 & 5 \\
\hline
\end{tabular}


respectively. From an examination of these spectra, it is evident that the only elements in the tailings at substantially higher concentrations than in ambient soil were selenium and uranium. These selenium concentrations were actually about 100 times that in ambient soil. The concentrations of selenium and uranium are compared in a core sample from the tailings pile in Table 4. The ratio of selenium to uranium varies by a factor of about 2.6 through the length of this $40-\mathrm{cm}$ core. One could, therefore, possibly use environmental measurements of selenium as an indication of the presence of tailings material.

One of the main reasons for characterizing the tailings material was to determine the relationship between particle size and radionuclide content. To provide a sample for such an analysis, 1/2-cm-deep samples from several positions across the tailings pile were collected. A portion of this collected material was dried in the laboratory under a heat lamp and subsequently pulverized and submitted for analysis using an air elutriation procedure. (a)

The results of measurements indicated that smaller particles were associated with larger particles and the particle size distribution was not likely to be the same as the tailings materials themselves. Therefore, a particle size separation based on sieving and sedimentation rates was conducted. A slurry of the tailings material was wet-sieved through sieve sizes down to $44 \mu \mathrm{m}$. Smaller size fractions were separated using a sedimentation column, and the Stokes law equations were applied to obtain size fraction down through less than $1.4 \mu \mathrm{m}$.

The percent of material in each of these fractions, along with its radionuclide composition and the amounts of the radionuclides that were dissolved in the water, is shown in Table 5. These data show that a relatively large fraction of the radioactivity is associated with particles smaller than $7 \mu \mathrm{m}$ in diameter. It is also apparent that specific activity of the smaller particles is about an order of magnitude greater than that of the large

(a) A Bahco particle size separator was employed for this work. 


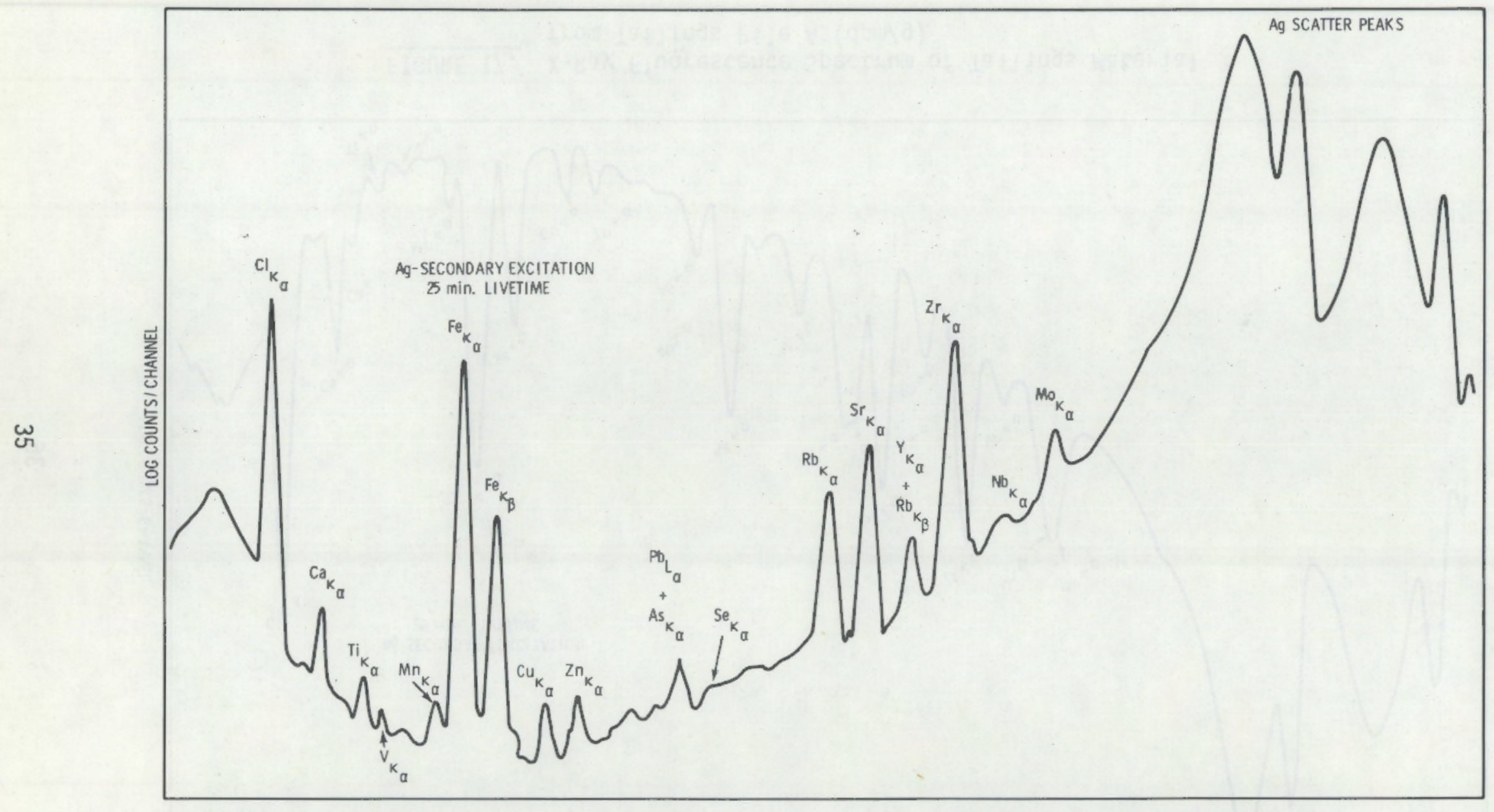

FIGURE 16. X-Ray Fluorescence Spectrum of Soil Taken Five Miles From Tailings Pile A at a Depth of One Foot 


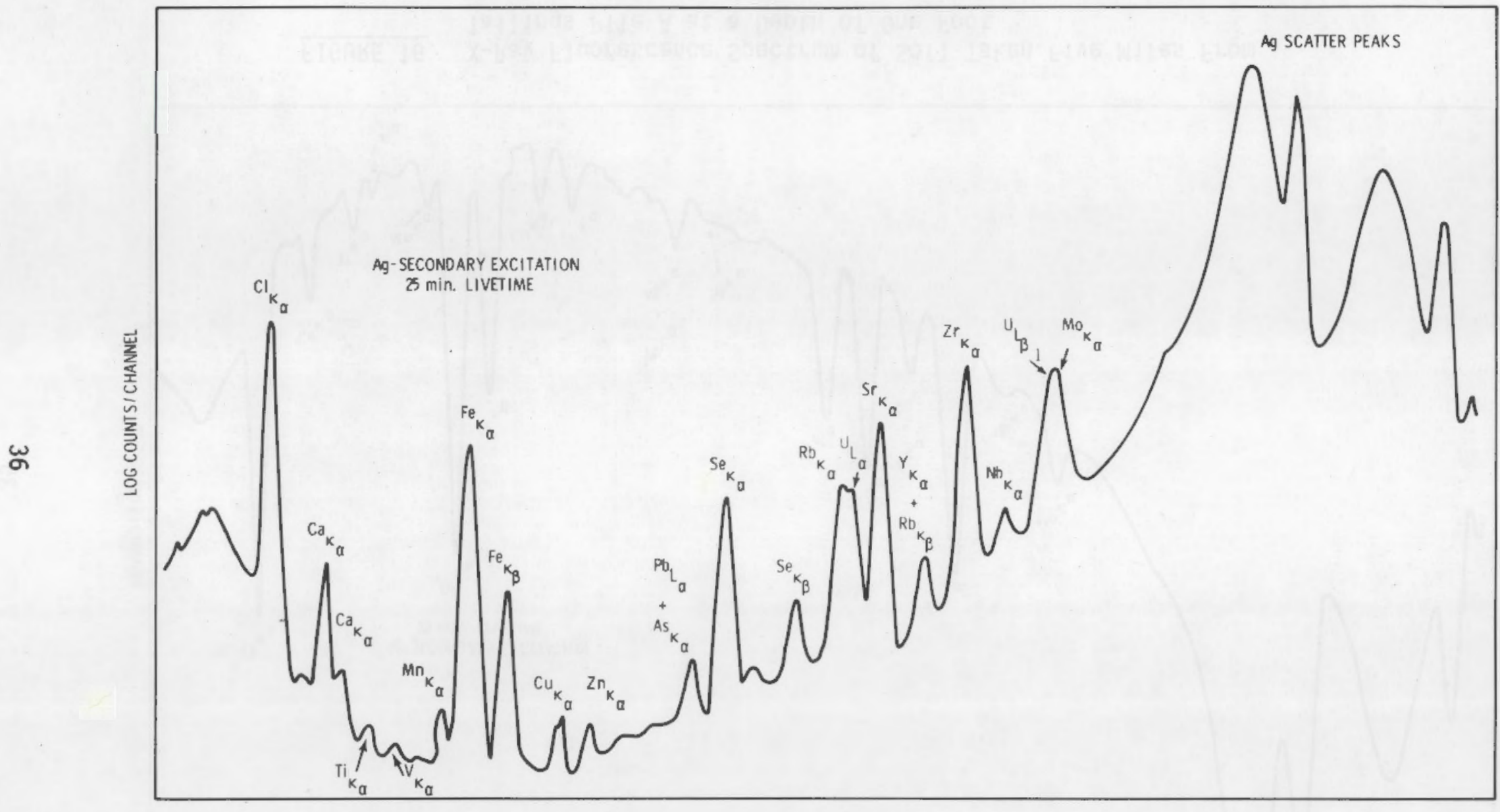

FIGURE 17. X-Ray Fluorescence Spectrum of Tailings Material from Tailings Pile $A(d p m / g)$ 
TABLE 4. Uranium and Selenium Concentration on Sediment Core from East Area of Tailings Pile PPM (Measured by X-ray Fluorescence Analys is)

\begin{tabular}{|c|c|c|c|}
\hline Depth, cm & $\underline{\mathrm{Se}}$ & U & $\underline{\mathrm{Se} / \mathrm{U}}$ \\
\hline 4 & 197 & 141.0 & 1.4 \\
\hline 8 & 195 & 228.0 & 0.9 \\
\hline 12 & 207 & 190.0 & 1.1 \\
\hline 16 & 234 & 229.0 & 2.0 \\
\hline 20 & 224 & 107.0 & 2.1 \\
\hline 24 & 185 & 108.0 & 1.7 \\
\hline 28 & 141 & 127.0 & 1.1 \\
\hline 32 & 84 & 107.0 & 0.9 \\
\hline 36 & 67 & 69.21 & 1.0 \\
\hline 40 & 93 & 86.4 & 1.1 \\
\hline
\end{tabular}

TABLE 5. Particle Size versus Radionuclide Composition of Tailings From Top $0.5 \mathrm{~cm}$ of Tailings Pile A

\begin{tabular}{|c|c|c|c|c|c|c|c|c|c|}
\hline \multirow[b]{2}{*}{$\begin{array}{c}\text { Particle Size } \\
\mu \mathrm{m}\end{array}$} & \multirow[b]{2}{*}{ Weight } & \multicolumn{8}{|c|}{$\mathrm{dpm} / \mathrm{g}$ and $(\%)$ activity } \\
\hline & & $210 \mathrm{~Pb}$ & (\%) & $238 \mathrm{U}$ & (\%) & ${ }^{230} \mathrm{Th}$ & (\%) & ${ }^{226} \mathrm{Ra}$ & $(\%)$ \\
\hline$>250$ & 60.3 & 319 & 21.7 & 38.0 & 17.0 & 198 & 14.4 & 299 & 20.0 \\
\hline $125-250$ & 7.5 & 385 & 3.3 & 40.4 & 2.2 & 269 & 2.4 & 370 & 3.1 \\
\hline $53-125$ & 4.2 & 476 & 2.3 & 55.0 & 1.7 & 420 & 2.1 & 475 & 2.2 \\
\hline $44-53$ & 3.8 & 429 & 1.8 & 50.4 & 1.4 & 497 & 2.3 & 551 & 2.3 \\
\hline $20-44$ & 7.8 & 1527 & 13.5 & 230 & 13.3 & 1825 & 17.2 & 1785 & 15.5 \\
\hline $7-20$ & 7.2 & 2415 & 19.7 & 379 & 20.2 & 2616 & 22.8 & 2222 & 17.8 \\
\hline $1.4-7$ & 9.1 & 3663 & 37.7 & 653 & 44.1 & 3514 & 38.7 & 3876 & 39.2 \\
\hline$<1.4$ & 0.1 & & & & & & & & \\
\hline $\begin{array}{l}\text { Water } \\
\text { Soluble }\end{array}$ & -- & & 2.6 & & 15.9 & & 1.6 & & 10.0 \\
\hline Bulk & 100 & & 915 & & 158 & & 872 & & 1012 \\
\hline
\end{tabular}


particles. The aerodynamic behavior of the tailings particles following ambient drying might possibiy be more like the lab-dried than pulverized sample; however, this is only speculative. Data on radioactivity associated with particle sizes sampled from the air is discussed in a subsequent section.

To verify further the distribution of radioactivity as a function of particle size, a second set of measurements was made in which the slurry material that comes to the tailings pile from the mill was collected and fractionated according to particle size as described above. These results are shown in Table 6 . A rather similar distribution of the uranium daughters as a function of particle size is observed in this material; therefore, these distributions are reasonably representative of the material on tailings pile A.

Apparently both uranium and radium are fairly soluble in the slurry and in the water used in conducting the sedimentation operations. The radium would be expected to be in the form of a carbonate, and this characteristic probably accounts for its fairly high degree of solubility. Because of this

TABLE 6. Particle Size versus Radionuclide Composition of Tailings in Input Slurry to Tailings Pile A

\begin{tabular}{|c|c|c|c|c|c|c|c|}
\hline $\begin{array}{c}\text { Particle Size } \\
\mu \mathrm{m}\end{array}$ & Weight & $210_{\mathrm{Pb}}$ & $(\%)$ & $\frac{230 \mathrm{Th}}{230}$ & b) act 1 & $\frac{11 \mathrm{y}}{226_{\mathrm{Ra}}}$ & $(\%)$ \\
\hline$>250$ & 39.6 & 229 & 16.2 & 148 & 11.0 & 166 & 20.8 \\
\hline $125-250$ & 26.0 & 252 & 11.7 & 187 & 9.1 & 184 & 15.1 \\
\hline $53-125$ & 7.1 & 316 & 4.0 & 289 & 3.8 & 217 & 4.9 \\
\hline $44-53$ & 1.6 & 345 & 1.0 & 345 & 1.0 & 214 & 1.1 \\
\hline $20-44$ & 4.0 & 707 & 5.1 & 1053 & 7.9 & 364 & 4.6 \\
\hline $7-20$ & 14.5 & 1900 & 49.2 & 2115 & 57.6 & 775 & 35.5 \\
\hline $1.4-7$ & 1.6 & 3119 & 8.9 & 2448 & 7.4 & 2128 & 10.7 \\
\hline$<1.4$ & 0.9 & 2402 & 3.9 & 1269 & 2.1 & 2555 & 7.3 \\
\hline Water Fraction & 1.0 & & & 1 & & 4 & \\
\hline
\end{tabular}


solubility, one would expect that it might migrate much more rapidly through soil than radium in tailings material from an acid leach process where radium is bound as an insoluble sulfate.

RESULTS OF MEASUREMENTS OF DEPOSITED TAILINGS PARTICLES IN VICINITY OF URANIUM MILLA

Figure 18 shows isopleths of ${ }^{226}$ Ra concentrations over the sampling network surrounding tailings pile $A$. Also shown are isopleths of radium concentrations extending out from tailings pile $B$, which contributed to the background concentration in this area. By integrating the areas between these various isopleths and using the average concentrations of radium in these areas, calculations of the radium inventories in these areas have been made.

These calculations required a knowledge of the depth distribution of radium at various locations within these isopleths. An example of these depth distributions for ${ }^{210} \mathrm{~Pb}$ is shown in Figure 19. Based on the concentrations between the isopleths and the depth distribution of ${ }^{226} \mathrm{Ra}$, the ${ }^{222} \mathrm{Rn}$ emis sion from the areas between the isopleths has been calculated (see Table 7). For these calculations, only the radium content of the top $5 \mathrm{~cm}$ of soil was used. Values found were corrected for the natural radium content in the soil. The emission rates are based on the assumption that one-half of the radon generated in this soil from the added tailings material will be released to the atmosphere.

Table 7 indicates an emission rate of $1.61 \mathrm{Ci} /$ day from this secondary source. This rate can be compared with an emission rate of about $5 \mathrm{Ci} /$ day from the tailings pile. Thus, the secondary source of radon emission amounts to approximately $30 \%$ of that from the tailings pile itself.

It would be expected that most of the material being transported from the tailings pile would be of a relatively small particle size. To determine the particle size distribution, material from the top centimeter of soil at a distance of one-half mile on the $45^{\circ}$ transect was collected (see Figure 2). This soil was classified according to particle size using the Bahco particle size separator. The particle size distributions observed are shown in Table 8. 


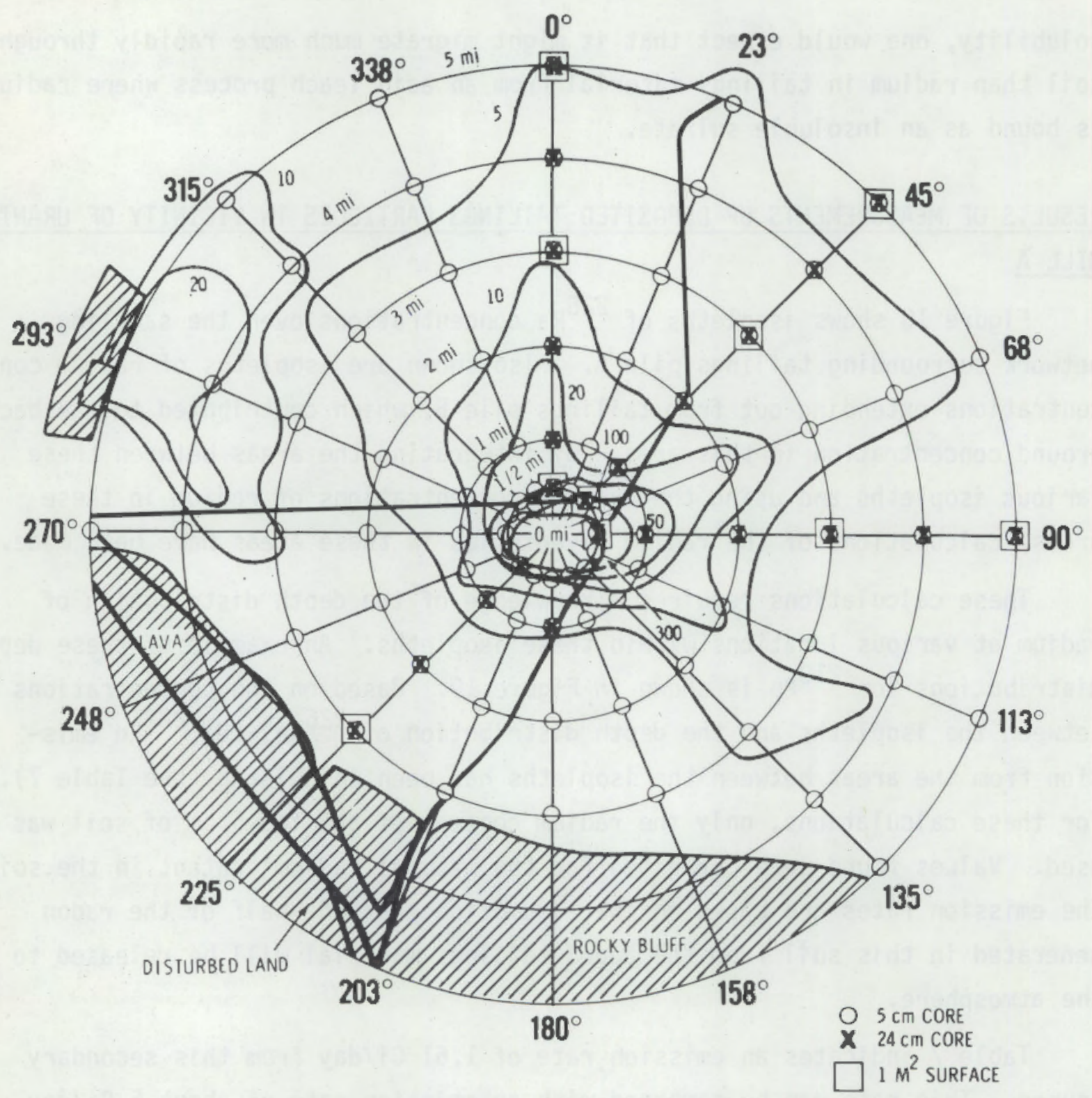

FIGURE 18. Isopleths of Radium Concentrations in Environs of Tailings Pile A $(\mathrm{dpm} / \mathrm{g})$

These data suggest that the majority of the radioactivity in soil is associated with particles greater than $10 \mu \mathrm{m}$ in diameter. Whether there has been substantial degradation of the tailings materials during the residence time in the soil is not known. It is also questionable whether this type of particle size analysis is a good indication of the actual particle size distribution in the soil. Plans have been made to carry out a wet-particle 


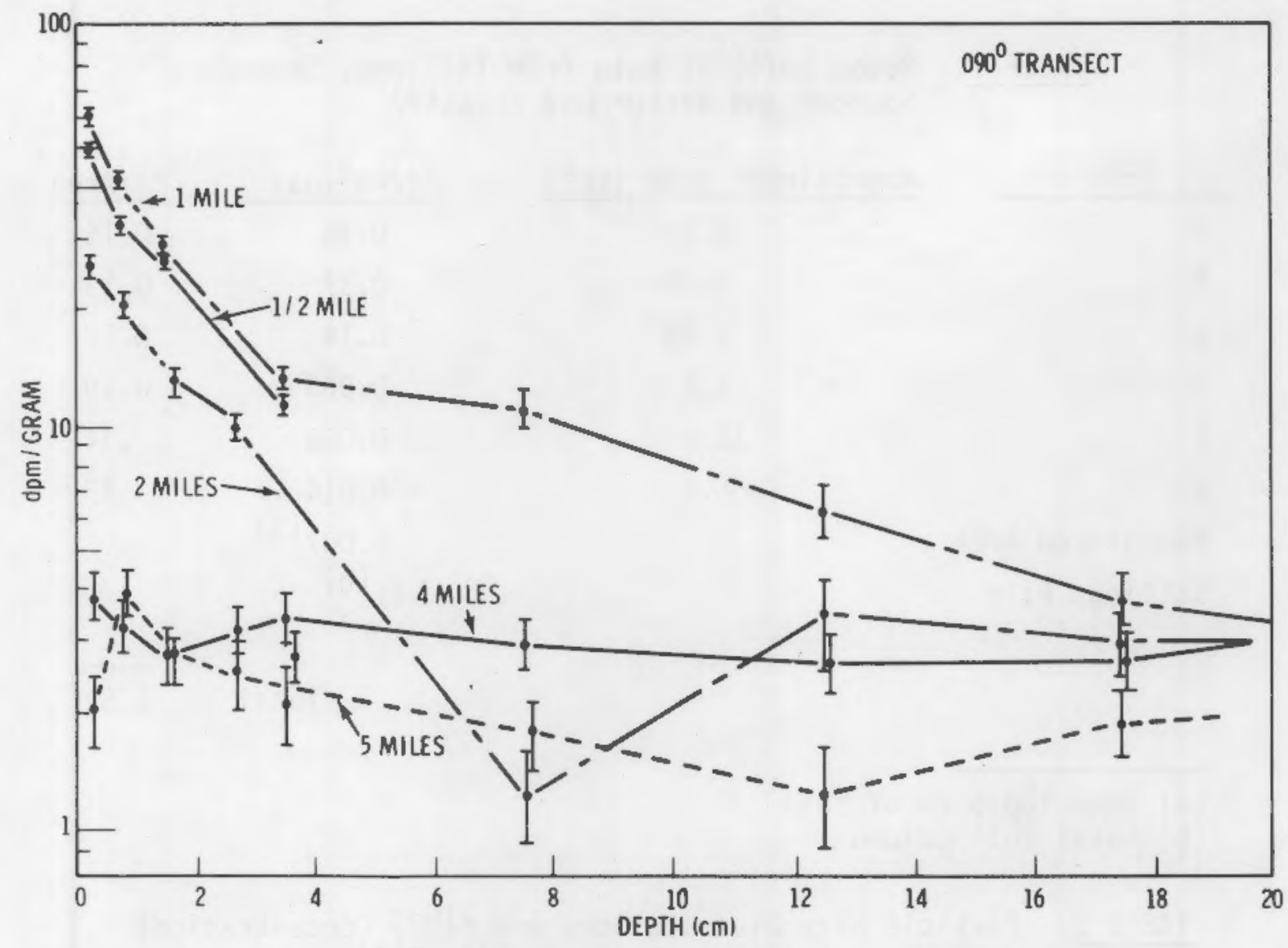

FIGURE 19. Depth Distribution of $210 \mathrm{pb}$ in the Environs of Tailings Pile A

separation of this soil material in the manner described earlier for the tailings material in order that the relationship between the transported tailings material present in the soil and that on the tailings pile can be better understood.

\section{AIRBORNE PARTICLES FROM TAILINGS PILE}

\section{Radionuclide Concentrations}

Airborne concentrations of radionuclides have been determined for samples taken during the time period August 10 to September 8, 1977. The samples were analyzed for ${ }^{238} \mathrm{U},{ }^{230} \mathrm{Th},{ }^{226} \mathrm{Ra}$, and ${ }^{210} \mathrm{~Pb}$. Concentrations were subsequently calculated in $\mu \mathrm{Ci} / \mathrm{cm}^{3}$ of radionuclide as well as the $\mathrm{dpm} / \mathrm{g}$ of airborne solid collected. Airborne material whose radionuclide content was determined was 
TABLE 7. Radon Emission Rate from Taijings, Secondary Sources and Background Areas (a)

\begin{tabular}{|c|c|c|c|}
\hline Area & Approximate Area $\left(\mathrm{km}^{2}\right)$ & $\mathrm{Ci} / \mathrm{km}^{2} /$ Day & Ci/Area \\
\hline A & 0.2 & 0.75 & 0.15 \\
\hline B & 0.35 & 0.37 & 0.13 \\
\hline C & 0.85 & 0.14 & 0.12 \\
\hline D & 1.6 & 0.063 & 0.10 \\
\hline E & 12.2 & 0.028 & .34 \\
\hline $\mathrm{F}$ & 55.1 & 0.014 & .77 \\
\hline Background Area & & $0.007^{(b)}$ & \\
\hline Tailings Pile & & $11^{(b)}$ & \\
\hline & & Total & 1.61 \\
\hline
\end{tabular}

(a) From top $5 \mathrm{~cm}$ of soil

(b) Total soil column

TABLE 8. Particle Size Distributions and 210pb foncentrations in Surface Soil. Near Tailings Pile B(a)

\begin{tabular}{|c|c|c|c|}
\hline \multirow[b]{2}{*}{ Size Fraction } & \multicolumn{2}{|c|}{ Surface Soij ${ }^{(a)}$} & \multirow[b]{2}{*}{ \%Tailings } \\
\hline & Wt.\% & $210 \mathrm{~Pb} \mathrm{dpm} / \mathrm{g}$ & \\
\hline$>100$ & 78 & 38 & 5 \\
\hline $10-100$ & 21 & 180 & 20 \\
\hline $3-10$ & 0.37 & 440 & 26 \\
\hline $1-3$ & 0.18 & 490 & 24 \\
\hline$<1$ & 0.05 & 460 & 30 \\
\hline
\end{tabular}

(a) One-half mile at $45^{\circ}$ from tailings pile

collected within particle cascade impactors. The radionuclide data are reported here for particle diameters corresponding to the $50 \Delta$ cut-off diameter of each of the five impactor stages. In addition, those particles 
collected on the cascade impactor backup stage are arbitrarily plotted at the 0.5 m particle diameter.

Samples were collected at Sites A, B, and C. Sampling was for all wind speeds as long as the wind direction was $211 \pm 30^{\circ}$ at Site A. Airborne concentrations, $\mu \mathrm{Ci} / \mathrm{cm}^{3}$, are shown as a function of particle diameter in Figures 20 through 23. In these figures, the one-sigma counting limits are shown around each data symbol. If the limits are not shown, the limits are within the data symbol. In these figures, one would expect that airborne concentrations were least at background Site $A$, and subsequently increased going from the background site to on-site, Site B to Site $C$.

Airborne ${ }^{238} \mathrm{U}$. concentrations are shown in Figure 20 . For the background Site $A$, airborne radionuclide concentrations were below radiochemical detection limits for all particle sizes méasured. Concentrations were measurable at Site B for all particle diameters. For the particle sizes studied, ${ }^{238} \mathrm{U}$ concentrations ranged from about $10^{-14}$ to $10^{-15} \mu \mathrm{Ci} / \mathrm{cm}^{3}$. The airborne concentration was greatest for particle collection on the backup filter and was nearly uniform for all other particle sizes collected within the cascade impactors.

The total respirable concentration would be approximately the sum of all these data points. The sum of $10^{-14} \mu \mathrm{Ci} / \mathrm{cm}^{3}$ is $0.3 \%$ of the $3 \times 10^{-12} \mu \mathrm{Ci} / \mathrm{cm}^{3}$ from Table II, Appendix B of 10 CFR 20 (Code of Federal Regulations 1977). Although respirable particles were resuspended, and elevated concentrations were measured at Site $B$, airborne ${ }^{238} U$ concentrations appeared to be insignificant for particles arising from the sloping banks of the uranium mill tailings pile.

A further increase in airborne ${ }^{238} \mathrm{U}$ concentrations was measured at downwind Site $C$. In this case, particles were resuspended from the flat surface of the mill tailings area. In Figure 21 data are shown only for the backup filter and for the first stage of the cascade impactor. For the . backup filter, the airborne concentration was $10^{-13} \mu \mathrm{Ci} / \mathrm{cm}^{3}$, which is $3 \%$ of Table II, Appendix B, 10 CFR 20, 1977, of $3 \times 10^{-12} \mu \mathrm{Ci} / \mathrm{cm}^{3}$. 


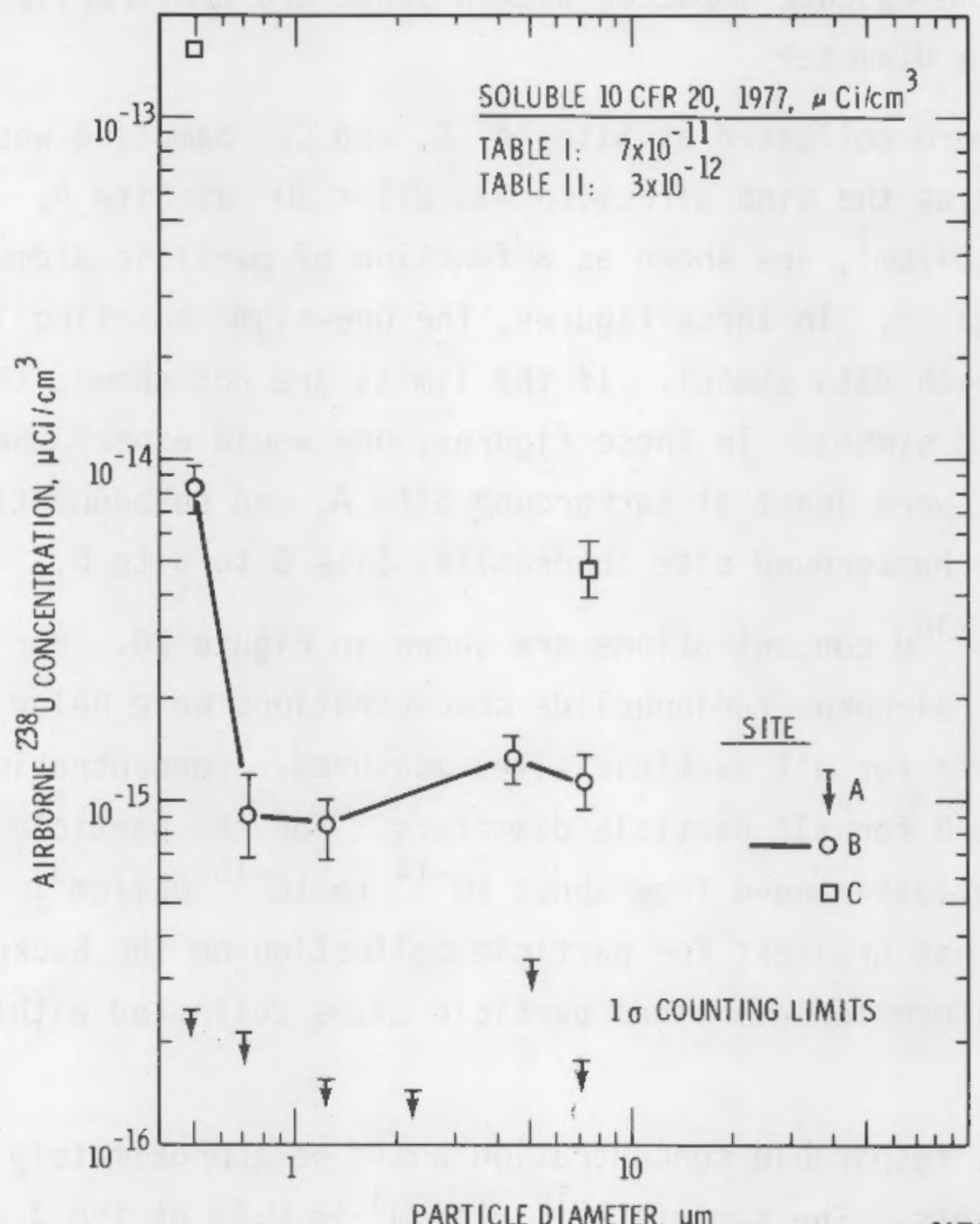

PARTICLE DIAMETER, $\mu \mathrm{m}$

NEG. $7807023-6$

FIGURE 20. Airborne $238 \mathrm{U}$ Concentrations at $1.5 \mathrm{~m}$ as a Function of Particle Diameter During August 10 to September 8, 1977 - Sampling All Winds with Direction $211^{\circ} \pm 30^{\circ}$ at Site $\mathrm{A}$

The airborne ${ }^{238} U$ concentrations at Site C--for particles collected on the back-up filter--were about 10 times greater than at Site B. In contrast, the concentration of the particles collected on the first stage was a factor of approximately six larger at Site $C$ than at Site B.

Airborne concentrations for ${ }^{230} \mathrm{Th}$ show similar patterns. As shown in Figure 21, airborne concentrations of the background, Site A, were below detection limits. Concentrations at Site $B$ ranged from about $10^{-14}$ to 


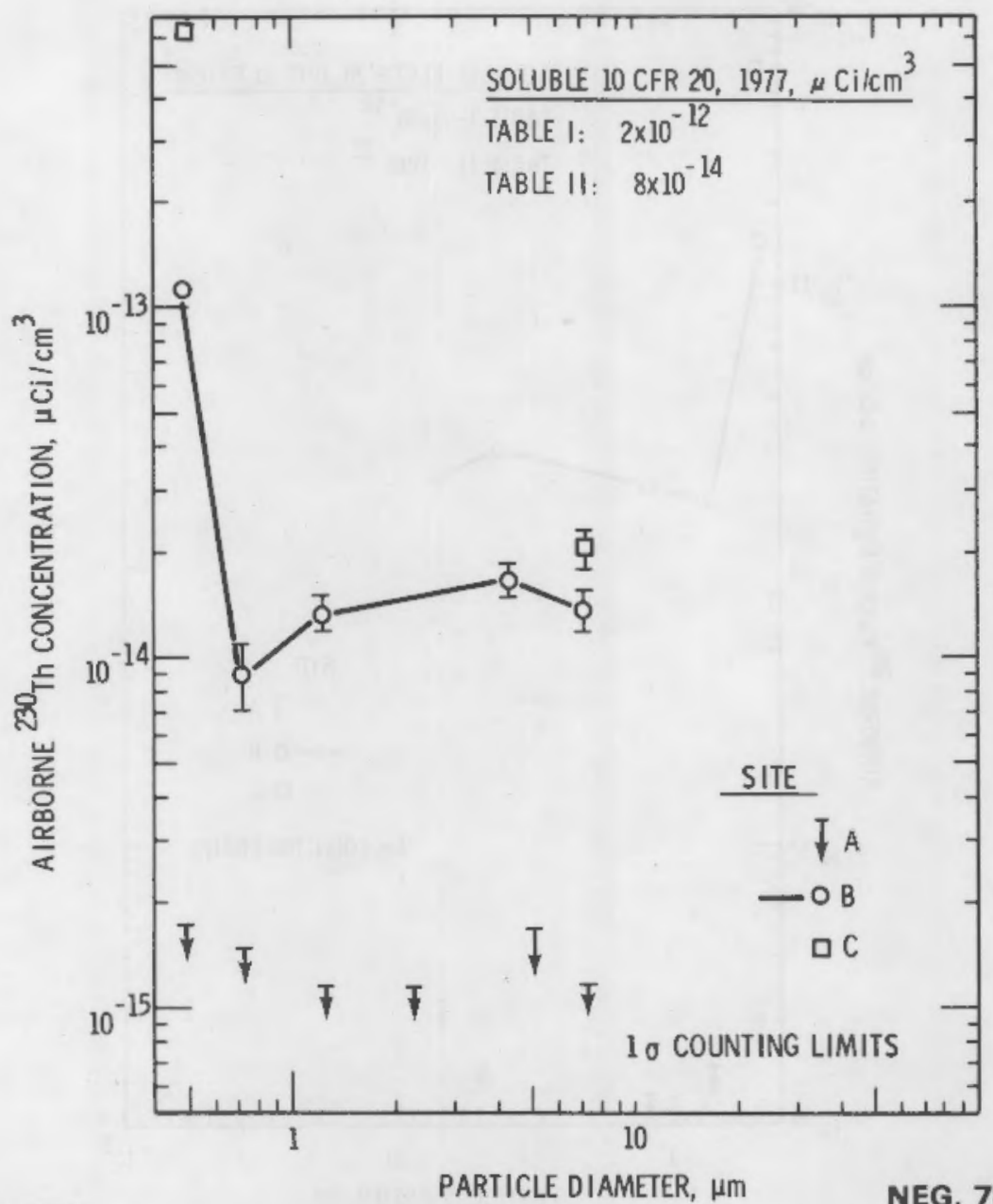

FIGURE 21. Airborne 230 Th Concentrations at $1.5 \mathrm{~m}$ as a

Function of Particle Diameter During August 10 to September 8, 1977 - Sampling al1 Winds with Direction $211^{\circ} \neq 30^{\circ}$ at Site $\mathrm{A}$

$10^{-13} \mu \mathrm{Ci} / \mathrm{cm}^{3}$. Thus, in comparison with data for ${ }^{238} \mathrm{U}$, airborne ${ }^{230} \mathrm{Th}$ concentrations are approximately one order of magnitude greater.

In addition to airborne ${ }^{230}$ Th concentrations being higher than for ${ }^{238} \mathrm{U}$ concentrations, the relative concern is even greater for ${ }^{230} \mathrm{Th}$ since the listing Tables I and II, Appendix B, 10 CFR 20, 1977 for ${ }^{230}$ Th is less that for ${ }^{238} \mathrm{U}$. The ${ }^{230} \mathrm{Th}$ concentrations were greatest for particles collected on the backup filter and were nearly uniform for other particle size ranges collected within the cascade impactors. 


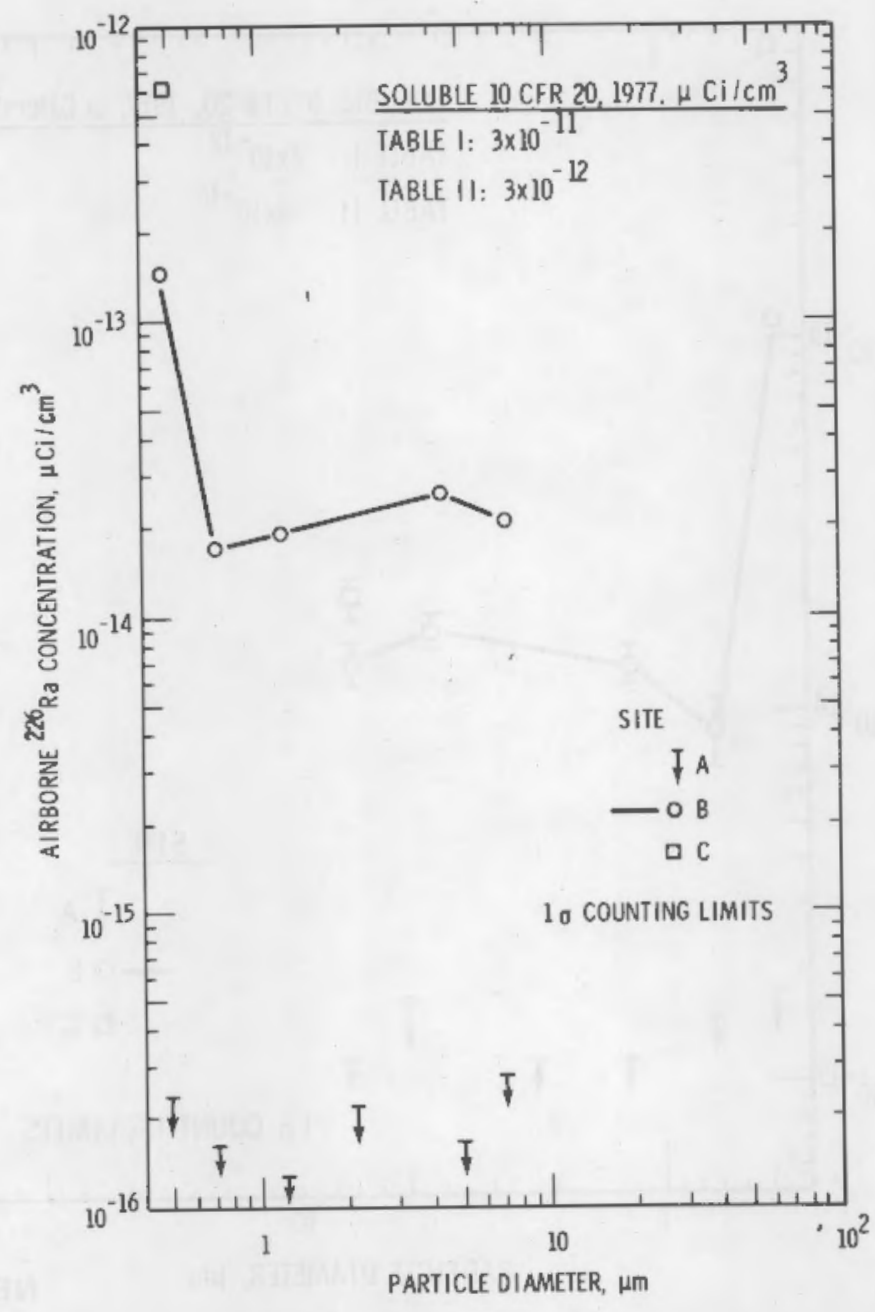

NEG. $7807023-2$

FIGURE 22. Airborne $226 \mathrm{Ra}$ Concentrations at $1.5 \mathrm{~m}$ as a Function of Particle Diameter During August 10 to September 8, 1977 - Sampling All Winds with Direction $211^{\circ} \pm 30^{\circ}$ at Site $A$

Airborne concentrations at Site $C$ were measured only for the backup filter and the first stage of the cascade impactor. For both cases, airborne ${ }^{230}$ Th concentrations were greater at Site $C$ than at Site $B$. This relative increase was a function of particle diameter. For particles collected on the backup filter, airborne concentrations were seven times greater at Site $C$ than at Site B. The increase was less, that is, two times, for calculated particle concentrations measured by collection on the first stage of each 


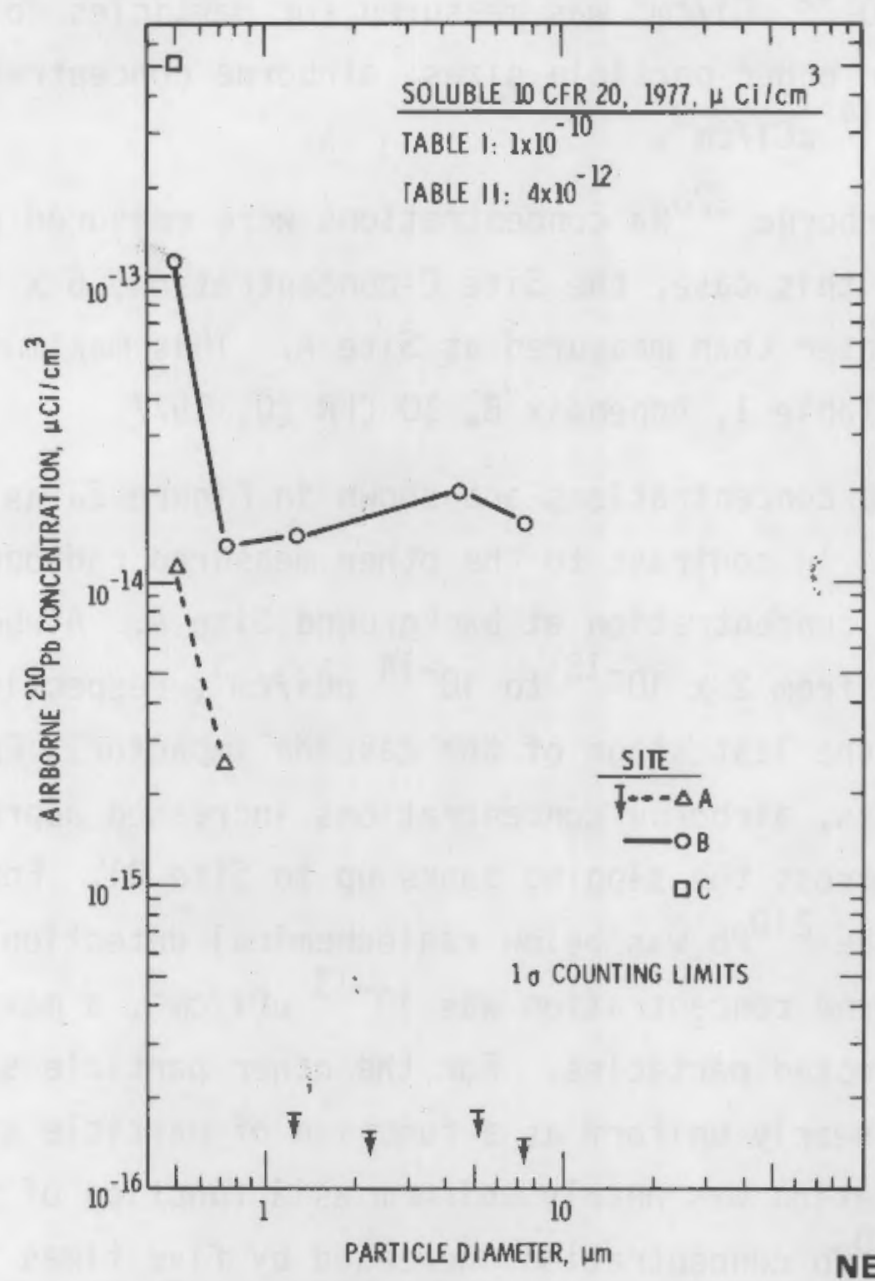

NEG. $7807023-3$

FIGURE 23. Airborne $210 \mathrm{pb}$ Concentrations at $1.5 \mathrm{~m}$ as a Function of Particle Diameter During August 10 to September 8, 1977 - Sampling all Winds with Direction $211^{\circ} \pm 30^{\circ}$ at Site $\mathrm{A}$

particle cascade impactor. The maximum ${ }^{230}$ Th concentration was 7.9 times the Table II, Appendix B, 1977, listing or 32\% of Table I, Appendix B, 10 CFR 20, 1977 .

Airborne ${ }^{226} \mathrm{Ra}$ concentrations at the three sites are shown in Figure 22. Airborne concentrations at background Site $A$, were below radiochemical detection limits. The Site $B$ airborne ${ }^{226} \mathrm{Ra}$ concentration ranged, as a function of particle size, from $10^{-14}$ to $10^{-13} \mu \mathrm{Ci} / \mathrm{cm}^{3}$. Concentrations were nonuniformly distributed as a function of particle diameter. A maximum 
concentration of $10^{-13} \mu \mathrm{Ci} / \mathrm{cm}^{3}$ was measured for particles collected on the backup filter. For other particle sizes, airborne concentrations were nearly uniform at $2 \times 10^{-14} \mu \mathrm{Ci} / \mathrm{cm}^{3}$.

At Site $C$, airborne ${ }^{226} \mathrm{Ra}$ concentrations were measured on ly for the backup filter. In this case, the site $C$ concentration, $6 \times 10^{-13} \mu \mathrm{Ci} / \mathrm{cm}^{3}$, was five times greater than measured at Site $A$. This maximum is on $1 y 20 \%$ of Table If or 2\% of Table I, Appendix B, 10 CFR 20, 1977.

Airborne ${ }^{210} \mathrm{~Pb}$ concentrations are shown in Figure 23 as a function of particle diameter. In contrast to the other measured radionuclides, there was a measurable ${ }^{210} \mathrm{~Pb}$ concentration at background site $\mathrm{A}$. Airborne ${ }^{210} \mathrm{~Pb}$ concentrations ranged from $2 \times 10^{-15}$ to $10^{-14} \mu \mathrm{Ci} / \mathrm{cm}^{3}$, respectively, for the backup filter and the last stage of the cascade impactor. For these two particle-size ranges, airborne concentrations increased approximately 10 times as the wind blew across the sloping banks up to Site B1. For other cascade impactor stages, the ${ }^{210} \mathrm{~Pb}$ was below radiochemical detection limits. At Site $B 1$, the airborne concentration was $10^{-13} \mu \mathrm{Ci} / \mathrm{cm}^{3}$, a maximum for the backup filter-collected particles. For the other particle sizes, the ${ }^{210} \mathrm{~Pb}$ concentration was nearly uniform as a function of particle size. For Site $C$, the ${ }^{210} \mathrm{~Pb}$ concentration was nearly uniform as a function of particle size. For site $C$, the ${ }^{210} \mathrm{~Pb}$ concentration increased by five times from site $B$ to Site $C$. This single measurement of $5 \times 10^{-13} \mu \mathrm{Ci} / \mathrm{cm}^{3}$ at Site $C$ was $12 \%$ of Table II or $0.5 \%$ of Table I, Appendix B, 10 CFR 20, 1977.

Airborne radionuclide concentration data are limited. Nevertheless, some general conclusions can be drawn:

- Only ${ }^{210} \mathrm{~Pb}$ was measurable at the background of Site A.

- Airborne radionuclide concentrations increased approximately one order of magnitude across the sloping sides of the pile.

- Airborne radionuclide concentrations increased approximately one order of magnitude across the flat surface of the mill tailings pile.

- Most airborne radionuclides collected in the impactor were respirable since collection was on the backup filter of the cascade impactor. 
- The measured maximum airborne radionuclide concentrations of ${ }^{230}$ Th was 31\% of Table I or 7.9 times Table II, Appendix B, 10 CFR 20, 1977.

Additional measurements of airborne radionuclides concentrations are needed to either substantiate or to modify these generalizations.

\section{Radionuclide Concentration (Activity Density) dpm/g of Airborne Particles}

Knowledge of activity associated with various size particles is important in assessing the fraction retained in the lung when the particle-containing air is breathed. The weight of particles of various size ranges was determined with the large-volume cascade impactors at Sites $A, B$, and $C$. In addition, the activity per gram of several radionuclides was determined. The resulting data are shown in Figures 24 through 27 . These data show generally that there is little change in activity per gram for different sizes of particles between about 0.5 and $10 \mu \mathrm{m}$. Data for Station A should be ignored except as noted below, since the relatively small mass of soil collected in each stage was in most cases too small to make meaningful radioactivity measurements as a function of particle size. (Less than detectable was found in most cases.)

Radionuclide concentrations, $\mathrm{dpm} / \mathrm{g}$, for ${ }^{238} \mathrm{U}$ are shown in Figure 24. At Site $B$, the $\mathrm{dpm} / \mathrm{g}$ was nearly uniform for all particle sizes. The activity per gram at Site $C$ is approximately two times greater than the $150 \mathrm{dpm} / \mathrm{g}$ measured at site $B$. This increase confirms that ${ }^{23 B} U$ was resuspended from the flat area of the pile. In addition, these data show ${ }^{238} \mathrm{U}$ was transported on all respirable particle-size ranges as determined by the particle cascade impactor data.

Similar dpm/g results are shown in Figure 25 for ${ }^{230} \mathrm{Th}$. At Site $\mathrm{B}$ the ${ }^{230} \mathrm{Th} \mathrm{dpm} / \mathrm{g}$ is nearly uniform as a function of diameter. This uniformity is similar to the uniformity shown for ${ }^{238} \mathrm{U}$. Unexpectedly, the ${ }^{230} \mathrm{Th} \mathrm{dpm} / \mathrm{g}$ concentrations decreased at Site $C$ compared to the measured concentration at Site B. The decrease is small, less than a factor of two. 


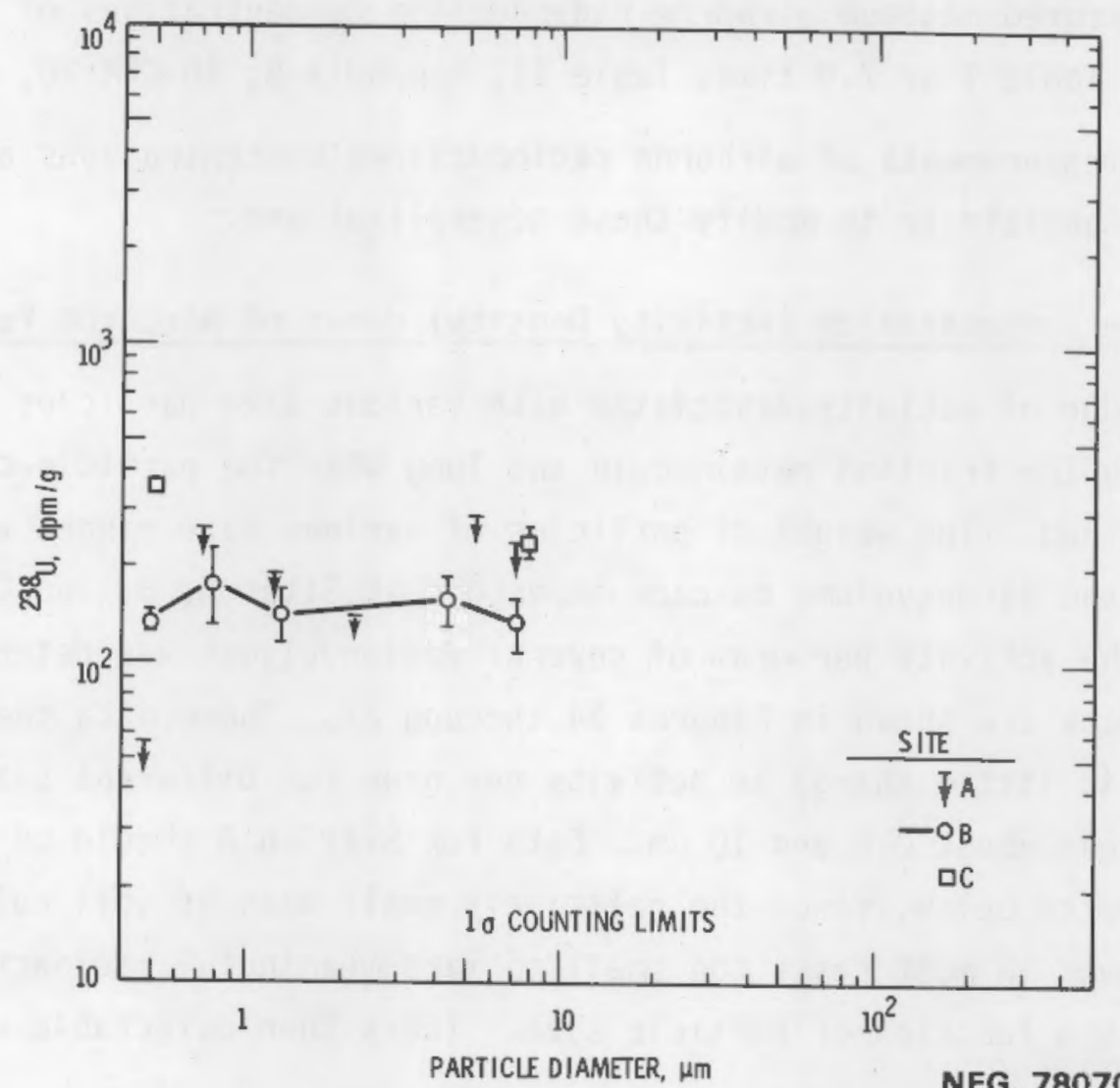

FIGURE 24. 238U Concentration on Airborne Solids as a Function of Particle Diameter

Although this apparent anomaly cannot be presently explained, the reasons for the anomaly might be explained thus: either ${ }^{230} \mathrm{Th}$ is preferentially resuspended on small particles from the sloping banks, or ${ }^{230} \mathrm{Th}$ is nonuniformly distributed in fines suspended from the flat surface of the pile. Such an explanation is speculative. The ${ }^{230}$ Th concentrations average about 2000 $\mathrm{dpm} / \mathrm{g}$, which is about one order of magnitude greater than for ${ }^{238} \mathrm{U}$.

Airborne ${ }^{226} \mathrm{Ra}$ concentrations, dpm/g, are shown in Figure 26 for the three sites. At Site $B$, the ${ }^{226}$ Ra concentration averaged about $250 \mathrm{dpm} / \mathrm{g}$ and was nearly independent of particle diameter. At Site $C$, the ${ }^{226}$ Ra concentration was one-half to about one-third the concentration at Site $B$. 


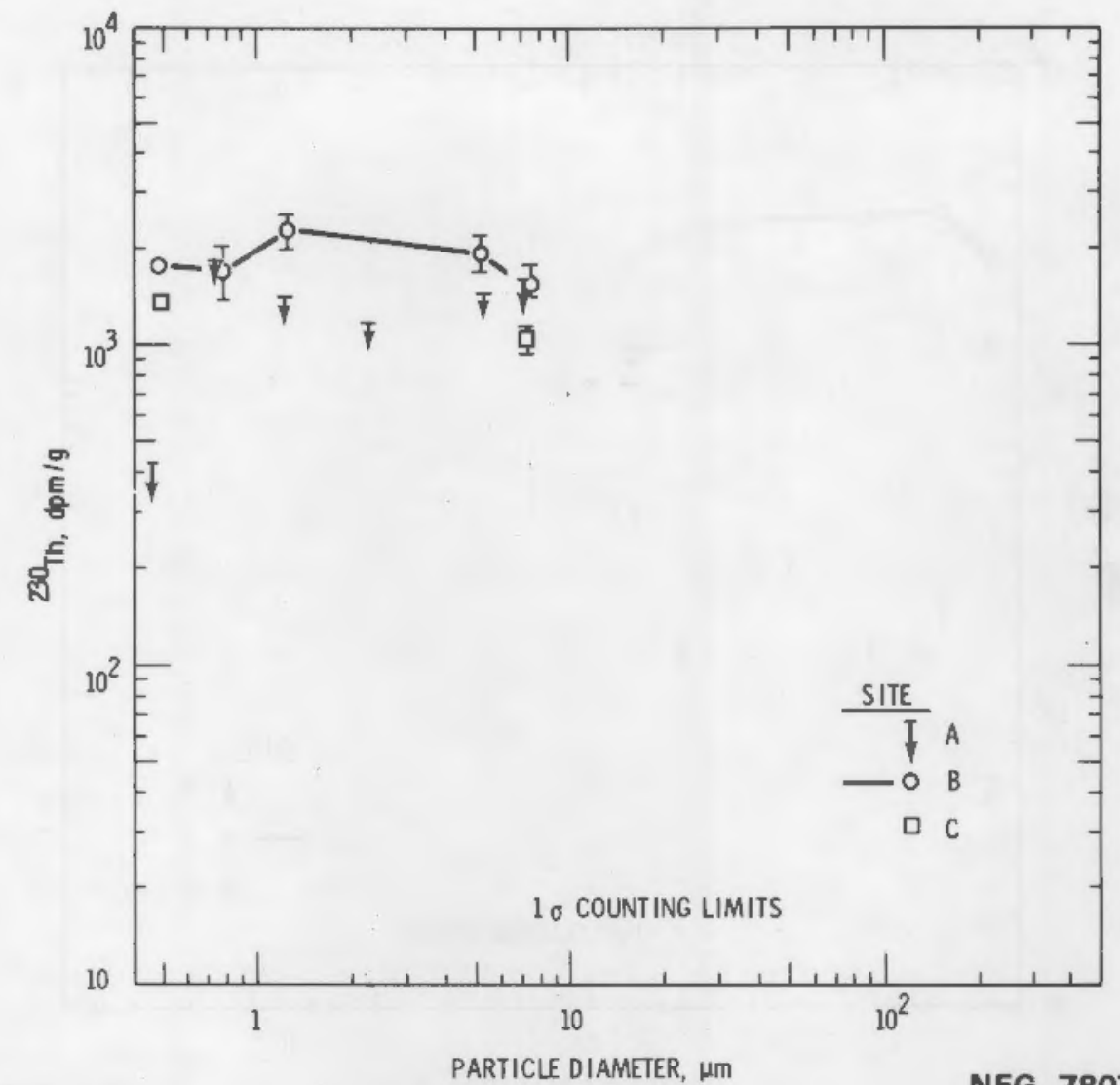

NEG. 7807023-13

FIGURE 25. ${ }^{230}$ Th Concentration on Airborne Solids as a Function of Particle Diameter

Airborne $210 \mathrm{~Pb}$ concentrations, $\mathrm{dpm} / \mathrm{g}$, are shown in Figure 27 . There are important differences in the ${ }^{210} \mathrm{~Pb}$ concentrations as compared to other radionuclides. At site $A$ the $210 \mathrm{~Pb}$ concentration averaged about $3000 \mathrm{dpm} / \mathrm{g}$ for solids collected on both the backup filter and the last stage of the cascade impactor, suggesting that the $210 \mathrm{~Pb}$ is associated with very small particles. Insufficient mass corresponding to large particles was collected at Site $A$ on the upper stages to make an accurate measurement of $210 \mathrm{~Pb} / \mathrm{g}$. The relatively high concentrations found associated with fine particles at the upwind site was not present at Site B or Site C. However, significant levels associated with all particle sizes up to $10 \mu \mathrm{m}$ were found at these two sites; the sample at Site $C$ showed about one-half the concentration at Site B, and both were less than the sample taken at Site A. Since ${ }^{210} \mathrm{~Pb}$ is the first 


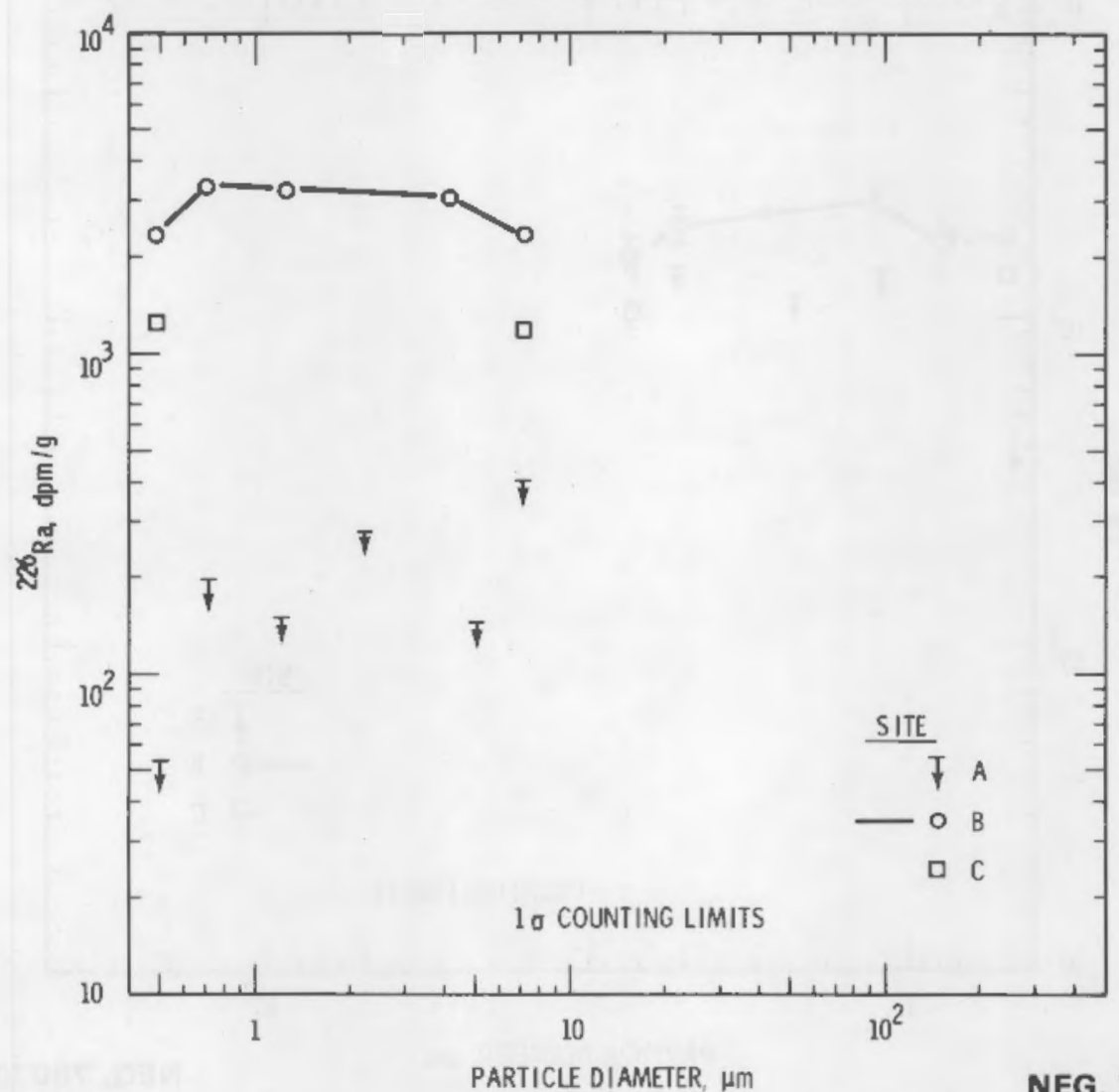

FIGURE 26. 226Ra Concentration on Airborne Solids as a Function of Particle Diameter

long-lived progeny of ${ }^{222} \mathrm{Rn}$, and ${ }^{222} \mathrm{Rn}$ is ubiquitous in the region, relatively high concentrations per gram in the very fine particle size might be expected in the vicinity of the tailings pile. Differences by a factor of two or three among the three sites are yet unexplained. In particular, the upwind sample appears to be more concentrated with ${ }^{210} \mathrm{~Pb}$ than are the samples taken on the tailings pile.

These data are regarded as an initial set and the conclusions tentative until more samples are taken and analyzed under conditions that permit the controlling variables to be manifest in the results.

The radionuclides associated with the larger airborne particles were determined for a sample taken near Site C. The sample was collected with a 


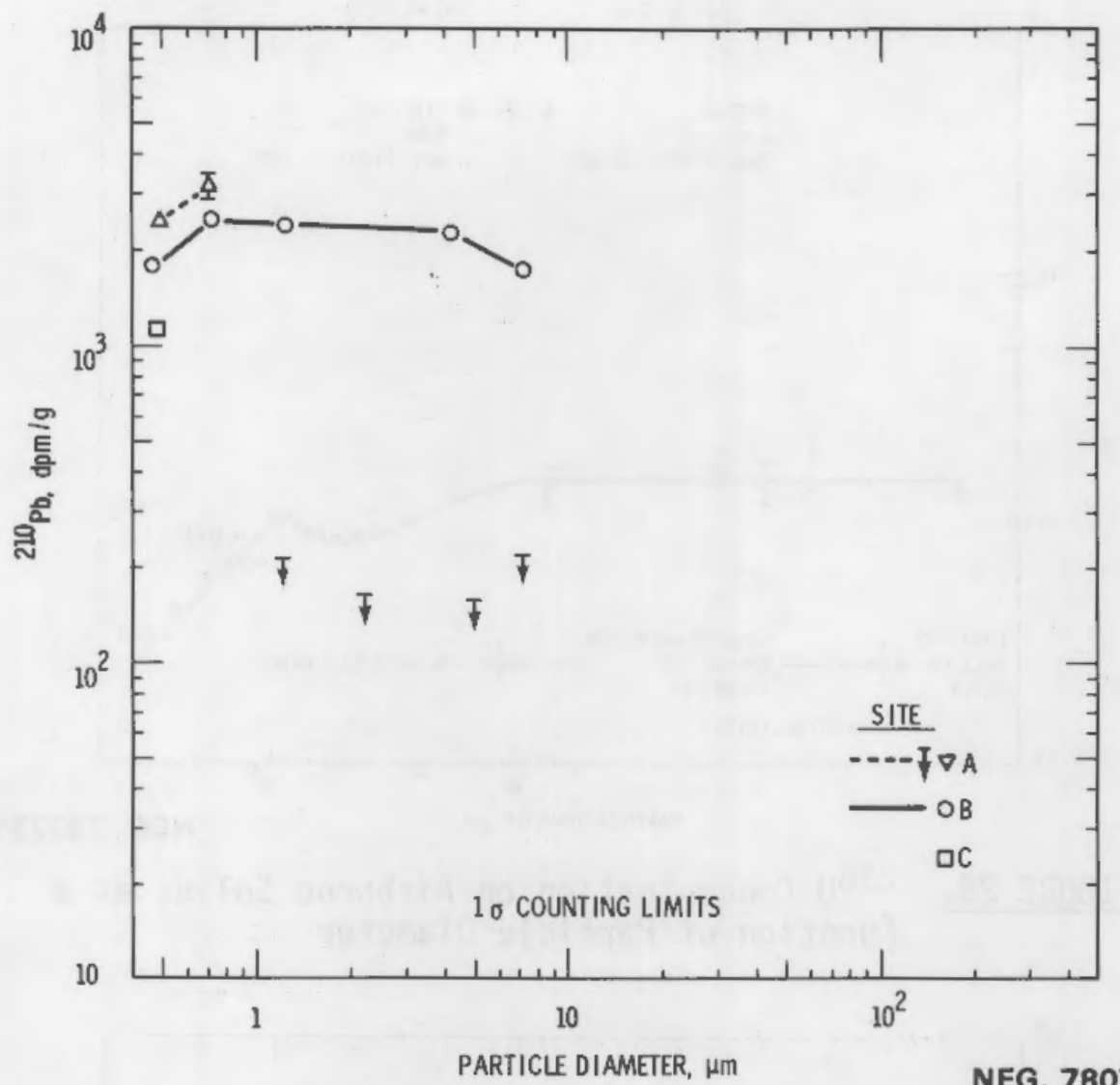

NEG. 7807023-12

FIGURE 27. $210 \mathrm{~Pb}$ Concentration on Airborne Solids as a Function of Particle Diameter

high-volume sampler located at $0.3 \mathrm{~m}$ above the surface. The inlet of the sampler acted as a settling chamber; hence, larger particles were found here. Enough mass was collected to permit sieving and measurement of radioactivity in each particle size range. Results of these measurements in terms of dpm/g versus particle size are shown plotted in Figures 28 through 31 . The relationship of activity per gram for larger particles and activity per gram for the impactor-collected respirable range particles at Site B1 is shown. Gram for gram, the larger particles contain less radioactivity. For particles $100 \mu \mathrm{m}$ to $300 \mu \mathrm{m}$ in diameter, the activity per gram decreases with size with a slope of 1 , suggesting that the larger particles have activity proportional to the surface area, rather than volume. Very small particles may be attached to 


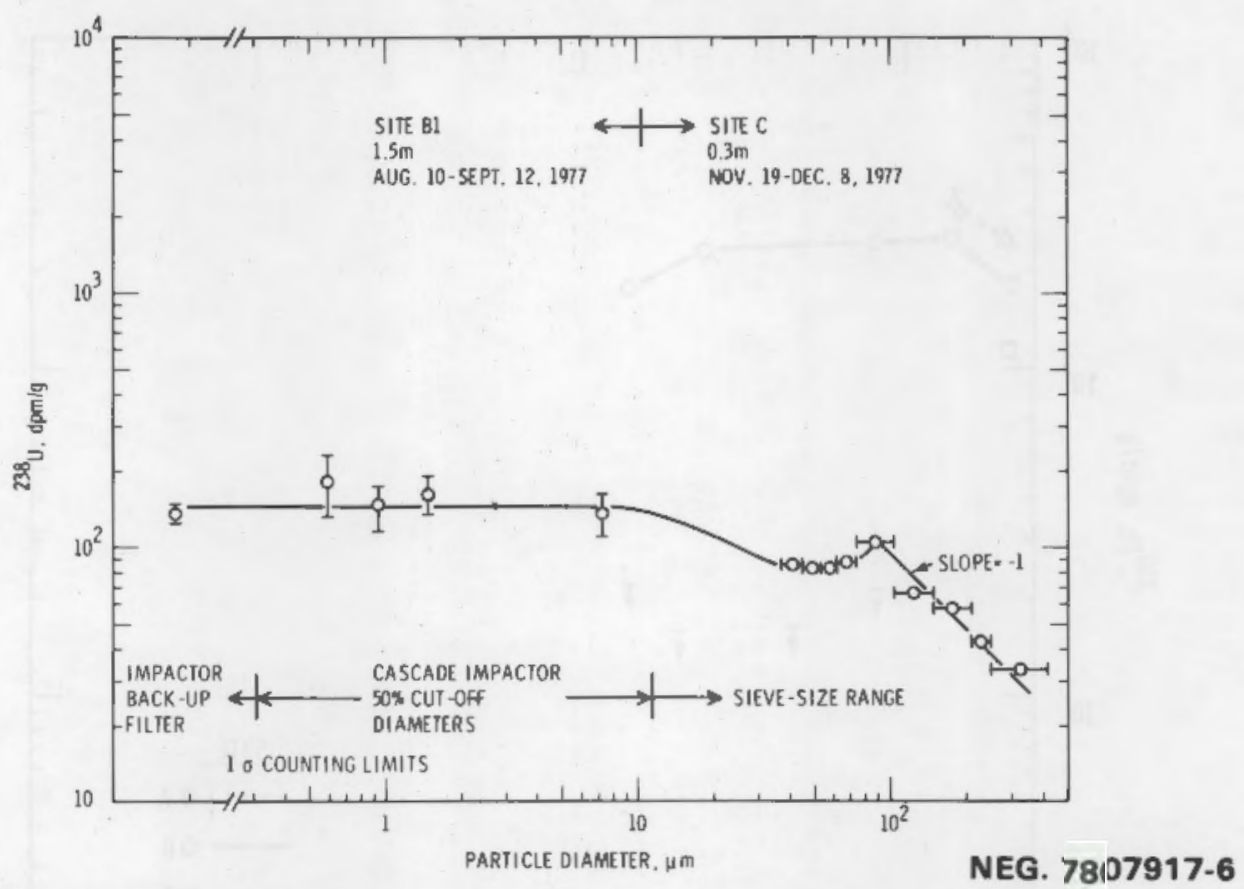

FIGURE 28. 238 U Concentration on Airborne Solids as a Function of Particle Diameter

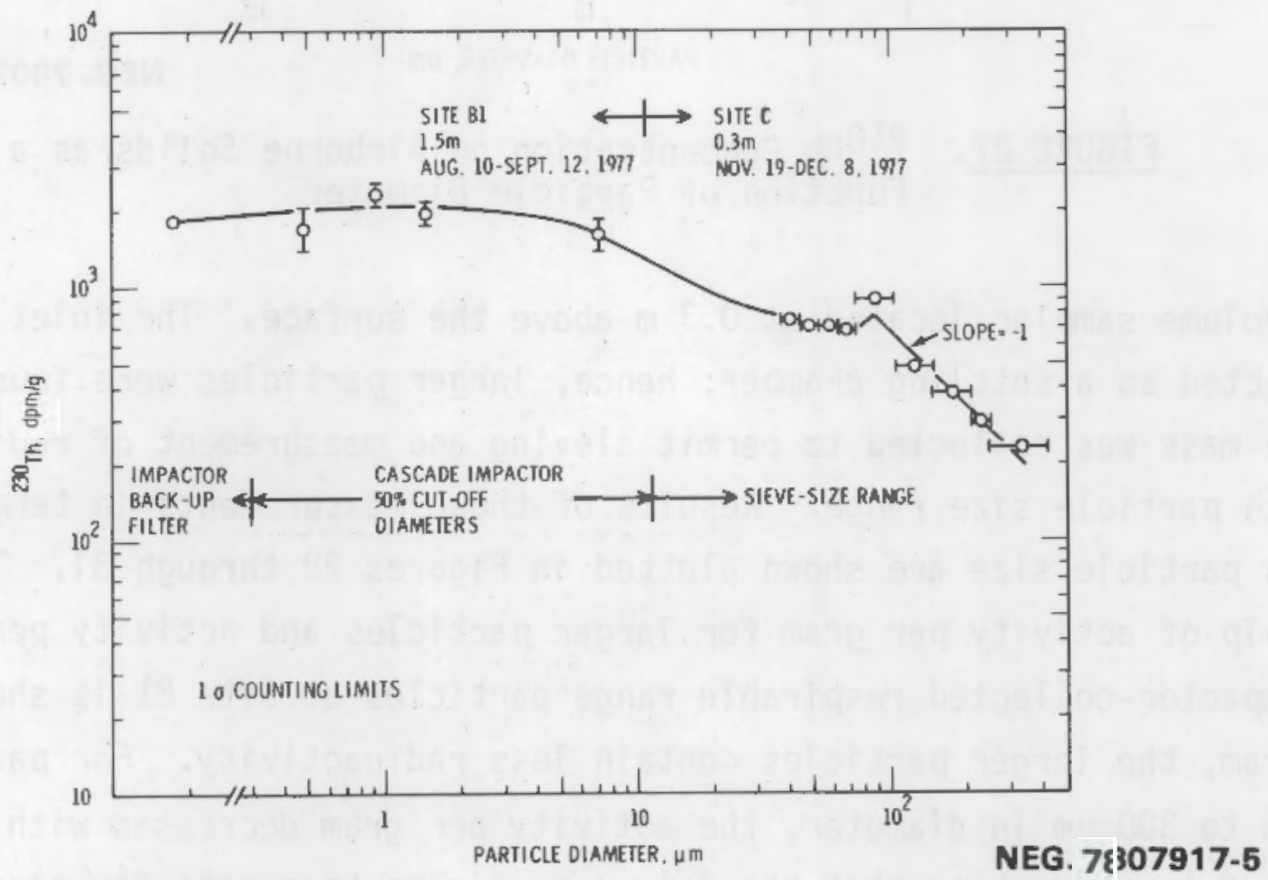

FIGURE 29. 230 Th Concentration on Airborne Solids as a Function of Particle Diameter 


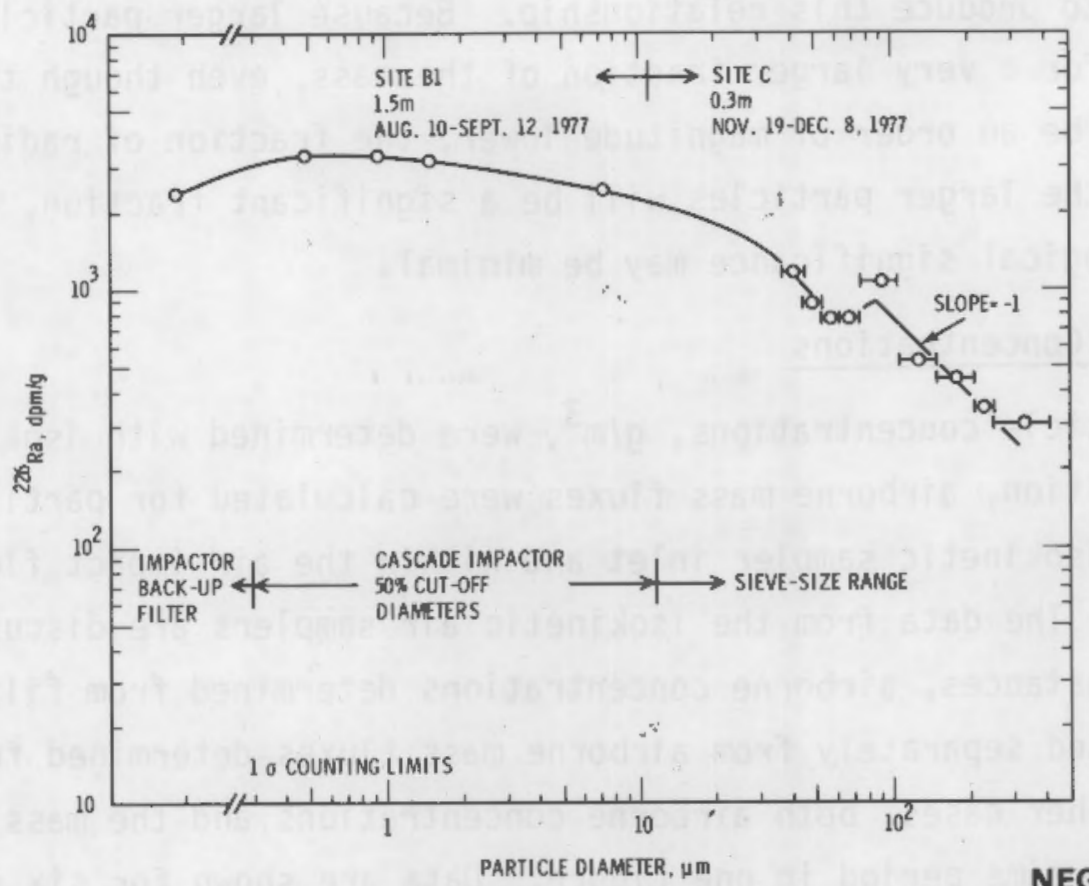

NEG. 7807917-2

FIGURE 30. ${ }^{226}$ Ra Concentration on Airborne Solids as a Function of Particle Diameter

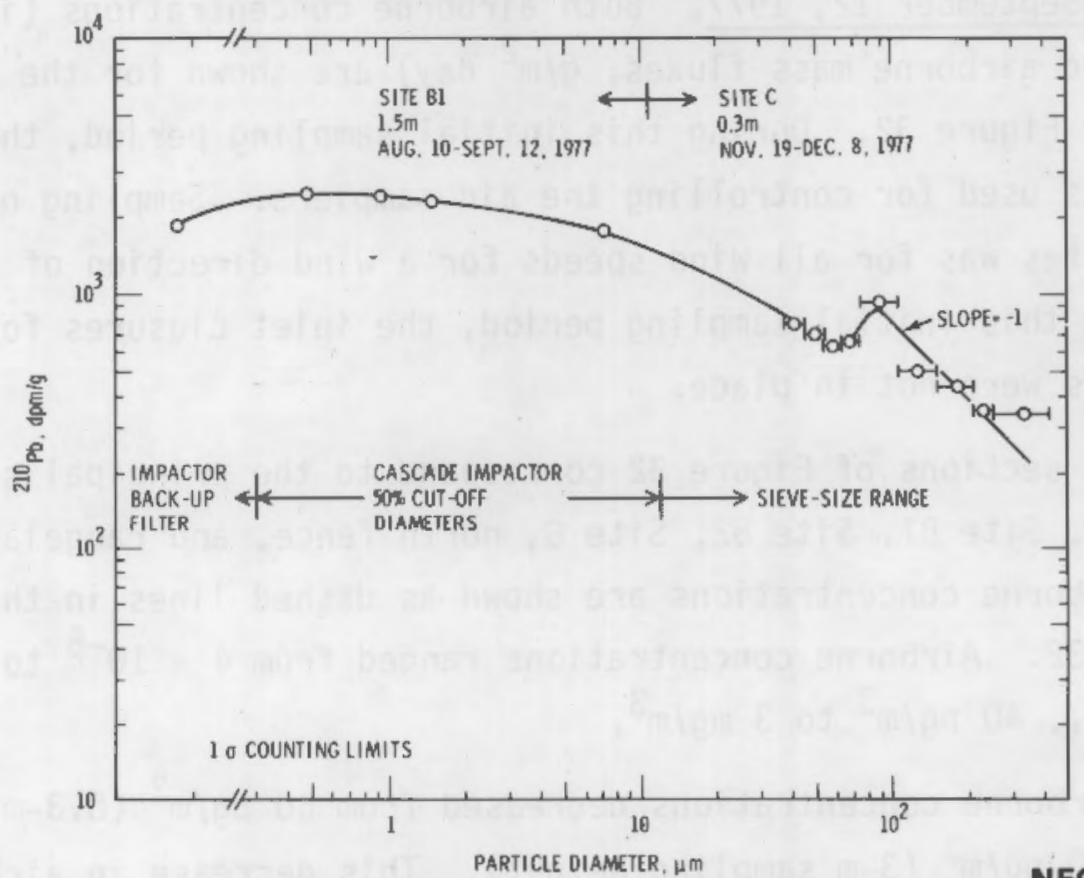

NEG. $7807917-4$

FIGURE 31 . $210 \mathrm{~Pb}$ Concentration on Airborne Solids as a Function of Particle Diameter 
larger particles to produce this relationship. Because larger particles $(>20 \mu \mathrm{m})$ account for a very larger fraction of the mass, even though the activity per gram may be an order of magnitude lower, the fraction of radionuclides transported with the larger particles will be a significant fraction, even though the radiological significance may be minimal.

\section{Airborne Particle Concentrations}

Airborne particle concentrations, $\mathrm{g} / \mathrm{m}^{3}$, were determined with isokinetic samplers. In addition, airborne mass fluxes were calculated for particles collected in the isokinetic sampler inlet and within the air impact flow particle collectors. The data from the isokinetic air samplers are discussed first. In some instances, airborne concentrations determined from filter collection are reported separately from airborne mass fluxes determined from inlet collection. In other cases, both airborne concentrations and the mass flux are shown for the same time period in one figure. Data are shown for six sampling time periods.

- August 10 to September 12, 1977. Both airborne concentrations (i.e., mass loadings, $\mathrm{g} / \mathrm{m}^{3}$, and airborne mass fluxes, $\mathrm{g} / \mathrm{m}^{2}$ day) are shown for the first sampling period in Figure 32. During this initial sampling period, the wind direction alone was used for controlling the air samplers. Sampling of airborne particulates was for all wind speeds for a wind direction of $211^{\circ} \pm 35^{\circ}$ at Site $A$. During this initial sampling period, the inlet closures for the isokinetic samplers were not in place.

Six different sections of Figure 32 correspond to the principal sampling locations: Site A, Site B1, Site B2, Site C, north fence, and rangeland offsite. Average airborne concentrations are shown as dashed lines in the upper portion of Figure 32. Airborne concentrations ranged from $4 \times 10^{-5}$ to $3 \times 10^{-3} \mathrm{~g} / \mathrm{m}^{3}$, i.e., $40 \mu \mathrm{g} / \mathrm{m}^{3}$ to $3 \mathrm{mg} / \mathrm{m}^{3}$.

At Site A, airborne concentrations decreased from $60 \mu \mathrm{g} / \mathrm{m}^{3}(0.3-\mathrm{m}$ sampling height) to $30 \mu \mathrm{g} / \mathrm{m}^{3}$ (3-m sampling height). This decrease in airborne 
concentration with increasing height is indicative of either a local or upwind resuspension source. A similar decreasing concentration with height is shown for Site B1. At a sampling height of $0.3 \mathrm{~m}$, the concentration was $1 \mathrm{mg} / \mathrm{m}^{3}$ and decreased to $300 \mu \mathrm{g} / \mathrm{m}^{3}$ at a sampling height of $3 \mathrm{~m}$. Obviously, at the Site $B 1$ the suspension source was the sloping side of the uranium mill tailings pile. Airborne concentrations increased about one order of magnitude over that measured at background Site A.

At sampling Site 82 , airborne concentrations also decreased with increasing sampling height. Differences exist between airborne concentrations at Site $\mathrm{B} 1$ and $\mathrm{B} 2$, which could be attributed to at least three factors: the sampling locations, crosswind variations in wind, and mill tailings pile geometry. At Site B1, the top of the perimeter dike was about $1 \mathrm{~m}$ higher than the base of the tower. In contrast, for sampling tower B2, the sampling tower base was approximately $3 \mathrm{~m}$ below the dike level.

A further increase in airborne concentration was measured at sampling Site $C$. The maximum measured concentration was $3 \mathrm{mg} / \mathrm{m}^{3}$ at a sampling height of $0.3 \mathrm{~m}$. Concentrations decreased with increasing height. At $3 \mathrm{~m}$, the concentration was $300 \mu \mathrm{g} / \mathrm{m}^{3}$, which is approximately the same concentration measured at a lower elevation of $0.3 \mathrm{~m}$ at Site B1. Obviously, the plume of resuspended particles increased in height in the downwind direction.

Concentrations measured at nine locations along the north fence are indicative of the average crosswind variations and also exhibit the minimum uncertainty anticipated by downwind concentration predictions. A variation of two is shown. Along the north fence, airborne concentrations were about 5 to 10 times greater than at background, Site A.

Airborne concentrations measured at off-site rangeland locations are shown on the right side of Figure 32. Concentrations decreased with distance from the pile and were approximately at a background level of $50 \mu \mathrm{g} / \mathrm{m}^{3}$ at a distance of $4 \mathrm{~km}$. Thus, a rule of thumb derived from these data is that airborne concentrations approach background $4 \mathrm{~km}$ from a mill tailings pile. 


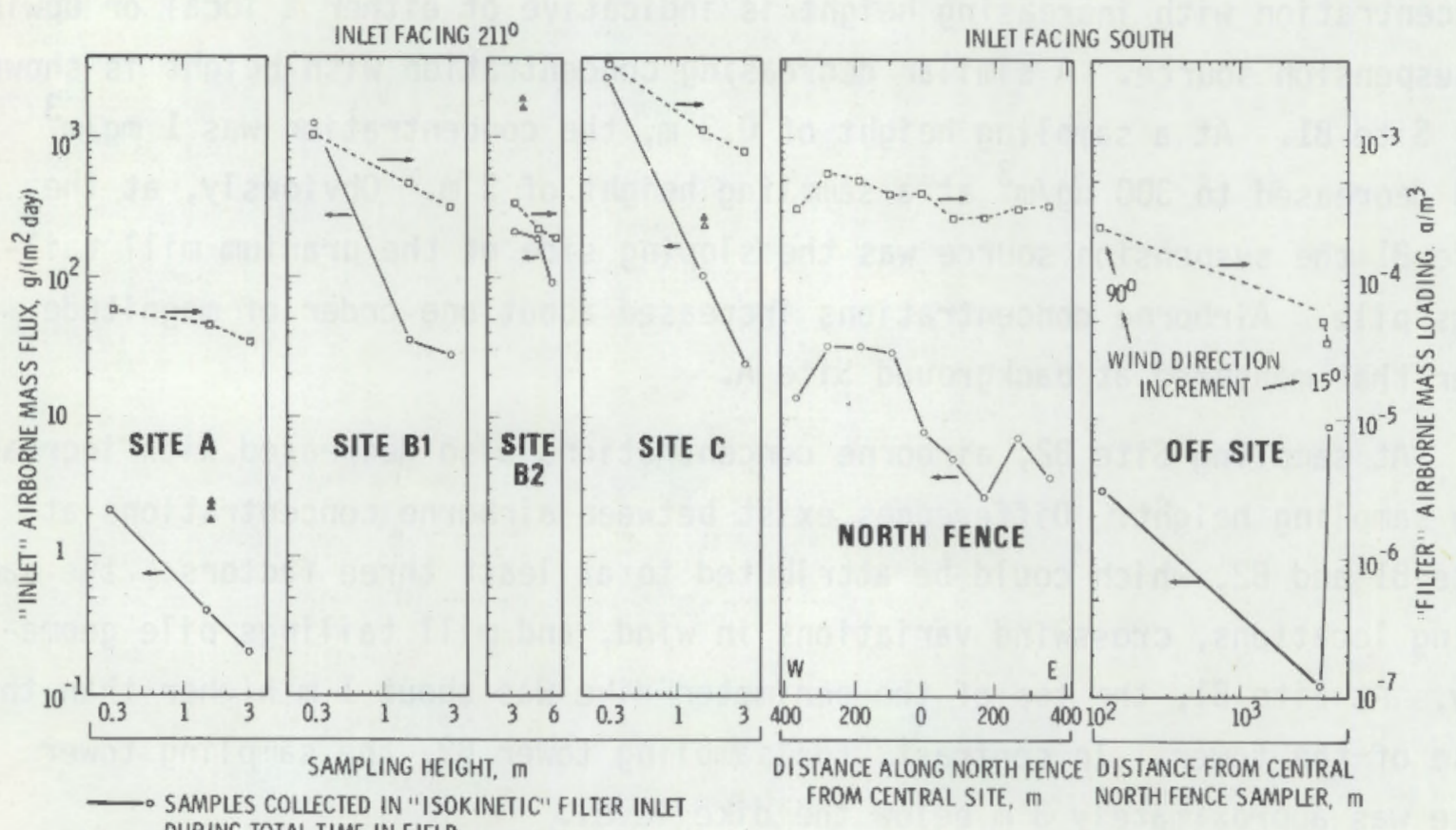
DURING TOTAL TIME IN FIELD

DURING TOTAL TIME IN FIELD
- SAMPLES COLLECTED ON "ISOKINETIC" FILTER

DURING AUL WIND FROM $211^{\circ} \pm 30$ AT SITE A

$\triangle$ CYCLONE INLET

NEG. $7807917-1$

FIGURE 32. Average Airborne Fluxes and Concentrations During August 10 to September 12, 1977

Airborne mass fluxes, $\mathrm{g} /\left(\mathrm{m}^{2}\right.$ day) for larger particles collected in the inlet section of the high-volume isokinetic samplers, are shown in the lower portion of Figure 32. Also shown for Sites A, B2, and C are mass fluxes calculated from the particle mass collected in the entry cyclone separators of the cascade impactors. There are differences in magnitude between mass fluxes calculated for the cyclone inlets and isokinetic sampler inlets. In all cases, the mass flux based on particles collected in the cyclone inlet was greater than for particles collected in the isokinetic inlet. Differences in calculated mass fluxes may result from differences in airflow patterns around the two sampler types. There is a basic difference between data for Sites $A$ and $C$ versus data for Site B2. For Site B2, cyclone samplers (cascade impactors) were located on the dike, whereas the sampling tower carrying the isokinetic samplers was located downwind on the fines area. 
Airborne mass fluxes calculated for the isokinetic sampler inlets are considered in more detail. At Sites A, B1, B2, and C, the mass flux decreased with increasing height. The decrease was a manifestation of resuspension occurring locally without significant deposition occurring. Airborne mass fluxes at Sites $B 1$ and $B 2$ were one to two orders of magnitude greater than background. A further increase was measured at Site $C$. The maximum measured flux, $2.3 \mathrm{~kg} /\left(\mathrm{m}^{2}\right.$ day) was at the $0.3-\mathrm{m}$ height of Site $C$.

Airborne mass fluxes decreased rapidly, two to three orders of magnitude, from Site $C$ to the north fence. However, along the north fence, the mass flux was as much as two orders of magnitude greater than background at Site $\mathrm{A}$. Along the north fence, there was an order of magnitude variation in the mass fluxes. This crosswind variation of the mass flux, $g /\left(m^{2}\right.$ day), is greater than the crosswind variation of the airborne concentration of the filter-collected particles, $\mathrm{g} / \mathrm{m}^{3}$. Thus, both variations must be considered in determining the total solids release and, thus, radionuclide release from the mill tailings area.

Off-site mass fluxes were within the same order of magnitude as the background mass fluxes. However, for the two sampling sites located at approximately $4 \mathrm{~km}$, there was almost a two-order magnitude variation between calculated mass fluxes. This large variation at $4 \mathrm{~km}$ is indicative of expected difficulties in either satisfactorily predicting or experimentally determining the crosswind-downwind variations. Experimentally, many sites would be required to adequately define this crosswind variation at $4 \mathrm{~km}$.

It must be borne in mind that the mass flux discussed is based upon a very nominal estimate of "large" particles carried in the air. Although both the cascade impactor and the isokinetic high-volume samplers operated only as a function of wind direction during this period, it is quite likely that crosswinds outside the control range could have delivered particles to the inlet (and to the filter to lesser degree). In later runs the inlet was closed to entry of particles until the wind direction and speed were satisfied for that group of samplers.

The radiological significance of particles of size collected in the inlet sections of these two samplers is certainly much less than for particles of 
respirable size. It was, nevertheless, believed necessary to determine the transport of all radioactive material to assure completeness in modeling. The degree to which this modeling will ultimately be possible rests very largely on the ability to sample the full spectrum of particle sizes efficiently.

- November 19 to December 8, 1977. During this sampling period, inlet closures for the isokinetic samplers were installed, which resulted in more accurate sampling as a function of wind-speed increments. Since closures were in place, airborne concentrations could be calculated from both filter collection as well as sampler inlet collection. Two airborne concentrations, $\mathrm{g} / \mathrm{m}^{3}$, are shown here: one was calculated from only filter-collected particles, whereas the other was calculated from filter plus inlet-collected particles.

Airborne concentrations were measured for three wind-speed increments: 3 to 5,5 to 7 , and 7 to $11 \mathrm{~m} / \mathrm{sec}$. These three wind speeds were used for activating isokinetic samplers at Sites $A, B 1$, and B2. Only one wind-speed increment, the entire range from 3 to $11 \mathrm{~m} / \mathrm{sec}$, was used for activating isokinetic air samplers along the north fence.

As shown in Figure 33, background airborne concentrations at Site $A$ ranged from $2 \times 10^{-5}$ to $3 \times 10^{-4} \mathrm{~g} / \mathrm{m}^{3}$. As expected, airborne solids concentrations increased at Sites $B 1$ and $B 2$ across the sloping sides of the pile. Airborne concentrations at Site $C$ were not measured during this time because of equipment problems. Average airborne concentrations along the north fence, $1 \mathrm{mg} / \mathrm{m}^{3}$, were approximately one order of magnitude greater than the average, $100 \mu \mathrm{g} / \mathrm{m}^{3}$, measured at Site A.

These increases in airborne concentrations at Sites B1 and B2 and along the north fence demonstrate that wind erosion was occurring from the mill tailings area. Erosion, however, was nonuniform; average airborne concentrations along the north fence show a variation of ten from the highest to lowest airborne concentration.

One would expect airborne concentrations to increase with increasing wind speed. It is surprising, however, that almost the opposite occurred. Even at 

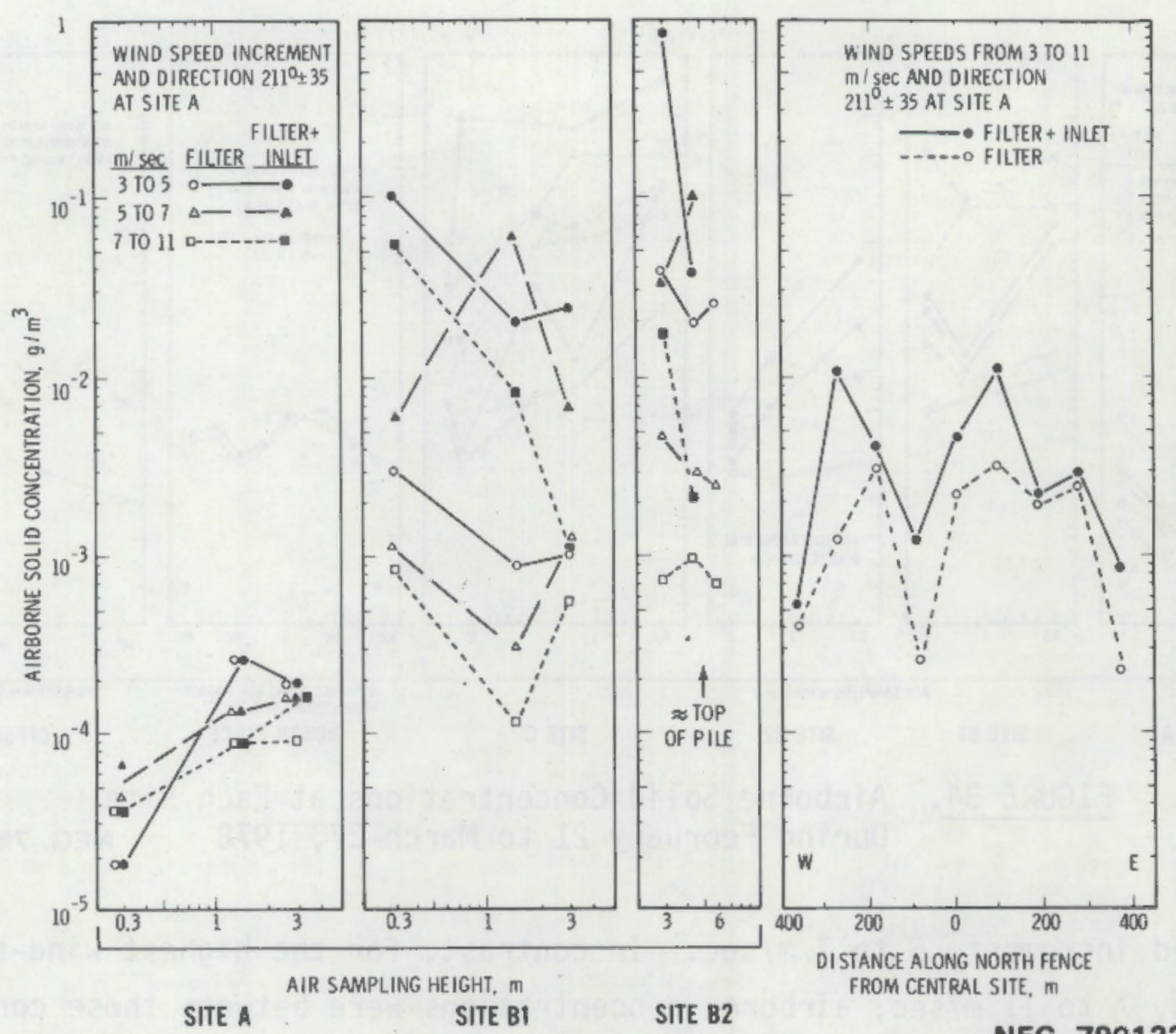

NEG. 7901225-1

FIGURE 33. Airborne Solid Concentrations at Each Site During November 19 to December 8, 1977

background, Site A, except for the 0.3-m level at the lowest wind speed, airborne concentrations at the lowest wind speed were greater than airborne concentrations for higher wind speeds.

- February 21 to March 27, 1978. Average airborne concentrations for this time period are shown in Figure 34 . The data set in this figure are airborne concentrations as a function of wind speed at Site $A$. The Site $C$ data are the first to show the average erosion plume height, to $15 \mathrm{~m}$, for the three windspeed increments. A significant fraction of the total collected airborne solid was collected on the inlet of the isokinetic air samplers.

For Site $\mathrm{C}$, airborne concentrations were least for the $3-$ to $5-\mathrm{m} / \mathrm{sec}$ windspeed increment. Airborne concentrations increased for the next 

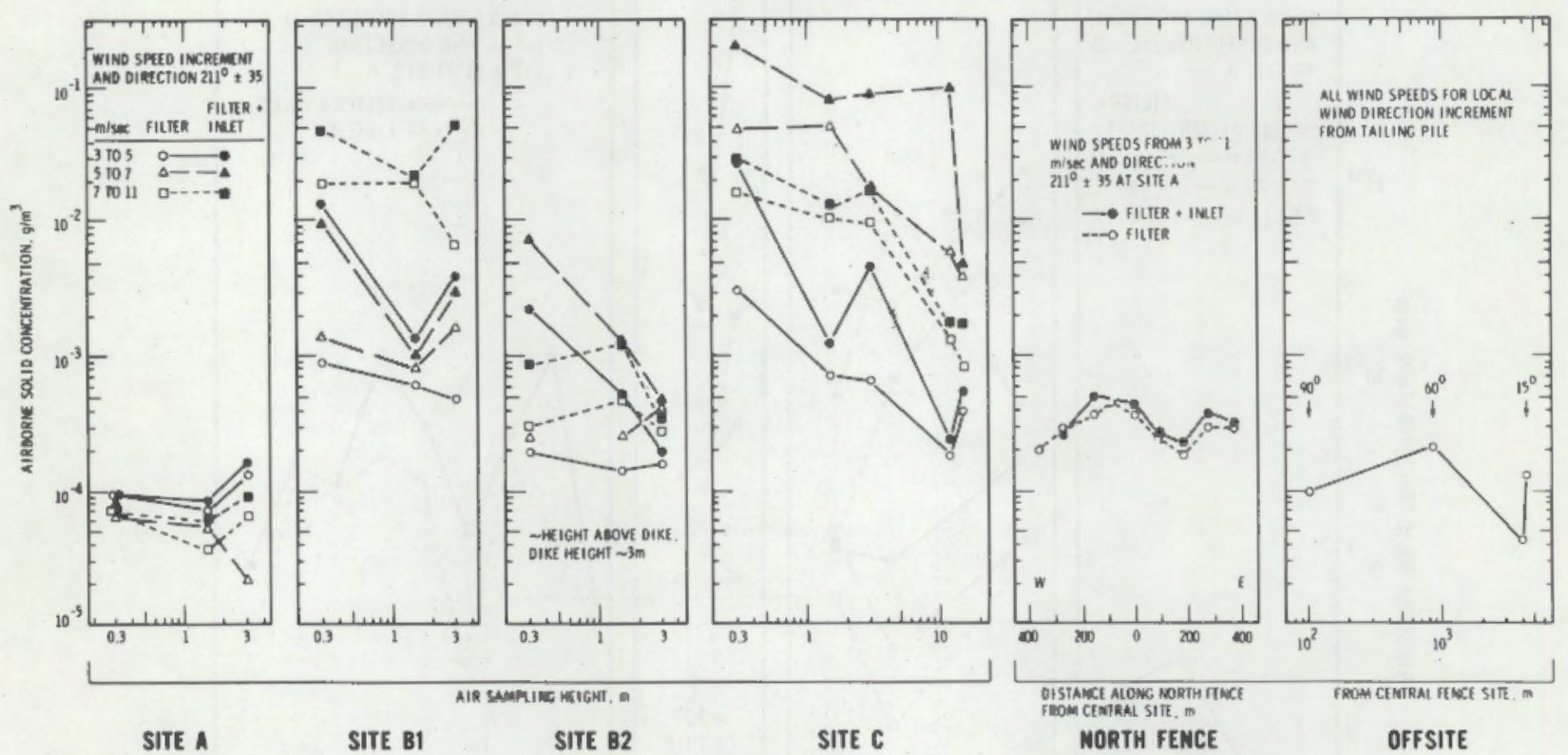

SITE A

SITE B1

SITE B2

SITE C

MORTH FENCE

OFFSITE

FIGURE 34. Airborne Sol id Concentrations at Each Site During February 21 to March 27, 1978

NEG. 7808002-4

wind-speed increment, 5 to $7 \mathrm{~m} / \mathrm{sec}$. In contrast, for the highest wind-speed increment, 7 to $11 \mathrm{~m} / \mathrm{sec}$, airborne concentrations were between those concentrations measured for the two lower wind-speed increments. At Sites B1 and B2 airborne concentrations increased as wind speeds increased.

Concentrations measured at distances from several hundred meters to $4 \mathrm{~km}$ downwind show that levels comparable to the concentration upwind of the tailings pile are present. The sample taken with the sampler at $100 \mathrm{~m}$ north of the north fence appears to be inconsistently low when compared with the general average of concentrations at the north fence. The two samples taken at R3 and R4, nearly the same distance downwind but separated in the W-E direction by approximately $600 \mathrm{~m}$, would be expected to be about the same in concentration. Taking into account possible crosswind differences and the lateral $(W-E)$ distance between samplers, significant differences might be expected in these samples.

- March 30 to April 17, 1978. Airborne concentrations for this sampling period are illustrated in Figure 35. Here, airborne concentrations show an 

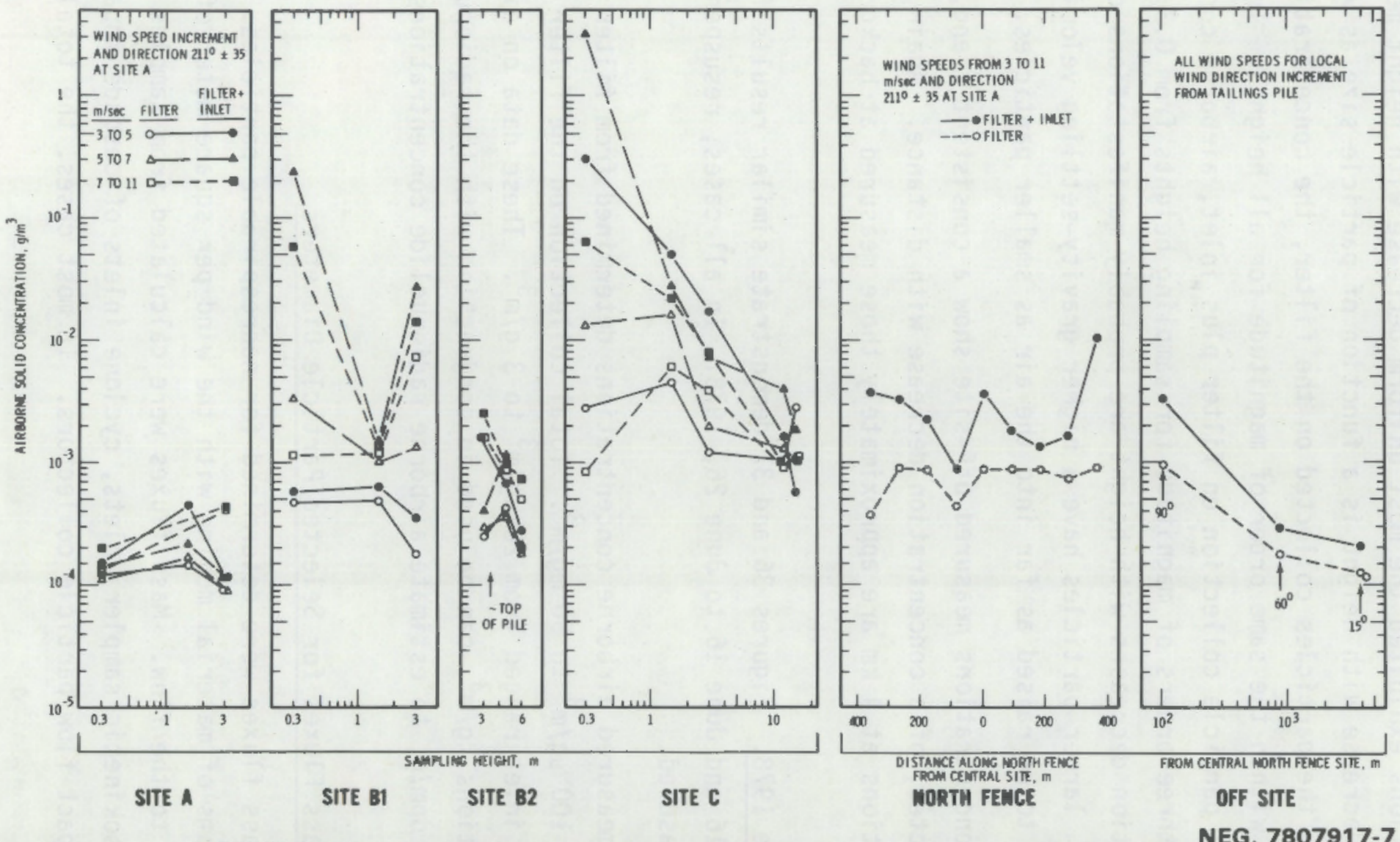

FIGURE 35. Airborne Solid Concentrations at Each Site During March 30 to April 17, 1978 
unexpected trend as a function of wind speed, the 7 to $11 \mathrm{~m} / \mathrm{sec}$ wind-speed samplers showing lower concentrations than for lesser speeds. At Site C, airborne concentrations exhibited the most uniform decrease with height measured to date. This decrease with height is a function of particle size as well as wind speed. For the particles collected on the filter, the concentrations decrease or are within the same order of magnitude for all heights. In contrast, for total particle collection on filter plus inlet, airborne concentrations decrease three orders of magnitude for sampling heights from 0.3 to $3 \mathrm{~m}$. These concentration decreases with height are probably manifestations of particle diameter: larger particles have a higher gravity-settling velocity and, hence, tend not to be raised as far into the air as smaller particles.

Airborne concentrations measured off-site show a consistent trend, as originally expected, of a concentration decrease with distance. Again, airborne concentrations at $4 \mathrm{~km}$ are approximately those measured at background, Site A.

- May to June 1978. Figures 36 and 37 demonstrate similar results for May 26 to June 16 and June 16 to June 26, 1978. In all cases, resuspended material was measured.

In brief, measured airborne concentrations determined from filter collection range from $100 \mathrm{\mu g} / \mathrm{m}^{3}$ to $50 \mathrm{mg} / \mathrm{m}^{3}$. Total collection on the filter plus isokinetic inlet ranged from $20 \mu \mathrm{g} / \mathrm{m}^{3}$ to $3 \mathrm{~g} / \mathrm{m}^{3}$. These data on airborne concentrations, $\mathrm{g} / \mathrm{m}^{3}$, can be used in conjunction with the radionuclide concentrations, $\mathrm{dpm} / \mathrm{g}$, to estimate airborne radionuclide concentrations, $\mu \mathrm{Ci} / \mathrm{cm}^{3}$.

Estimation of Mass Fluxes for Selected Particle Diameters

Airborne mass fluxes were determined for nonrespirable particles. The mass flux is grams of material moving with the wind per square meter of area measured normal to the flow. Mass fluxes were calculated from samples collected within isokinetic sampler inlets, cyclone inlets of cascade impactors, and from air impact flow particle collectors. In most cases, the total mass 

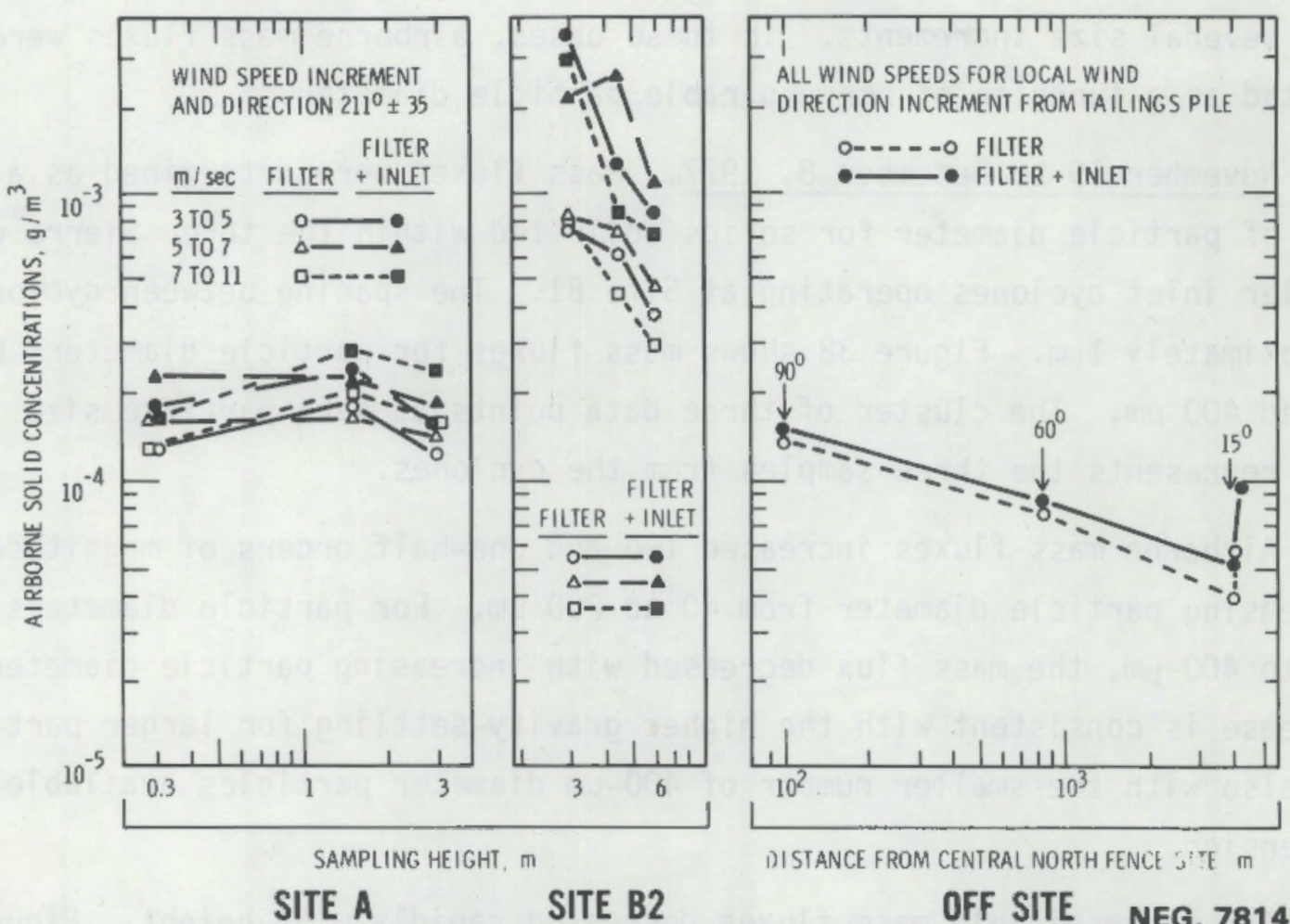

DISTANCE FROM CENTRAL NORTH FENCE I: $\mathrm{T}$

OFF SITE

NEG. 7814185-1

FIGURE 36. Airborne Solid Concentrations at Each Site During May 26 to June 16, 1978

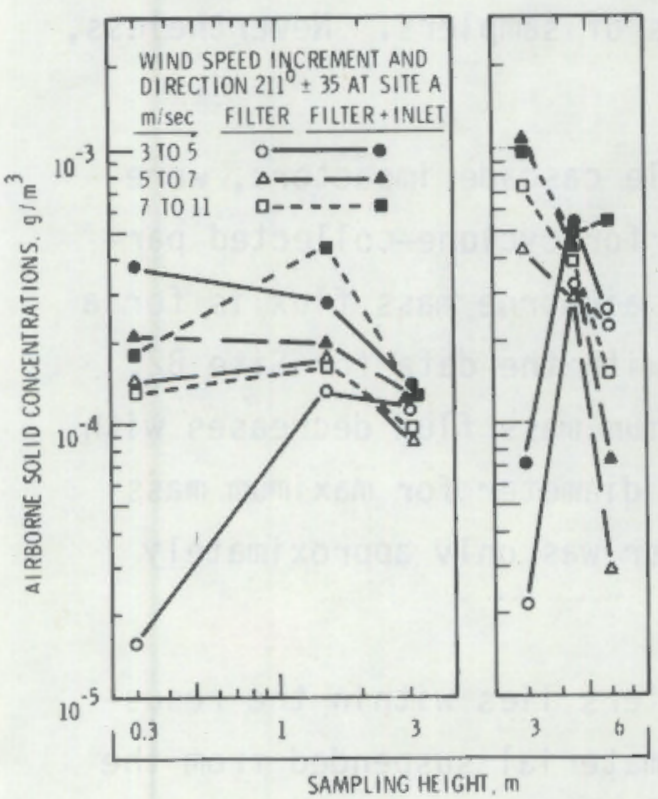

SITE A

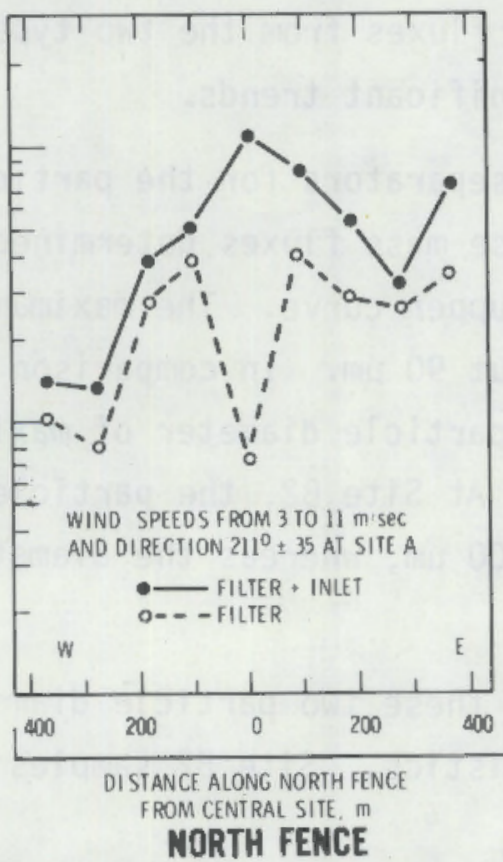

NORTH FENCE

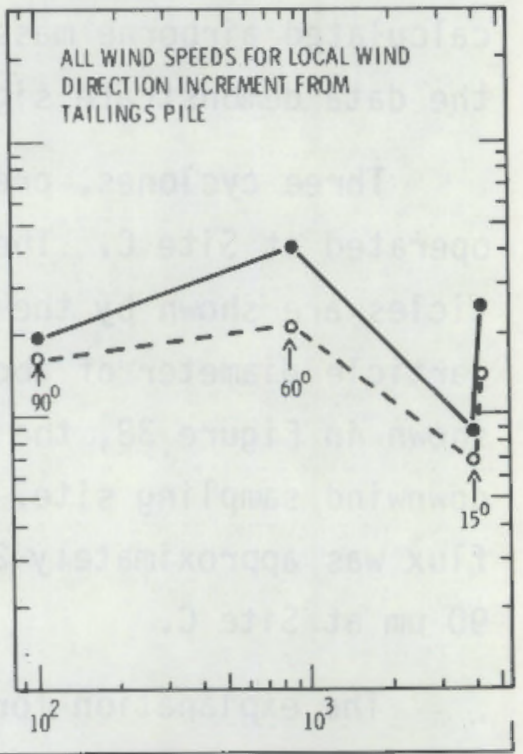

FROM CENTRAL NORTH FENCE SITE, m

OFF SITE

\section{FIGURE 37. Airborne Solid Concentrations at Each Site} During June 16 to June 26, 1978 
flux was calculated. However, in some cases a collected sample was sieved into several size increments. In these cases, airborne mass fluxes were calculated as a function of nonrespirable particle diameter.

- November 19 to December 8, 1977. Mass fluxes were determined as a function of particle diameter for solids collected within the three Sierra cascade sampler inlet cyclones operating at Site Bl. The spacing between cyclones was approximately $1 \mathrm{~m}$. Figure 38 shows mass fluxes for particle diameters between 40 and $400 \mu \mathrm{m}$. The cluster of three data points at each particle size increment represents the three samples from the cyclones.

Airborne mass fluxes increased two and one-half orders of magnitude with increasing particle diameter from 40 to $200 \mu \mathrm{m}$. For particle diameters from 200 to $400 \mu \mathrm{m}$, the mass flux decreased with increasing particle diameter. The decrease is consistent with the higher gravity-settling for larger particles and also with the smaller number of $400-\mu m$ diameter particles available for suspension.

The nonrespirable mass fluxes decreased rapidly with height. Figure 39 shows mass fluxes for Site $C$ that were calculated from collection in both the cyclone and wind-impact collectors. There are numerical differences in the calculated airborne mass fluxes from the two types of samplers. Nevertheless, the data demonstrate significant trends.

Three cyclones, preseparators for the particle cascade impactors, were operated at Site $C$. These. mass fluxes determined for cyclone-collected particles are shown by the upper curve. The maximum airborne mass flux is for a particle diameter of about $90 \mu \mathrm{m}$. In comparison with the data for Site B2, shown in Figure 38, the particle diameter of maximum mass flux decreases with downwind sampling site. At Site B2, the particle diameter for maximum mass flux was approximately $200 \mu \mathrm{m}$, whereas the diameter was only approximately $90 \mu \mathrm{m}$ at Site $\mathrm{C}$.

The explanation for these two particle diameters lies within the resuspension source characteristics. Site $B 2$ samples material suspended from the 


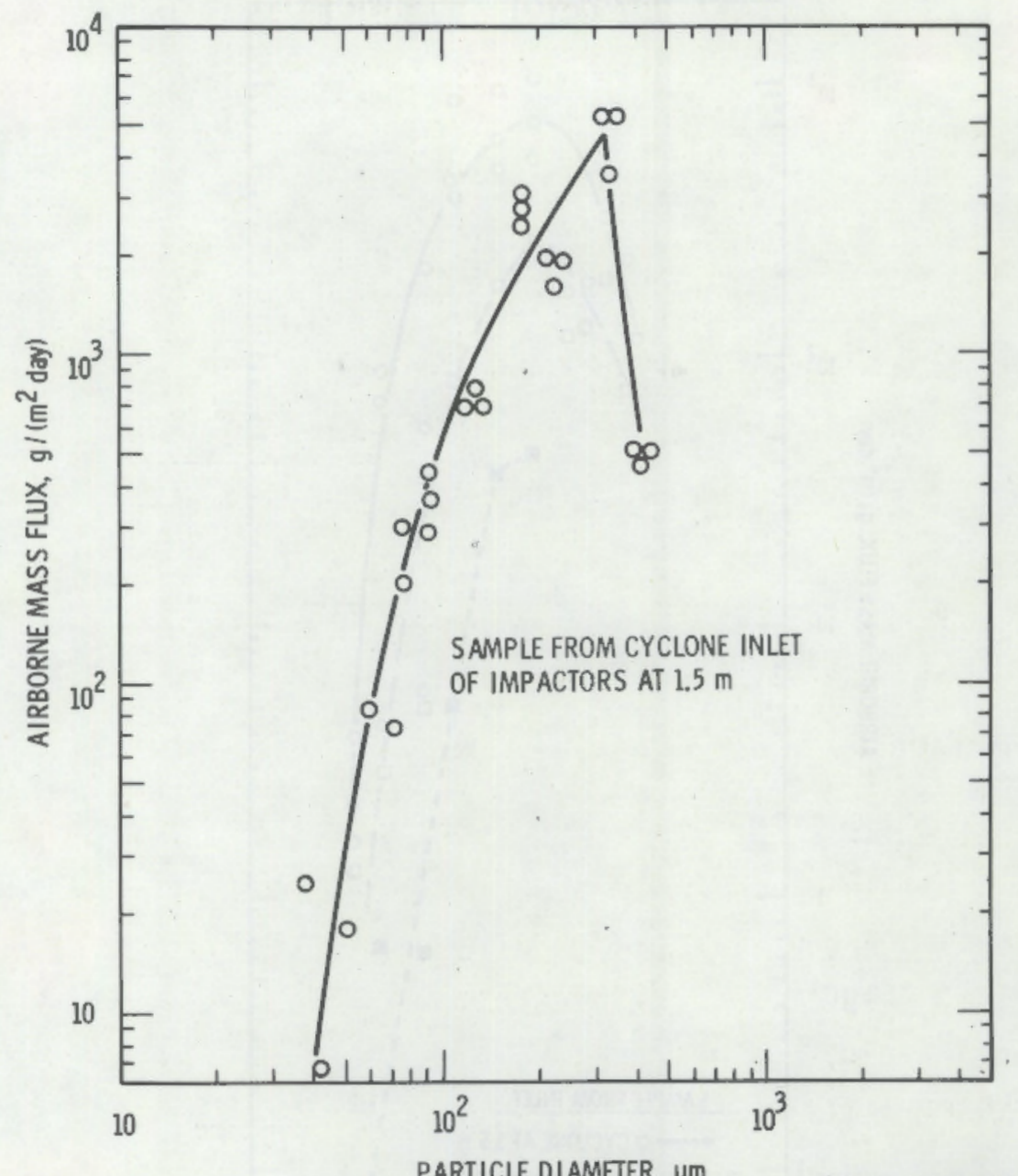

NEG. 7807023-8

FIGURE 38. Airborne Mass Flux as a Function of Particle Diameter at Site B2 During November 19 to December 8, 1977

sloping sides of the pile, the area at which the coarse particles are preferentially deposited while the pile is being built. In contrast, samplers at Site $C$ tended to sample particles arising from the flat surface of the pile. This surface is where the fines are preferentially deposited.

The transport distance for $400-\mu \mathrm{m}$-diameter particles can be inferred from these data. At Site $C$, the approximately $3 / g\left(\mathrm{~m}^{2}\right.$ day) airborne mass flux was on $7 y 0.6 \%$ of the $500 \mathrm{~g} /\left(\mathrm{m}^{2}\right.$ day) mass flux at Site B2. Obviously, these large particles deposit rapidly between Sites $B 2$ and $C$. 


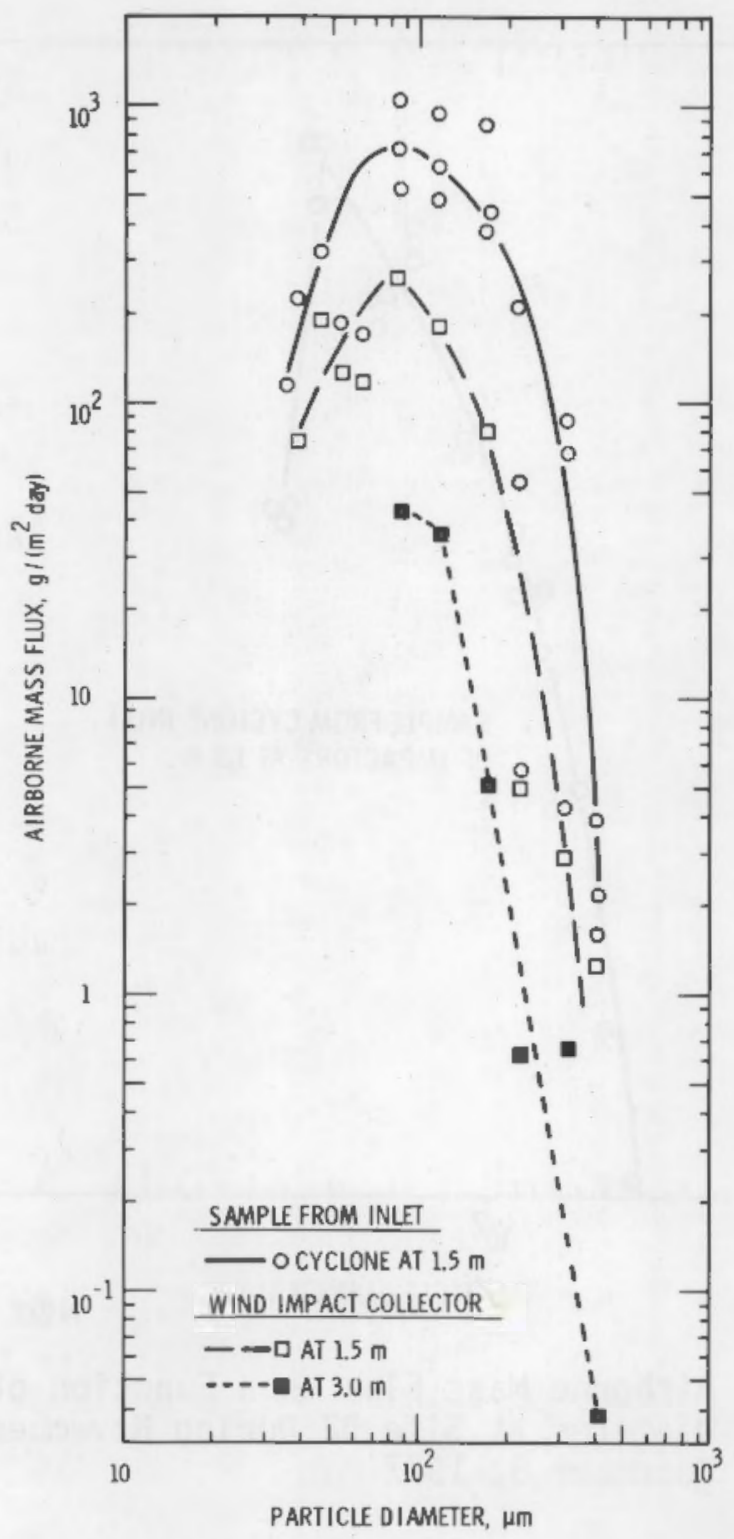

NEG. 7807023-1

FIGURE 39. Airborne Mass Flux as a Function of Particle Diameter at Site C During November 19 to December 8, 1977

Also shown in Figure 39 are airborne mass fluxes calculated from windimpact particle collectors at elevations of 1.5 and $3 \mathrm{~m}$. Again, the flux of these nonrespirable particles decreases rapidly with increasing height. The mass flux at $1.5 \mathrm{~m}$ is approximately twice the flux at $3 \mathrm{~m}$. 
There are consistencies as well as discrepancies between mass fluxes calculated from cyclones and wind-impact flow collectors. Calculated mass fluxes from both samplers indicate a maximum flux for a particle diameter of approximately $90 \mu \mathrm{m}$. However, the calculated flux for the cyclone collector is greater than for the wind-impact flow collector.

The difference is likely caused by the fact that the impact-flow collectors have a dissimilar cut-off diameter, and the air sampling rate is not known as accurately as for the cyclone (Sierra) samplers. Samplers were $11 \mathrm{~m}$ away from the wind impact samplers. Any nonuniformity in concentrations will result in nonreproducibility.

Airborne mass fluxes of nonrespirable particles collected in the inlet section of the high-volume samplers were calculated as a function of wind speed. These data are shown in Figure 40 for sampling Site B1. For the three samples studied'as a function of particle size, the maximum mass flux was for a particle diameter of approximately $200 \mu \mathrm{m}$. This particle diameter is consistent (see Figure 38) with the 200-um diameter determined for the cyclone inlet particles at Site B2. Since both Sites B1 and B2 sampled from material suspended from the sloping banks of the pile, the similarity in the maximum particle diameter is expected.

Mass fluxes were also calculated for two different wind-speed increments at the same sampling elevation' of $0.3 \mathrm{~m}$. Mass fluxes for the lowest wind speed increment, 3 to $5 \mathrm{~m} / \mathrm{sec}$, were always less than mass fluxes for the higher windspeed increments, 7 to $11 \mathrm{~m} / \mathrm{sec}$. This increase is expected and reflects local wind stress suspending larger nonrespirable particles.

Also shown in Figure 40 are mass fluxes at a higher elevation of $1.5 \mathrm{~m}$ for the intermediate wind speed, 5 to $7 \mathrm{~m} / \mathrm{sec}$. At this higher elevation, the maximum mass flux also occurs for a particle diameter of approximately $200 \mu m$.

Mass fluxes at Sites B2 (Figure 38 ) and B1 (Figure 40 ) are significantly different. At Site $B 1$, the maximum mass flux, $500 \mathrm{~g} /\left(\mathrm{m}^{2}\right.$ day $)$ is approximately $10 \%$ of the maximum flux, $5000 \mathrm{~g} /\left(\mathrm{m}^{2}\right.$ day) at site B2. These differences may be caused, in part, by the relative locations of Sites B1 and B2. 


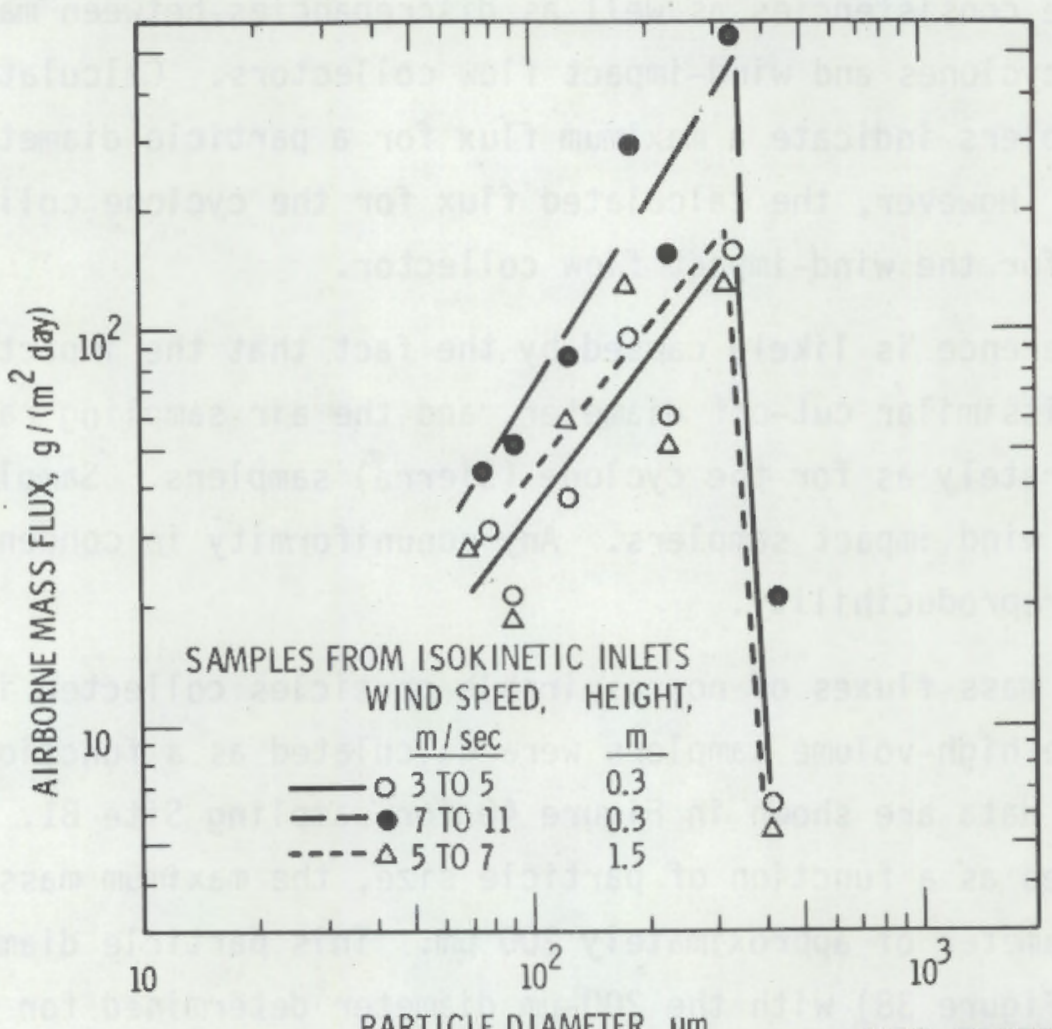

PARTICLE DIAMETER, $\mu \mathrm{m}$

NEG. 7807023-23

FIGURE 40. Airborne Mass Flux as a Function of Particle Diameter at Site B1 During November 19 to December 8, 1977

The cyclones for Site B2 were placed on the retaining dike, a location of maximum mass flux from sloping banks, whereas Site B1 was further downwind from the dike. Apparently, Site Bl was at a sufficient distance for significant deposition to occur between the dike and sampler. As was earlier mentioned in the cross comparison of data for Site B2 (Figure 38) and Site C (Figure 39), significant deposition of these nonrespirable particles apparently occurs rapidly with distance.

\section{Short-Term Mass Flux Variations}

- August 10 to October 24,1977 . Relative changes in mass flux during a reasonably short time period were determined during this initial sampling period. Airborne mass fluxes, as determined for particles collected on the inlet of high-volume samplers along the north fence, are shown in Figure 41. 


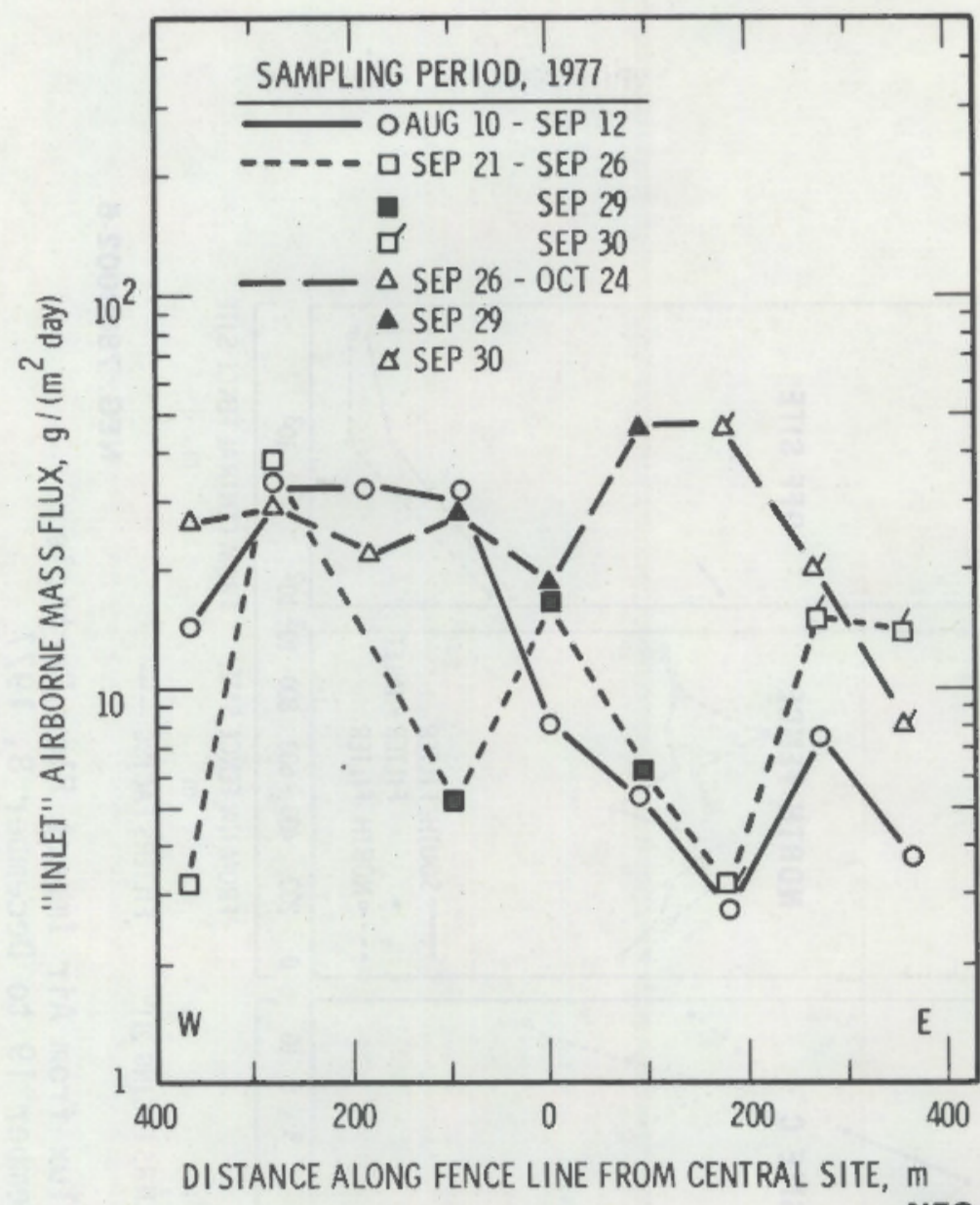

NEG. 7809038-3

FIGURE 41. Average Airborne Fluxes Toward North

These average mass fluxes show variation within one order of magnitude. The airborne mass flux at a sampling location is not always high or low as compared to other sampling locations. These variations in crosswind mass fluxes may be one of the limiting considerations in the accuracy of model predictions. Mass Fluxes--Air Impact Collectors

Average airborne mass fluxes were calculated from the air impact flow particle collectors. Mass fluxes were calculated for the total time collectors were in the field. Results for five time periods are shown in Figures 42 through 46: November 19 to December 8, 1977; March 30 to April 17, 1978; April 8 to May 29, 1978; May 26 to June 26, 1978; and June 28 to August 9, 1978. 


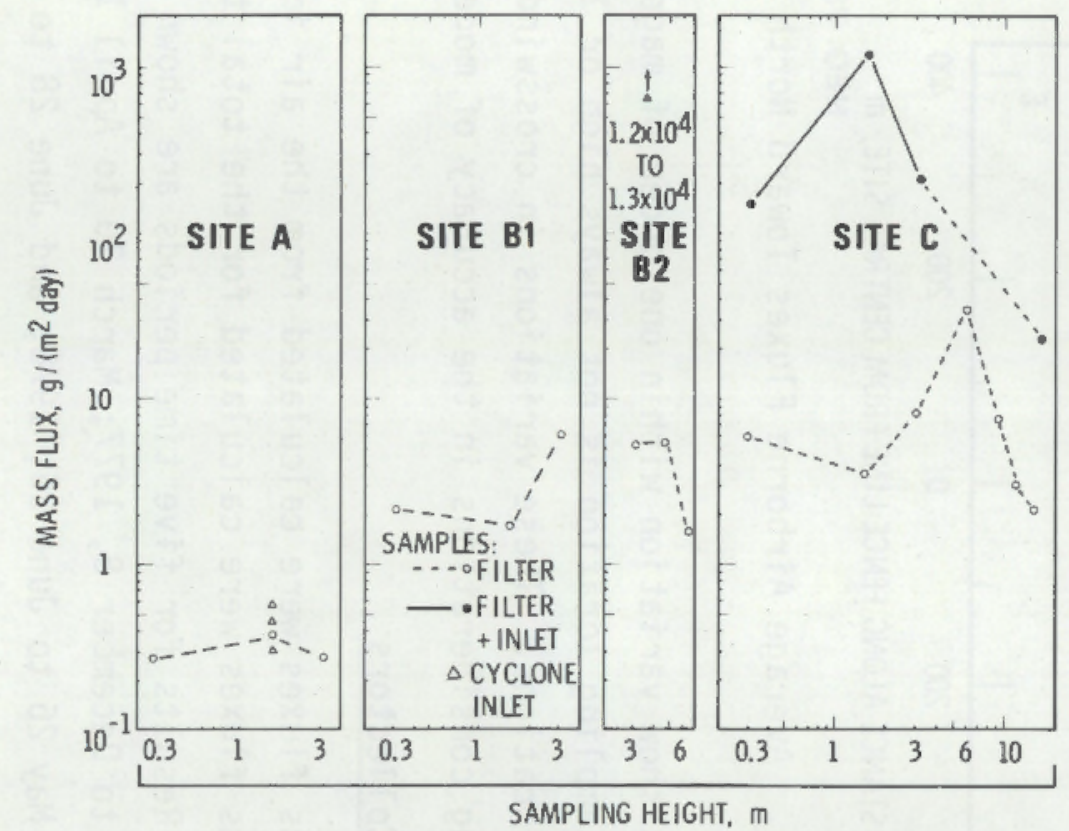

$\longleftarrow$ FILTERS FACING $211^{\circ}$

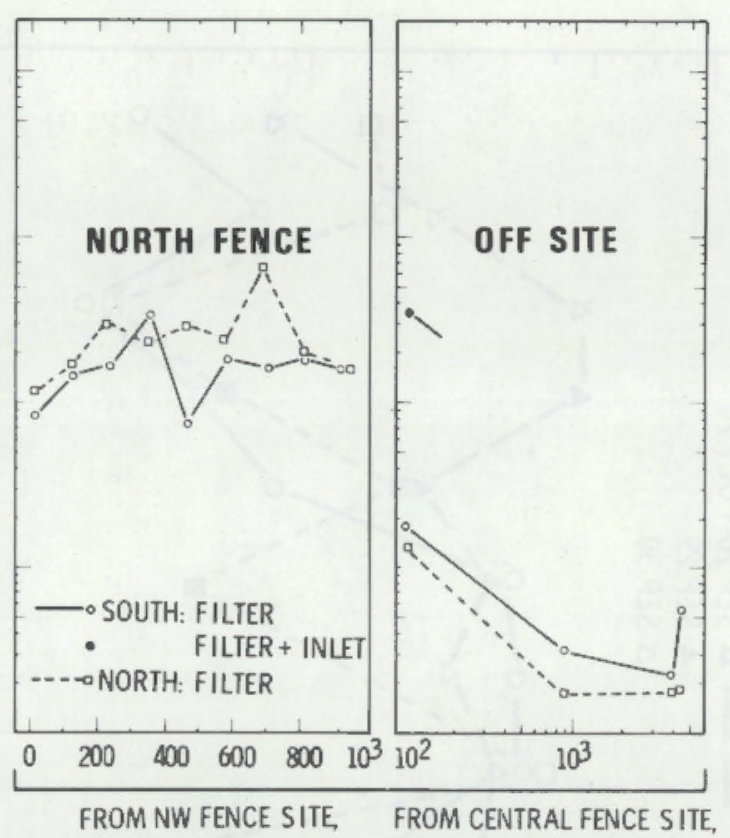

FILTERS FACING $\longrightarrow$

NEG. $7808002-5$

FIGURE 42. Airborne Mass Flux from Air Impact Flow Particle Collectors, November 19 to December 8, 1977 

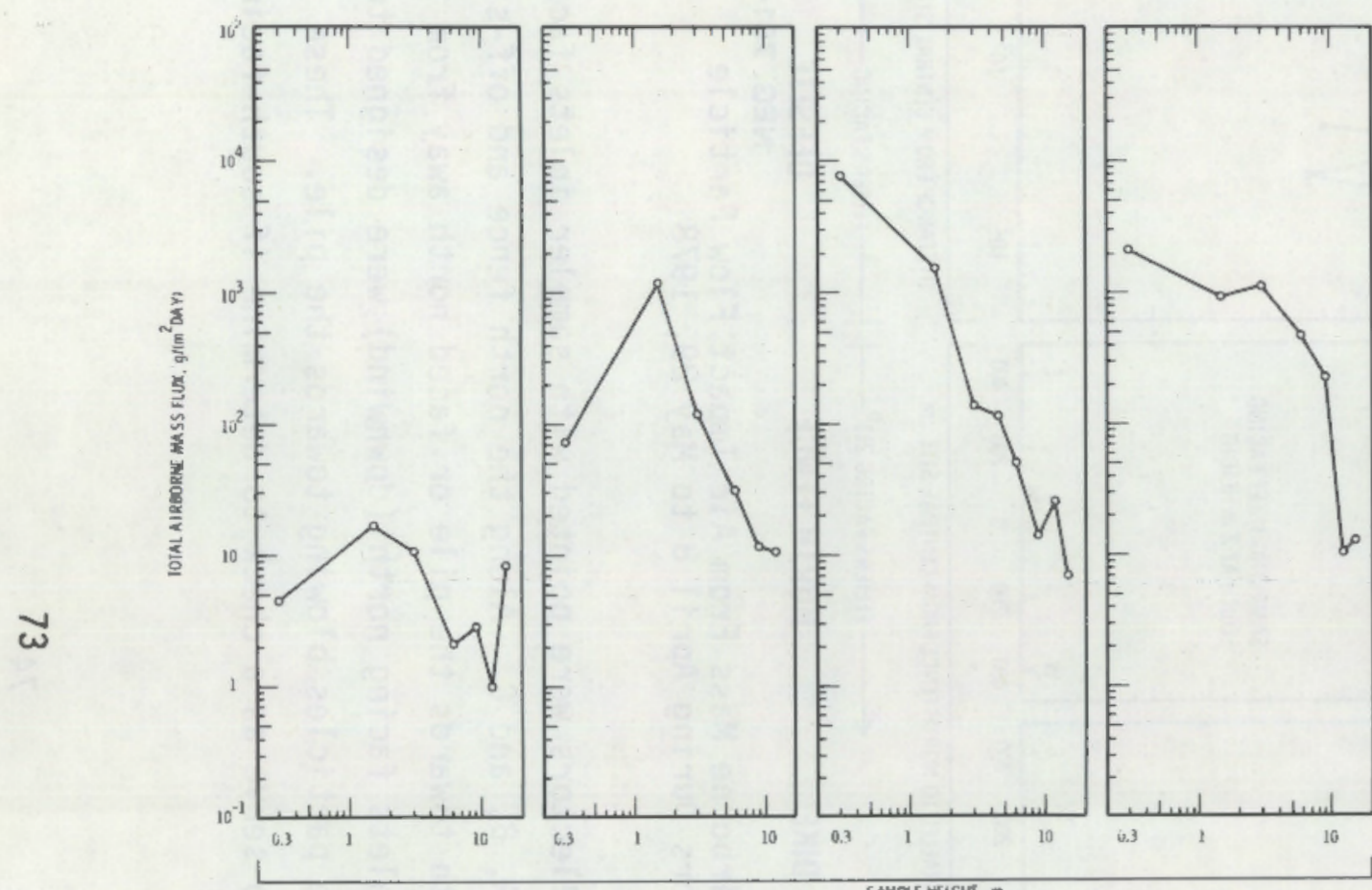

SITE A

SITE B1

SITE B2

FIGURE 43. Total Airborne Mass Flux from Air Impact Flow Particle Collectors During March 30 to April 17, 1978
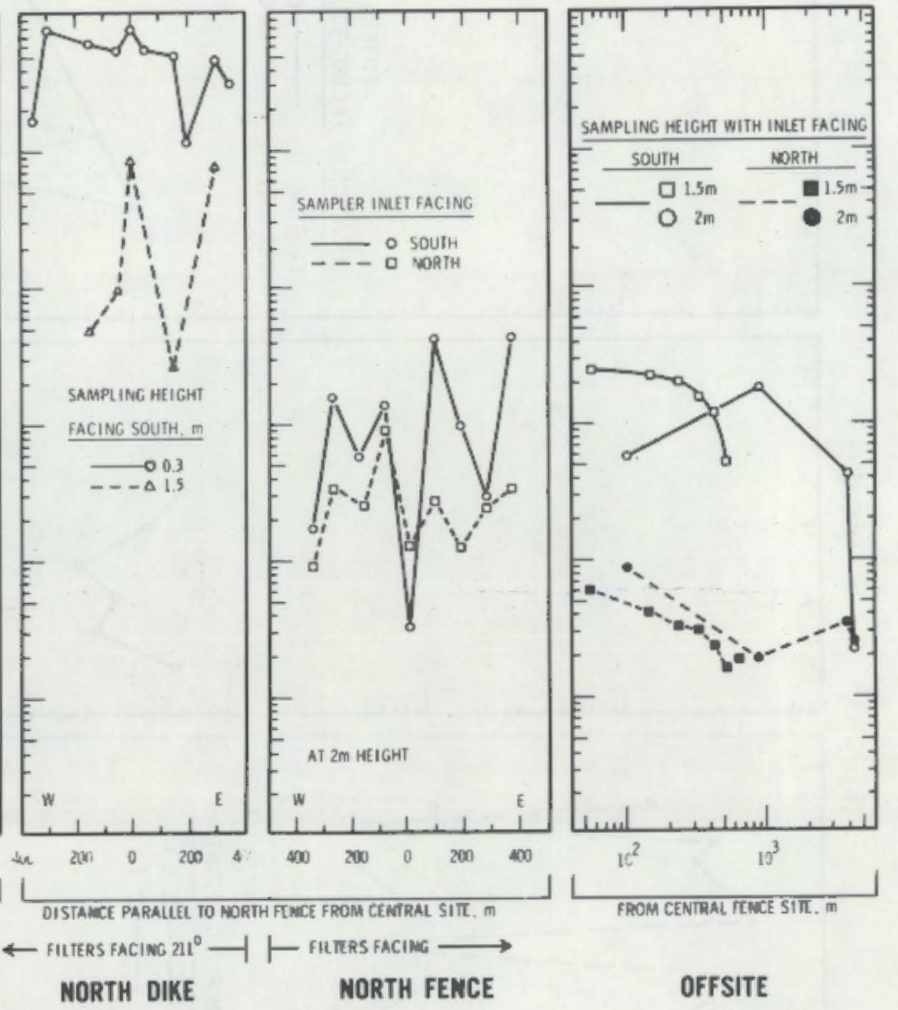

NEG. 7814185-7 

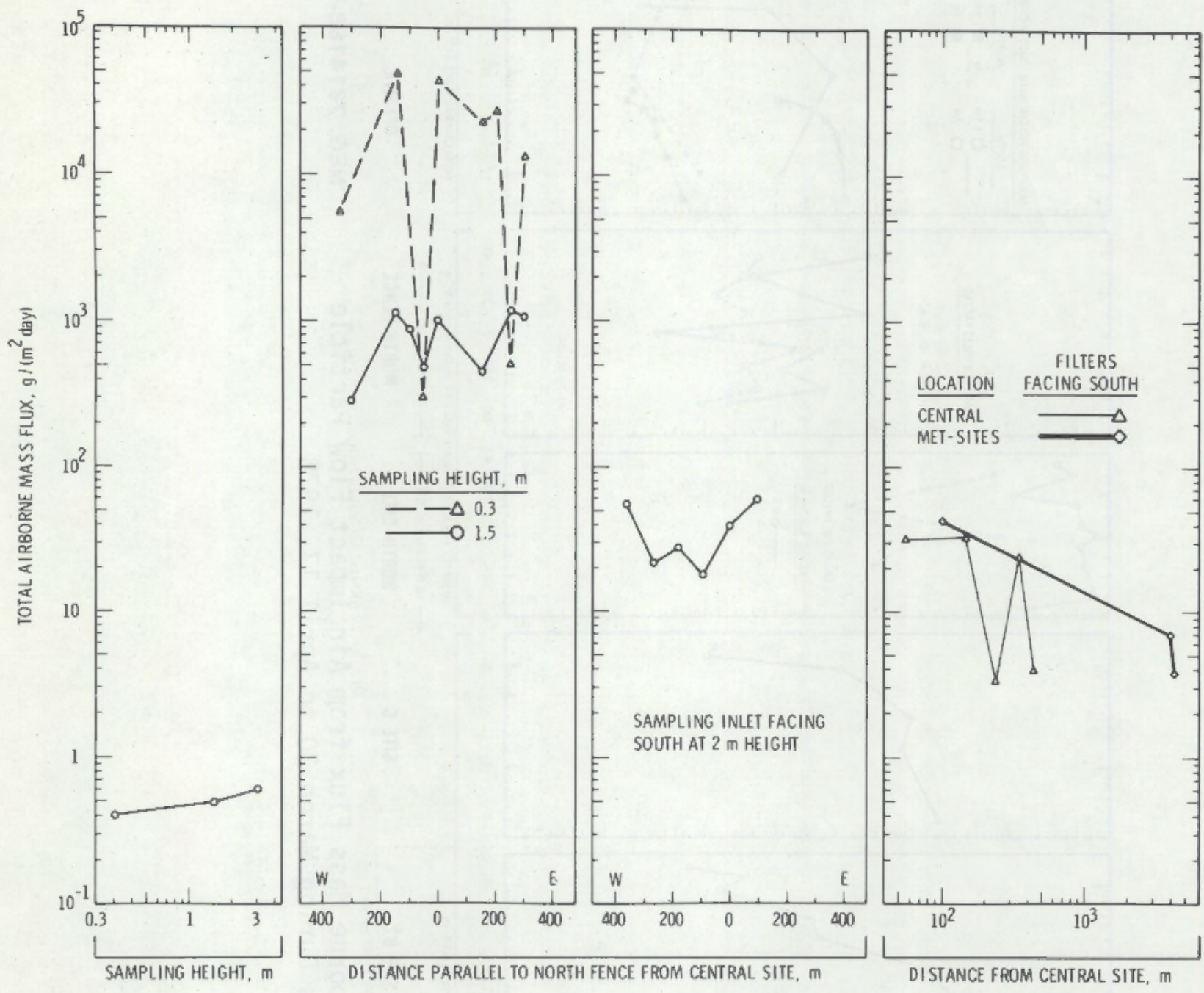

SITE A NORTH DIKE

$\longleftarrow$ FILTERS FACING $211^{\circ}$ NORTH FENCE

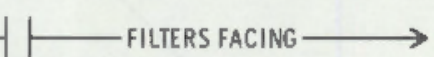

OFFSITE

NEG. 7814185-4

FIGURE 44. Total Airborne Mass From Air Impact Flow Particle Collectors During April 8 to May 29, 1978

Impact-flow particle collectors were pointed with sampler inlets facing approximately $211^{\circ}$ at Sites A, B, and C. Along the north fence and off-site, in lets were faced either south towards the pile or faced north away from the pile. Those samplers with inlets facing north (downwind) were designed to collect ambient nonrespirable particles blowing towards the pile. These north-facing samplers were to serve as a check to determine if south-facing 

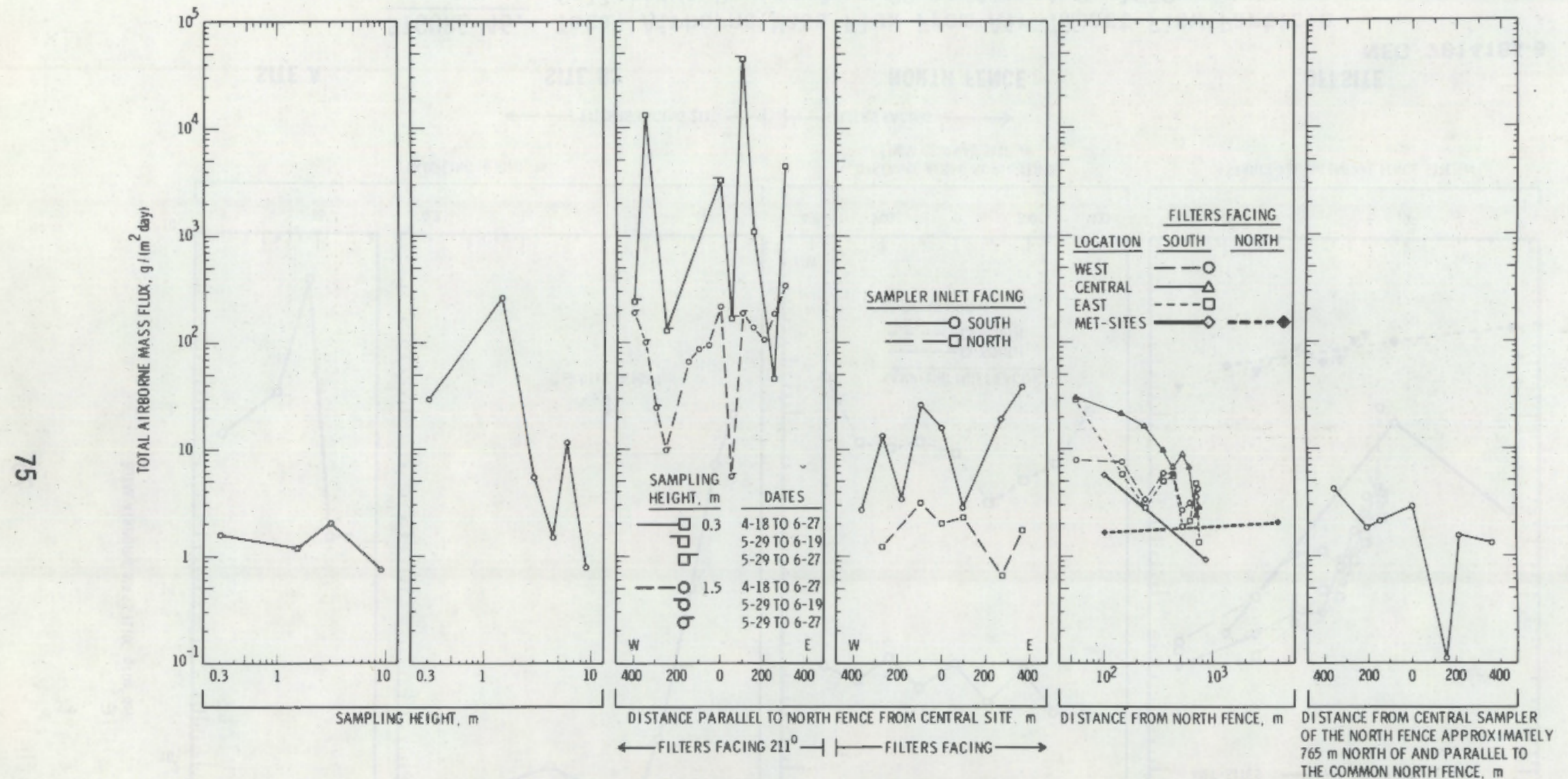

SITE A

SITE B2

NORTH DIKE

NORTH FENCE

OFFSITE

FIGURE 45. Total Airborne Mass Flux From Air Impact Flow Particle Collectors During May 26 to June 26, 1978

NEG. $7814185-5$ 

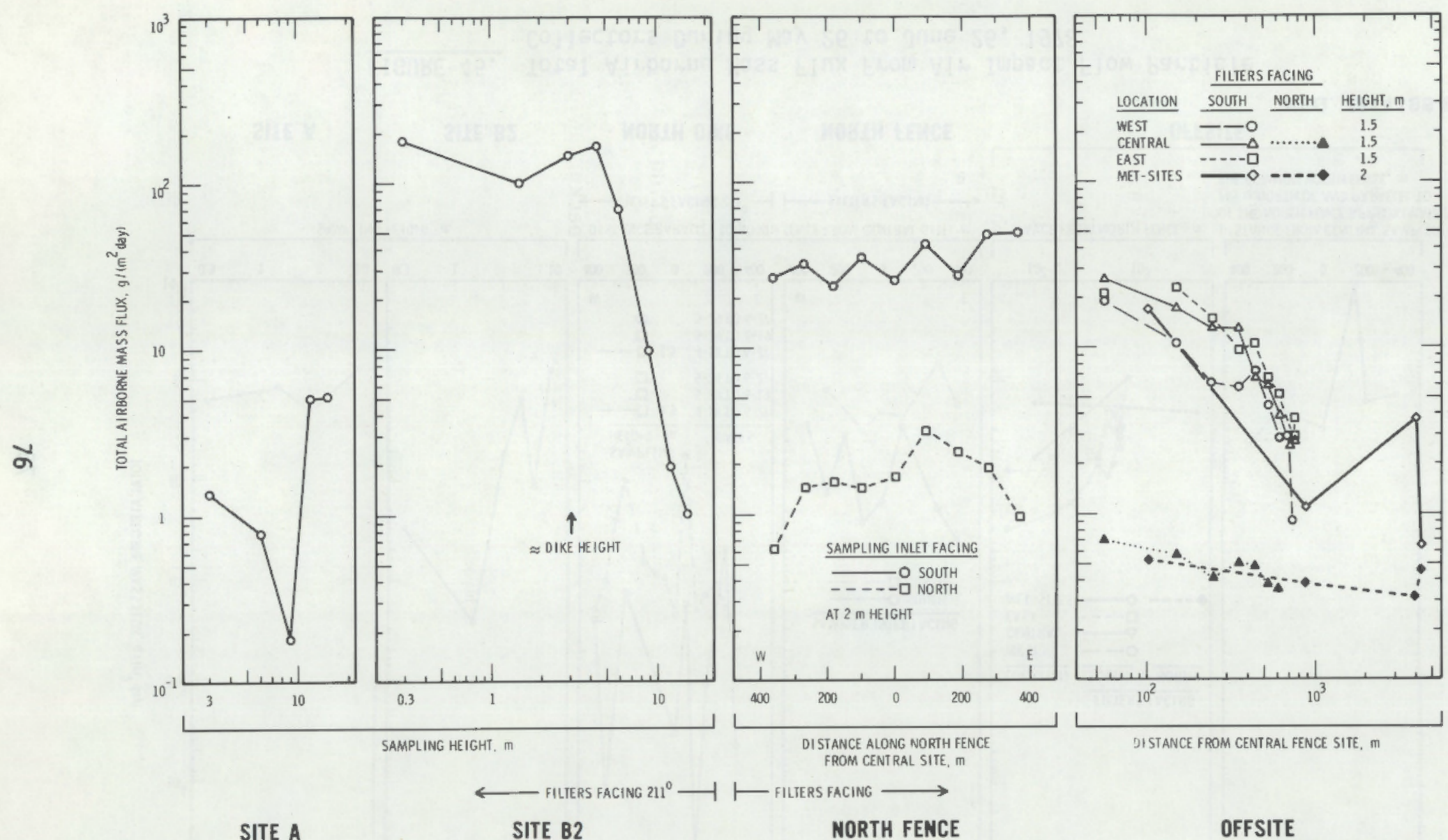

SITE A

SITE B2

NORTH FENCE

NEG. 7814185-6

FIgURE 46. Total Airborne Mass Flux From Air Impact Flow Particle

Collectors During June 28 to August 9, 1978 
samplers were collecting material being suspended from the mill tailings pile or being suspended locally from around the off-site sampling sites. If both the north- and south-facing samplers indicated the same mass flux, one could assume that the net flux of nonrespirable particles was zero for north and south winds.

- November 19 to December 8, 1977. Airborne mass fluxes calculated for this time period are shown in Figure 42. At Site $A$, airborne mass fluxes were nearly uniform with height, approximately $0.3 \mathrm{~g} /\left(\mathrm{m}^{2}\right.$ day). In addition, there was good agreement between calculated mass fluxes for air impact flow particle collectors and cyclone inlets at a height of $1.5 \mathrm{~m}$.

Sites B1 and B2 airborne mass fluxes determined with air impact flow particle collectors were similar. Mass fluxes increased approximately one order of magnitude above background. However, at Site B2, there was a large difference between mass fluxes calculated from cyclone collection and air impact flow particle collectors. The Sierra sampler inlet cyclones, on top of the dike, indicated a mass flux of approximately $1.2 \times 10^{-4} \mathrm{~g} /\left(\mathrm{m}^{2}\right.$ day). The impact-flow particle collectors indicated a mass flux of approximately $3 \mathrm{~g} /\left(\mathrm{m}^{2}\right.$ day $)$. These samplers were located beyond the dike.

Mass fluxes at Site $C$ were calculated from solids collected either on the 25- $\mu \mathrm{m}$ filter or from the total solids on this filter plus inlet. The total collection was one to two orders of magnitude greater than for collection only on the 25- $\mu \mathrm{m}$ filter. A dashed line is shown or the total mass flux between 3 and $15 \mathrm{~m}$. This dash is indicated since sample separation was not maintained in the field for these 7- to 9-m samplers; that is, the inlet and filter samples were combined. The data at these two heights are shown as filter collection.

The total mass flux curve indicates a maximum flux at $1.5 \mathrm{~m}$. A decreased mass flux at $0.3-m$ elevation is attributed to deposition between the suspension source and sampling location. At the highest sampling elevation of $15 \mathrm{~m}$, the total mass flux is two orders of magnitude greater, whereas filter-collected mass flux is one order of magnitude greater than the background flux measured 
at Site A. This increase at $15 \mathrm{~m}$ compared to background indicates the total suspended plume was not contained within the 15-m sampling height.

Mass fluxes along the north fence are shown for both air impact flow particle collectors faced toward the south and north. In general, mass fluxes coming from the north were greater than mass fluxes leaving the mill tailings boundary. This increased mass flux from the north might be attributed to resuspension from the dirt-gravel road immediately north of the north fence.

Airborne mass fluxes in the rangeland off-site are shown on the right side of Figure 42. Aithough mass fluxes decreased to near background for distances of 1 to $4 \mathrm{~km}$ from the central north fence site, a mass flux originating from the mill tailings pile is indicated even at distances of $4 \mathrm{~km}$. That is, the mass flux from the south was greater than from the north.

- March 30 to April 17, 1978. Airborne mass fluxes determined for this time period are shown in Figure 43. Airborne mass fluxes from two additional data sets are shown: along the north dike and from additional samplers as a function of distance off-site in the rangeland.

For sites $A, B 1, B 2$, and $C$, the total airborne mass flux was measured for sampling heights from 0.3 to $15 \mathrm{~m}$ above ground. The mass flux at the background Site $A$ ranged from about 1 to $20 \mathrm{~g} /\left(\mathrm{m}^{2}\right.$ day), whereas mass fluxes at Site $B 1, B 2$, and $C$ ranged from about 10 to $8000 \mathrm{~g} /\left(\mathrm{m}^{2}\right.$ day $)$.

At each site, the mass flux data showed consistent trends as a function of height. Plume depletion caused by deposition is indicated at the $0.3-m$ height for Site B1. In contrast, at Site B2 and C the mass flux continually increased as the ground surface was approached. Thus, at these two sites local resuspension sources without significant deposition are indicated in the figure. However, the data for Site B2 were influenced by particles whose trajectories carried them over the edge of the dike down towards Site B2.

The next section of Figure 43 shows airborne mass fluxes along the north dike. Mass fluxes ranged from $10^{4}$ to $10^{5} \mathrm{~g} /\left(\mathrm{m}^{2}\right.$ day) at a sampling height of $0.3 \mathrm{~m}$. At the higher elevation of $1.5 \mathrm{~m}$, mass fluxes ranged from about $10^{2}$ to $10^{4} \mathrm{~g} /\left(\mathrm{m}^{2}\right.$ day). For each height the west to east crosswind variation in mass flux is approximately one order of magnitude. 
Mass flux variation along the north fence is shown for both north- and south-facing air impact flow samplers. For the time period in question, the mass flux from the south, i.e., from the pile, was greater than the mass flux coming from the north. In contrast, Figure 42 showed a larger mass flux from the north.

Airborne mass fluxes estimated from off-site air impact flow particle collectors are shown on the right side of Figure 43. These samplers were located at elevations of 1.5 and $2 \mathrm{~m}$. The $2-\mathrm{m}$ samplers were used for the preceding time periods. In nearly all cases, except for the 4-km distance, the mass flux from the south was greater than the mass flux from the north by one to two orders of magnitude. Mass fluxes appear to be a function of height and crosswind location as indicated by the differences for $1.5-\mathrm{m}$ and $2-\mathrm{m}$ heights.

- April 8 to May 29, 1978. Airborne mass fluxes for this time period are shown in Figure 44. During this time period air impact flow particle collectors were located only at Site A along the north dike, along the north fence, and off-site. For the off-site locations, the central samplers were located at an elevation of 1.5 m whereas the MET site samplers were at an elevation of $2 \mathrm{~m}$.

For this time period, the off-site mass flux at $4 \mathrm{~km}$ at Site $A$ was over one order of magnitude greater than the background mass flux. Therefore, the measurable downwind extent of the airborne plume had to be at some distance beyond $4 \mathrm{~km}$. This observation contrasts with preceding mass flux data (Figures 42 and 43 ) that suggest the plume was not distinguishable from Site $A$ at $4 \mathrm{~km}$. Obviously then, plume transport from the mill tailings area is a function of the wind speed and direction during the sampling time period. As is shown elsewhere in this report on surface soil sampling, the surface soil concentrations approach background at distances of $10 \mathrm{~km}$.

- May 26 to June 26, 1978. Airborne mass fluxes for this time period are shown in Figure 45. For this period additional air-impact flow particle collectors were located off-site. The MET sites are the original four off-site locations, R1, R2, R3, and R4. These four samplers were located at an elevation of $2 \mathrm{~m}$. 
The new sampler locations shown in Figure 45 are impact flow samplers mounted on steel posts $1.5 \mathrm{~m}$ from the ground. These new off-site arrays were placed to indicate the relative changes in airborne mass fluxes as a function of crosswind and downwind distances.

At Site $A$, the total airborne mass flux was nearly uniform as a function of height up to $10 \mathrm{~m}$. At Site B2, the maximum mass flux was at a height of $1.5 \mathrm{~m}$ and was over two orders of magnitude greater than the background mass flux at Site A. At B2, mass fluxes at 4.5 and $10 \mathrm{~m}$ were similar to background. However, at the 6-m intermediate sampling height, the mass flux at B2 was one order of magnitude greater than background.

Airborne mass fluxes along the north dike are shown for sampling heights of 0.3 and $1.5 \mathrm{~m}$ in the third section of Figure 45 . For this overall time period, several shorter periods were used for sampling as indicated. In general, mass fluxes at the $0.3-\mathrm{m}$ height were one to two orders of magnitude greater than at the $1.5-\mathrm{m}$ sampling height.

Total airborne mass fluxes were measured along the north fence with sampler inlets facing either south or north. Mass fluxes calculated from samplers faced toward the south (i.e., samplers measuring mass fluxes blowing from the pile) were always greater than mass fluxes blowing from the north. Mass fluxes were within two orders of magnitude in the crosswind direction for south-facing samplers. For north-facing samplers, mass flux variations were less, within one order of magnitude.

For the off-site MET sites, airborne mass fluxes are shown for both north and south-facing samplers. Mass fluxes for the MET sites were in reasonable agreement with the west, central and east arrays of air impact flow particle collectors. The maximum airborne mass fluxes were from the central sampler locations, which is expected since the central samplers were located approximately at mid-pile. Mass fluxes decreased nonuniformly with distance. Nevertheless, mass fluxes decreased approximately one order of magnitude within $1 \mathrm{~km}$. 
A crosswind variation in mass flux $765 \mathrm{~m}$ off-site is shown on the right side of Figure 45. Mass fluxes tend to decrease from west to east. Although there are sampler-to-sampler location variations, the mass flux decrease was nearly uniform with distance except for one sampler mass flux at about $10^{-1} \mathrm{~g} /\left(\mathrm{m}^{2}\right.$ day $)$. The reason for this rapid decrease is unknown. For average wind directions, one would have expected a maximum mass flux near the central sample with decreasing mass flux to both the west and east. Although the measured crosswind profile was different from the expected profile, airborne mass fluxes were reasonably close to background mass fluxes measured at Site A.

- June 28 to August 9, 1978. Total airborne mass fluxes for this period are shown in Figure 46 . The background mass flux at Site $A$ was maximum at $15 \mathrm{~m}$, the highest sampling elevation. The minimum airborne mass flux was at an intermediate height of $9 \mathrm{~m}$. Apparently, during this time period two principal airborne plumes were measured. For sampling heights of $9 \mathrm{~m}$ and less, the airborne mass flux decreased with increasing height. This decrease indicates that a suspended plume of local source was being sampled. In contrast, for sampling heights of $9 \mathrm{~m}$ to $15 \mathrm{~m}$ the increased airborne mass flux with increasing height suggests that an upwind source was being sampled with deposition occurring between the source and sampling location.

At Site B2, suspension from the pile masks any influence of the upwind suspension source. The airborne mass flux decreased with increasing sampling height. The exception is approximately the dike height at which an intermediate maximum was measured.

The mass flux along the north fence tended to increase from west to east, the opposite trend of that in Figure 45. Mass fluxes were one to two orders of magnitude greater than background. For sampler inlets facing north, average mass fluxes were within the same order of magnitude as background fluxes measured at Site A.

Additional samplers were used at off-site locations for this time period and were placed along the central sampling array to measure mass fluxes from the north. For this time period, mass fluxes from the north are shown for 
both the central array as well at the MET sites (see the lower portion of Figure 46). Mass flux agreement is shown for these samplers.

For south-facing samplers, mass fluxes were one to two orders of magnitude greater than for north-facing samplers. Mass fluxes were more uniform in the crosswind direction than for the previous time period shown in Figure 45. Mass fluxes tended to decrease one order of magnitude within $1 \mathrm{~km}$ and approach background mass fluxes at $1 \mathrm{~km}$.

Particle Fractionation Between Inlet and Filter-Isokinetic Samplers

A rough index of the airborne particle-size distribution was estimated from the isokinetic sampler data. The estimate is the percent of solids collected on the filter of the total mass found in the inlet and on the filter. It is assumed that the particles collected on the filters are mainly respirable, but also include some nonrespirable particles. Airborne solids collected on the filter ranged from about $0.5 \%$ to $100 \%$. The percentage was a function of sampling site, sampling elevation, and wind speed. Results are discussed for three time periods.

- November 9 to December 8,1977. The percent of airborne solids collected on filters during this period are shown in Figure 47 . At Site A, 60\% to 100\% of the solids were collected on the filter. In contrast, at Sites B1 and B2 the filter collection decreased to as low as $0.5 \%$. Obviously, the decrease percentage was caused by increased collection of nonrespirable particles in the isokinetic sampler inlet. Increased inlet collection is expected since Site B sample particles were suspended from the sloping sides of the mill tailings pile. Along the north fence, the airborne solids collected on the filter ranged from about $10 \%$ to $80 \%$. Significant variation was measured as a function of sampling site along the north fence.

- February 10 to March 27, 1978. For this sampling period, airborne solids collected on the filter are shown in Figure 48. In this figure, data are also shown for Site $C$ and off-site. At Site $C$, a significant trend appears as a function of wind speed for heights below $10 \mathrm{~m}$. At the lowest wind speeds, 


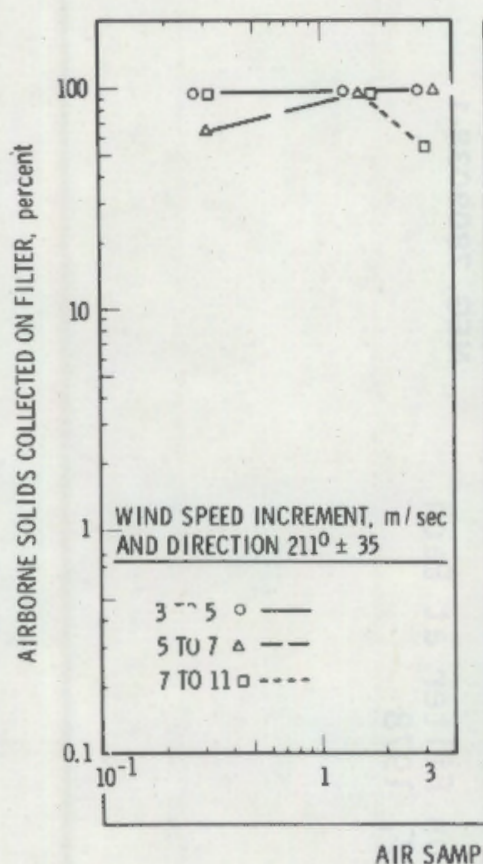

SITE A

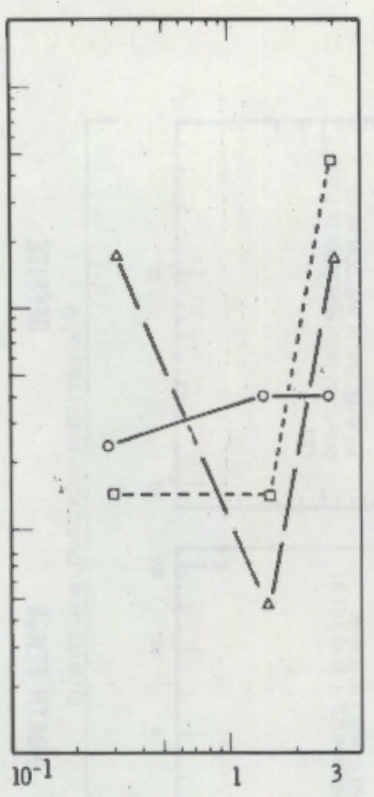

SITE B1

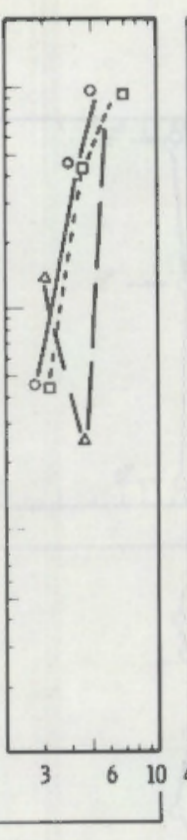

SITE B2

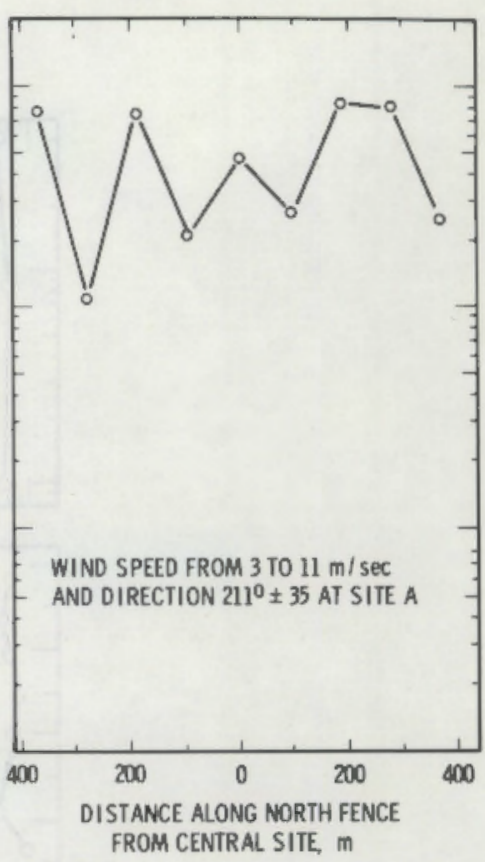

NEG. $7809038-6$

FIGURE 47. Percent Airborne Soilds Collected on Filter at Each Site During November 19 to December 8, 1977

3 to $5 \mathrm{~m} / \mathrm{sec}$, the percent solids collected on the filter is the least. For the highest wind speeds, 7 to $11 \mathrm{~m} / \mathrm{sec}$, the percent solids collected on the filter is the greatest. At Sites A and B, a wind-speed dependency is not apparent.

- March 30 to April 17, 1978. For this time period, the percent filter collections are shown in Figure 49. Any wind-speed dependency is not distinguishable. At Site $C$, the maximum percent filter collection for heights less than $2 \mathrm{~m}$ occurred for the intermediate rather than for the highest wind-speed increment. 

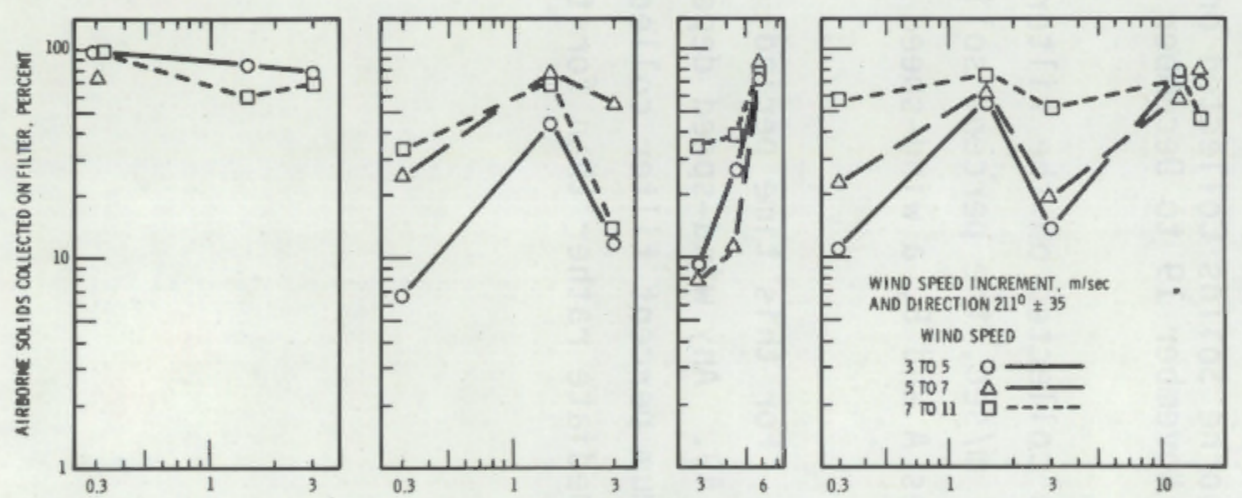

SITE B1
SITE A SITE 82

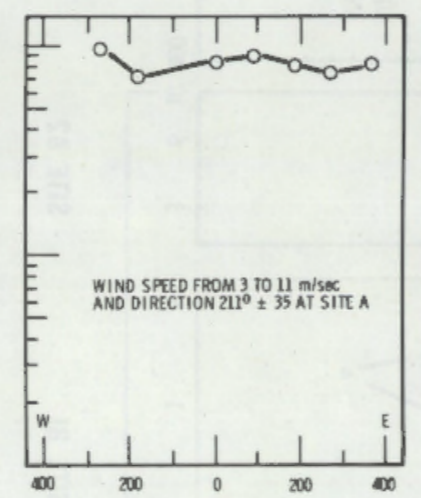

NORTH FENCE

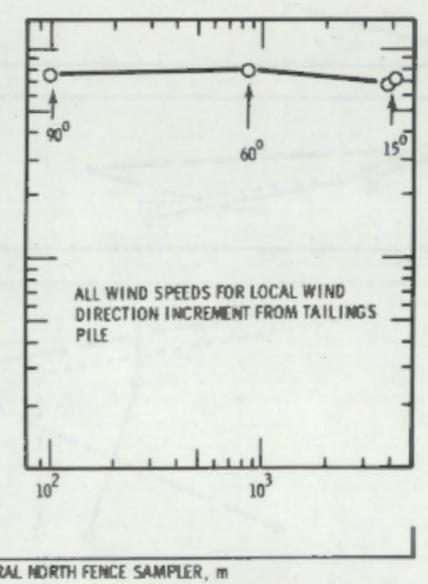

OFFSITE

FIGURE 48. Percent Airborne Solids Collected on Filter at Each

NEG. 7809038-1

Site During February 21 to March 27, 1978 

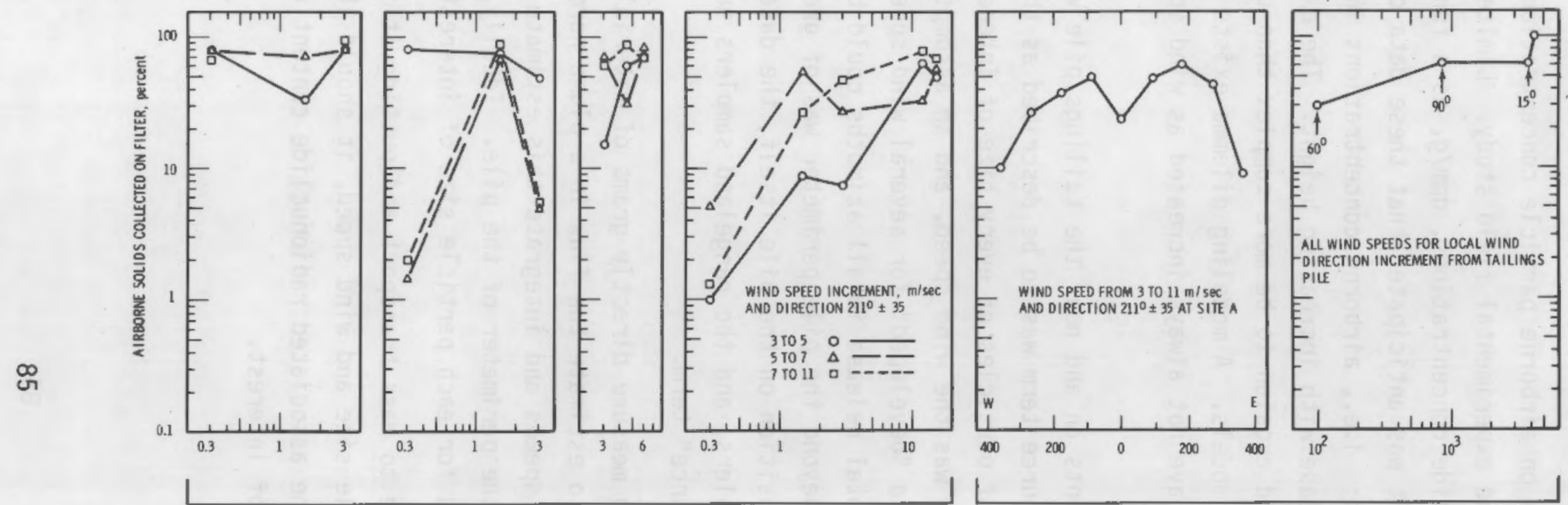

AIR SAMPLIMG HEIGH, I

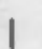

DISTANCE ALONG MORTH FENCE FROM CEITRAL SITE, M

SITE A

SITE C

NORTH FENCE

FIGURE 49. Percent Airborne Solids Collected on Filter at Each Site During March 30 to April 17, 1978
OFFSITE

NEG. 7809038-2 


\section{AIRBORNE PARTICLE DATA--DISCUSSION AND INTERPRETATION}

A considerable body of data on airborne particle concentrations and mass fluxes were determined during the experimental field study. Limited data were determined on airborne radionuclide concentrations, $\mathrm{dpm} / \mathrm{g}$, as a function of particle diameter. Initially, it was anticipated that these data could confirm prior resuspension concepts: i.e., airborne concentrations increase as a function of wind speed and decrease with increasing height. The experimental results suggest mill tailing wind erosion to be more complex than usually considered within simple transport models. A modeling dilemma exists in that airborne concentrations, $\mathrm{g} / \mathrm{m}^{3}$, have not always increased as wind speed has increased.

Conceptually, the measurements on and near the tailings pile were to develop a "source" term. The source term was to be described as the grams released per second to the air of particles of every size of interest. The anticipated independent variable was the wind speed, and an assumption was made that if the source term were "developed" for several wind speeds in a reasonably narrow sector, the total release in all azimuths could be readily computed. Since the transport beyond the pile perimeter was of greater importance than resuspension and deposition on the pile itself, the data taken from the $\mathrm{C}$ site, the north fence samplers, and the rangeland samplers are of greatest value in developing the "source" term.

Since it isn't practical to measure directly grams of material released per unit time, it is necessary to estimate the flux in a plume normal to the wind direction for various wind speeds and integrate this estimate with respect to width and height at the perimeter of the pile. Ideally, this source term should be calculated for each particle size of interest.

Examining the data relative to mass transport and putting it in some perspective with respect to particle size and wind speed, it should then be possible to convert mass data to the associated radionuclide content of each gram of particle in each size range of interest. 
Having thus described the source term, dispersion models could be used with deposition and resuspension accounted for in order to estimate downwind air concentrations, the desired objective.

The field experiments have not yielded the abundance of detailed data required for this well-defined concept needed for developing the source term. This state of affairs is partly due to the following: measurements do not fit a rational pattern; crosswind variations are highly significant; some data are missing due to equipment breakdown; and particle size data are not readily attained with adequate accuracy.

The total radionuclide release rate is the sum of the transport on respirable particles as defined by the sampling system (p. 10), plus transport on non-respirable particles. For respirable particles, the release rate, $Q_{R}$, i.e., $\mu \mathrm{Ci} /$ day, can be calculated from the double integral

$$
Q_{R}=\int_{0}^{1300 m} \int_{0}^{h} \Psi(y) x u_{y} d z d y
$$

over crosswind distance $y$ and sampling height $z$. The product contains air velocity, $u$, as a function of height; the airborne radionuclide concentration, $x, \mu \mathrm{Ci} / \mathrm{cm}^{3}$; and a crosswind variation of the radionuclide concentration, $\Psi(y)$. Similarly, the radionuclide release rate on nonrespirable particles is calculated from the airborne mass flux, N, with the double integral over crosswind distance and sampling height

$$
Q_{N R}=\int_{0}^{1300 m} \int_{0}^{h} \psi^{\prime}(y) X^{\prime} N d z d y .
$$

where $\psi^{\prime}(y)$ describes the crosswind mass flux variation, and $X^{\prime}$ is the $\mu \mathrm{C} i / g$ of nonrespirable particles. 
Ideally, these integrations for both respirable and nonrespirable particles could be performed at each sampling site, A, B1, B2, and C. These are the sites at which, at least, some air samplers were located at sampling elevations from 0.3 to $15 \mathrm{~m}$. The mass flux of nonrespirable particles was measured for heights up to $15 \mathrm{~m}$ as compared to on $1 \mathrm{y} 3 \mathrm{~m}$ for respirable particles, i.e., measured by the isokinetic samplers. Thus, in evaluating the total release rate for both respirable and nonrespirable particles, the atmospheric release-rate estimation for nonrespirable particles is more valid.

Additional assumptions are required for release rate calculations. For respirable particles the average air velocity as a function of height is required in Equation (1). In contrast, for the nonrespirable particles the total release rate could be calculated with either dependent isokinetic inlet data or independent, air impact sampler data (of wind speed).

To date, only nonrespirable total mass fluxes for the highest sampling location were calculated for selected time periods. These correspond to sampling sites and times for which air impact flow samplers were in operation for heights from 0.3 to $15 \mathrm{~m}$. Total nonrespirable particle release rates were calculated in units of $\mathrm{g} /(\mathrm{m}$ width)/day. Release rates are shown in Tables 9 and 10 .

Total airborne mass fluxes of nonrespirable particles were calculated from Equation (2) for two time periods. For these calculations, the integral limit was changed from $1300 \mathrm{~m}$ to $1 \mathrm{~m}$. In addition, total mass fluxes were calculated from ground level up to each sampling height.

Integrated mass fluxes are shown for sampling Sites A, B1, B2, and C in Table 9 for the time period February 21 to March 27, 1978. Mass fluxes for Site A ranged from $0.2 \mathrm{~g} / \mathrm{m} /$ day for heights below $0.3 \mathrm{~m}$ to $5.9 \mathrm{~g} / \mathrm{m} /$ day for heights below $15 \mathrm{~m}$.

Integrated mass fluxes for Sites $\mathrm{B} 1$ and $\mathrm{B} 2$ were significantly greater than background, as was expected. The calculated mass flux at Site 82 , $772 \mathrm{~g} / \mathrm{m} /$ day, was 15 times greater than the mass flux, $50 \mathrm{~g} / \mathrm{m} /$ day, at Site 81 . 
TABLE 9. Average Airborne Mass Flux Per m Width During February 21 to March 27, 1978(a)

\begin{tabular}{|c|c|c|c|c|c|c|c|c|}
\hline \multirow[b]{2}{*}{$\begin{array}{c}\text { Sampling } \\
\text { Height } \\
\mathrm{m} \\
\end{array}$} & \multicolumn{4}{|c|}{ Site B1 } & \multicolumn{2}{|c|}{ Site B2 } & \multicolumn{2}{|c|}{ Site C } \\
\hline & $\begin{array}{l}\text { Accumu- } \\
\text { lative } \\
\mathrm{g} / \mathrm{m} / \text { day }\end{array}$ & $\%$ & $\begin{array}{l}\text { Accumu- } \\
\text { lative } \\
\mathrm{g} / \mathrm{m} / \text { day }\end{array}$ & $\%$ & $\begin{array}{l}\text { Accumu- } \\
\text { lative } \\
\mathrm{g} / \mathrm{m} / \mathrm{day}\end{array}$ & $\%$ & $\begin{array}{l}\text { Accumu- } \\
\text { lative } \\
\mathrm{g} / \mathrm{m} / \text { day } \\
\end{array}$ & $\%$ \\
\hline 0.3 & 0.2 & 3 & 7.1 & 14 & 154 & 20 & 353 & 32 \\
\hline 1.5 & 0.8 & 14 & 17 & 34 & 568 & 74 & 818 & 74 \\
\hline 3 & 1.3 & 22 & 24 & 48 & 720 & 93 & 946 & 85 \\
\hline 4.5 & NA & $x^{2}$ & NA & 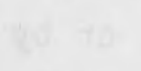 & 742 & 96 & NA & \\
\hline 6 & 2.4 & 41 & 39 & 78 & 753 & 98 & 1033 & 92 \\
\hline 9 & 3.4 & 58 & 47 & 94 & 765 & 99 & 1077 & 96 \\
\hline 12 & 4.6 & 78 & 50 & $100^{(b)}$ & 769 & 100 & 1104 & 99 \\
\hline 15 & 5.9 & $100^{(b)}$ & & & 772 & $100^{(b)}$ & 1117 & $100^{(b)}$ \\
\hline
\end{tabular}

(a) Based on the mass of particles collected on the inlet section of the static samplers.

(b) Maximum sampling height.

TABLE 10. Average Airborne Mass Flux Per m Width During May 26 to June 26, 1978

Accumulative Mass

Sampling Flux to Sampling Height

Height
m

0.3

0.5

4 g/m/day $\%$

1.5

2.1

18

8.6

3

3

4.5

39

169

62

4.5

NA

250

92

6

NA

254

93

9

11.5

100

262 96

273

100 
At Site B2, over $90 \%$ of the flux was below $3-m$ height. A further increase was measured at Site $C$. The total mass flux was $1117 \mathrm{~g} / \mathrm{m} /$ day. In this case, over $90 \%$ of the flux was below $6 \mathrm{~m}$.

Integrated fluxes are shown in Table 10 for May 26 to June 26, 1978. During this time period, mass fluxes were measured at Sites A and B2 for heights up to $9 \mathrm{~m}$. At Site $A$ the integrated flux was $11.5 \mathrm{~g} / \mathrm{m} /$ day. At B2 the flux increased to $273 \mathrm{~g} / \mathrm{m} /$ day. During this second time period, the total integrated mass flux at B2 was less than for the time period shown in Table 9.

The total release rate of nonrespirable particles could be estimated from either data shown in Tables 9 or 10 , or by an average calculation. In either case, the flux, $\mathrm{g} / \mathrm{m} / \mathrm{day}$, must be multiplied by the pile width (1300 $\mathrm{m}$ in the east-west direction) to determine the total release. Using the data in Table 9 for Site $C$, the total release rate is $(1117 \mathrm{~g} / \mathrm{m} /$ day $)(1300 \mathrm{~m})=1.4 \times$ $10^{6} \mathrm{~g} / \mathrm{m} /$ day. If a radionuclide concentration of $100 \mathrm{dpm} / \mathrm{g}$ is assumed for these nonrespirable particles, the radionuclide release rate is $64 \mu \mathrm{C} i /$ day.

Hypothetical radionuclide release rates can also be calculated. In this case, a range of mass fluxes are used to determine the release rate. Average mass fluxes of 1,10 , and $100 \mathrm{~g} / \mathrm{m} /$ day are used in Table 11 . The total release rate was calculated from the product of (mass flux) (10-m sampling height) $(1000 \mathrm{~m})$. An average pile width of $1000 \mathrm{~m}$ was assumed as a correction factor for the wind rose effect.

For the nonrespirable solids, hypothetical release rates ranged from 10 to $1000 \mathrm{~kg} /$ day. The $1000 \mathrm{~kg} /$ day release rate approximates the $1400 \mathrm{~kg} /$ day release rate that was calculated for Table 9. For illustrative purposes, the radionuclide concentration was assumed to range from 500 to $20 \mathrm{dpm} / \mathrm{g}$. In the last column, radionuclide release rates range from 0.4 to $225 \mu \mathrm{Ci} /$ day on nonrespirable particles. Release rates for other mass fluxes and radionuclide concentrations could be calculated from simple ratios using these results.

Hypothetical radionuclide releases on respirable particles were also calculated for assumed conditions. In Table 12 an average wind speed of $10 \mathrm{~m} / \mathrm{sec}$ is used for the calculation. The solids release rate is the product of (wind 
TABLE 11. Calculated Nonrespirable Airborne Radionuclide Release Rates For Assumed Conditions

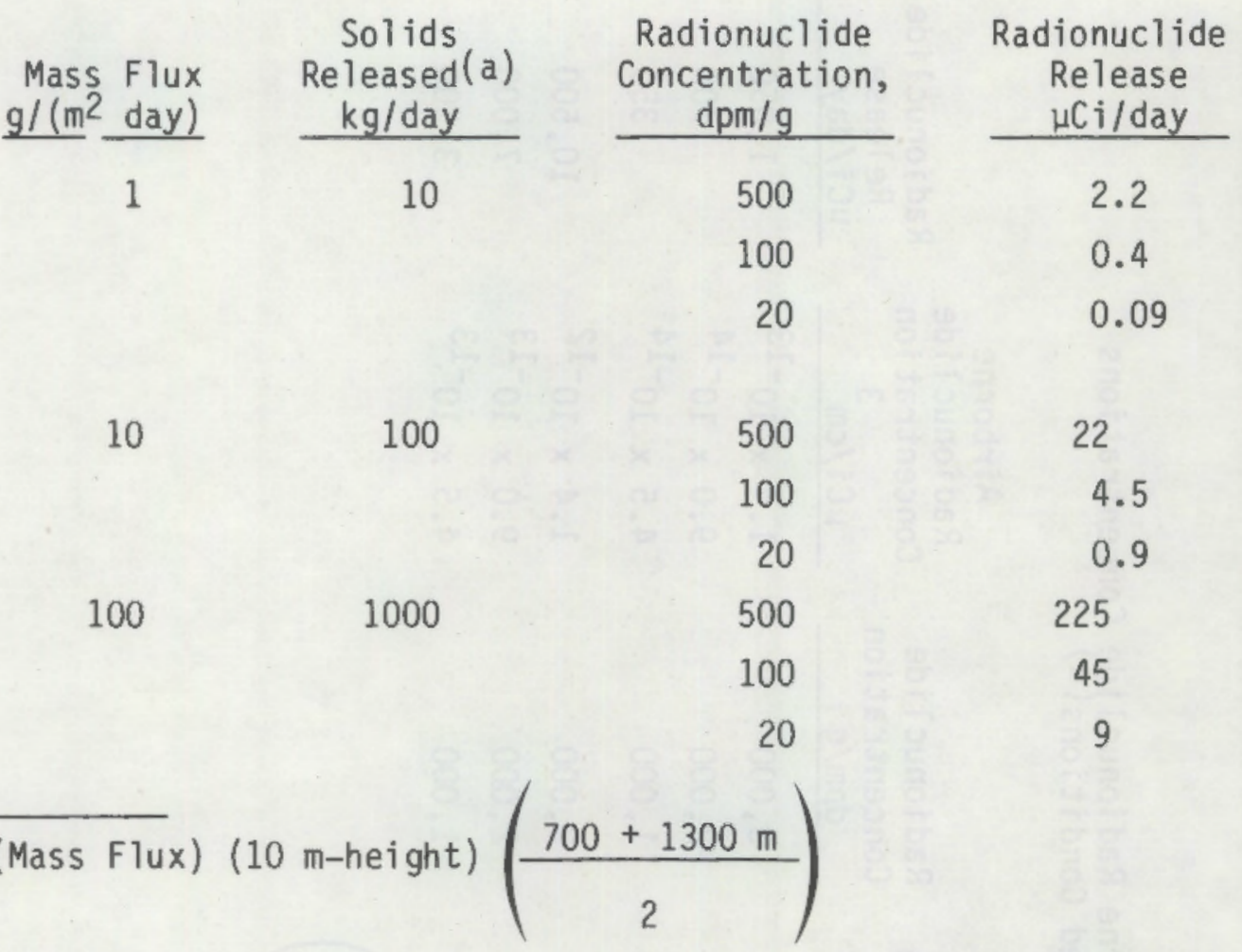

speed) (10-m sampling height) $(1000 \mathrm{~m})$ (solid concentrations, $\left.\mathrm{g} / \mathrm{m}^{3}\right)$. For a range of airborne solids concentrations from $100 \mathrm{~g} / \mathrm{m}^{3}$ to $1 \mathrm{mg} / \mathrm{m}^{3}$, the solids release rate ranged from 10 to $100 \mathrm{~g} /$ day. A range of radionuclide concentration from 20 to $3000 \mathrm{dpm} / \mathrm{g}$ was assumed. Based on these assumptions the airborne radionuclide concentration range from $9 \times 10^{-16}$ to $1.4 \times 10^{-12} \mu \mathrm{Ci} / \mathrm{cm}^{3}$. The experimentally measured airborne radionuclide concentration (see Figures 14 to 17 ) of $10^{-15}$ to $10^{-13} \mu \mathrm{Ci} / \mathrm{cm}^{3}$ are within this range. As shown in the last column, the total radionuclide release rates range from $350 \mu \mathrm{Ci} /$ day to $10 \mu \mathrm{Ci} /$ day.

Based on the hypothetical release rates in Tables 11 and 12, the radionuclide release rate on respirable particles is more significant than the release rate on nonrespirable particles. Nevertheless, there are still unanswered questions. Respirable particles will be transported much further downwind before depositing. Nonrespirable particles will deposit closer to the 
TABLE 12. Calculated Respirable Airborne Radionucljde Concentrations and Release Rates for Assumed Conditions (a)

\begin{tabular}{|c|c|c|c|c|c|}
\hline $\begin{array}{l}\text { Average Wind } \\
\text { Speed, } \mathrm{m} / \mathrm{sec} \\
\end{array}$ & $\begin{array}{c}\text { Airborne Solids } \\
\text { Concentration }\end{array}$ & $\begin{array}{l}\text { Solids (a) } \\
\text { Released } \\
\text { g/day }\end{array}$ & $\begin{array}{l}\text { Radionuclide } \\
\text { Concentration } \\
\text { dpm/g } \\
\end{array}$ & $\begin{array}{c}\text { Airborne } \\
\text { Radionuclide } \\
\text { Concentration } \\
\mu \mathrm{Ci} / \mathrm{cm} \\
\end{array}$ & $\begin{array}{l}\text { Radionuclide } \\
\text { Release } \\
\mu \mathrm{C} i / \text { day } \\
\end{array}$ \\
\hline \multirow[t]{6}{*}{10} & $100 \mu \mathrm{g} / \mathrm{m}^{3}$ & 10 & 3,000 & $1.4 \times 10^{-13}$ & 1,050 \\
\hline & & & 2,000 & $9.0 \times 10^{-14}$ & 700 \\
\hline & & & 1,000 & $4.5 \times 10^{-14}$ & 350 \\
\hline & $1 \mathrm{mg} / \mathrm{m}^{3}$ & 100 & 3,000 & $1.4 \times 10^{-12}$ & 10,500 \\
\hline & & & 2,000 & $9.0 \times 10^{-13}$ & 7,000 \\
\hline & & & 1,000 & $4.5 \times 10^{-13}$ & 3,500 \\
\hline
\end{tabular}

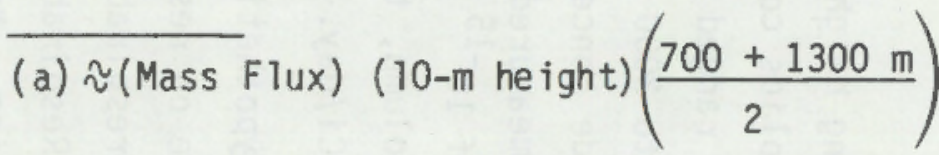


pile; i.e., the ground surface contours (see Figure 18) show nonrespirable particles deposited at least to $5 \mathrm{~km}$. These nonrespirable particles are a potential large area source for releases of respirable particles and radon. The relative release rate of respirable particles from this area source versus the mill tailings pile is yet to be determined. In addition, the total respirable particle release from the mill pile needs better definition. To define this release, sampling equipment is being prepared for placement approximately $200-m$ north of the north fence.

Existing Sites $B 1, B 2$, and $C$ are being moved to this new location. The new Site $C$ will be along the central off-site array of air impact collectors, whereas the new Sites $B 1$ and $B 2$ will be along the west and east sampling arrays of the air impact flow particle collectors. Airborne concentration and flux data from these new sites will yield information concerning the integrated suspension process from all upwind sources. 


\section{ATMOSPHERIC TRANSPORT PREDICTION}

\section{INTRODUCTION}

Applying the preceding experimental data to a different set of conditions requires that data be used to create and verify models of the resuspensiontransport-deposition process. The data that have been collected lend themselves to four model predictions:

1) Suspension. The suspension of particulates from the tailings pile can be modeled as a function of the meteorology and the source distribution. This model can be verified by comparison with the airborne concentrations and fluxes measured at the downwind edge of the tailings pile.

2) Downwind Airborne Concentration. If the fluxes at the downwind edge of the tailings pile are used as the source, the predictions of atmospheric dispersion and deposition models can be compared to measurements of the airborne concentration downwind of the tailings pile.

3) Downwind Deposition. Using the models for suspension, dispersion and deposition developed above, the total suspension and downwind deposition during the entire life of the tailings pile can be predicted by summing over all of the meteorological conditions during the existence of the tailings pile. This prediction can be compared to the measured soil contamination.

4) Resuspension. The soil contamination surrounding the tailings pile is a source for resuspended airborne contamination. Using the measured soil contamination, the resuspended airborne particle concentration can be predicted. This prediction can be compared to measurements of the airborne contamination upwind of the tailings pile, but the resuspended airborne contamination may be less than the detection threshold of the current experimental design.

\section{SITE METEOROLOGICAL DATA}

Atmospheric diffusion and deposition models require meteorological data, as well as data characterizing the contaminant aerosol. The aerosol data have 
been discussed previously. The basic meteorological data requirements are wind speed, wind direction and atmospheric stability. The wind speed determines the downwind dilution of the contaminant; wind direction as a function of time determines the direction of travel, as well as the lateral spread of the contaminant; and atmospheric stability determines the vertical spread of the contaminant. The deposition velocity is also roughly proportional to wind speed because of the dependence of atmospheric turbulence on wind speed.

Meteorological data are required for two time scales. For model predictions 1), 2) and 4), data is required for the specific days and hours during which the aerosol samples are collected. For model predictions 3) and 4), an annual frequency distribution of wind speed, wind direction and atmospheric stability is necessary to estimate annual-averaged deposition and resuspension.

The meteorological data available for the mill site are limited. The mill owners have recorded wind speed, wind direction and precipitation from May 21, 1977 to the present. Fortunately, this data is concurrent with the aerosol sampling. However, the period of data recording is shorter than the five years that is usually desired for determining a diffusion climatology, i.e., the past year of data may not be representative of the meteorology during the lifetime of the tailings pile. The frequency distribution of wind direction is shown in Figure 50 for all wind speeds and in Figure 51 for winds greater than or equal to $6 \mathrm{~m} / \mathrm{sec}$. The higher wind speeds occur for winds from SSE and from WSW to WNW.

Another source of meteorological data are the weather observations routinely recorded for the National Weather Service, commonly at airports. The closest airport reporting to the National weather Service is at Milan, NM, and the only readily available data is for the period May 1953 to December 1954. Unfortunately, the Milan airport is located in a "valley" bounded by a $600-\mathrm{ft}$ mesa to the northeast and a mountain ridge rising over $1000 \mathrm{ft}$ to the southwest. Consequently, as seen in Figure 50, the airport winds are predominantly from NW and SE and are distributed quite differently than the mill site winds. The wind speed distributions for the mill site and the airport are also quite different. 


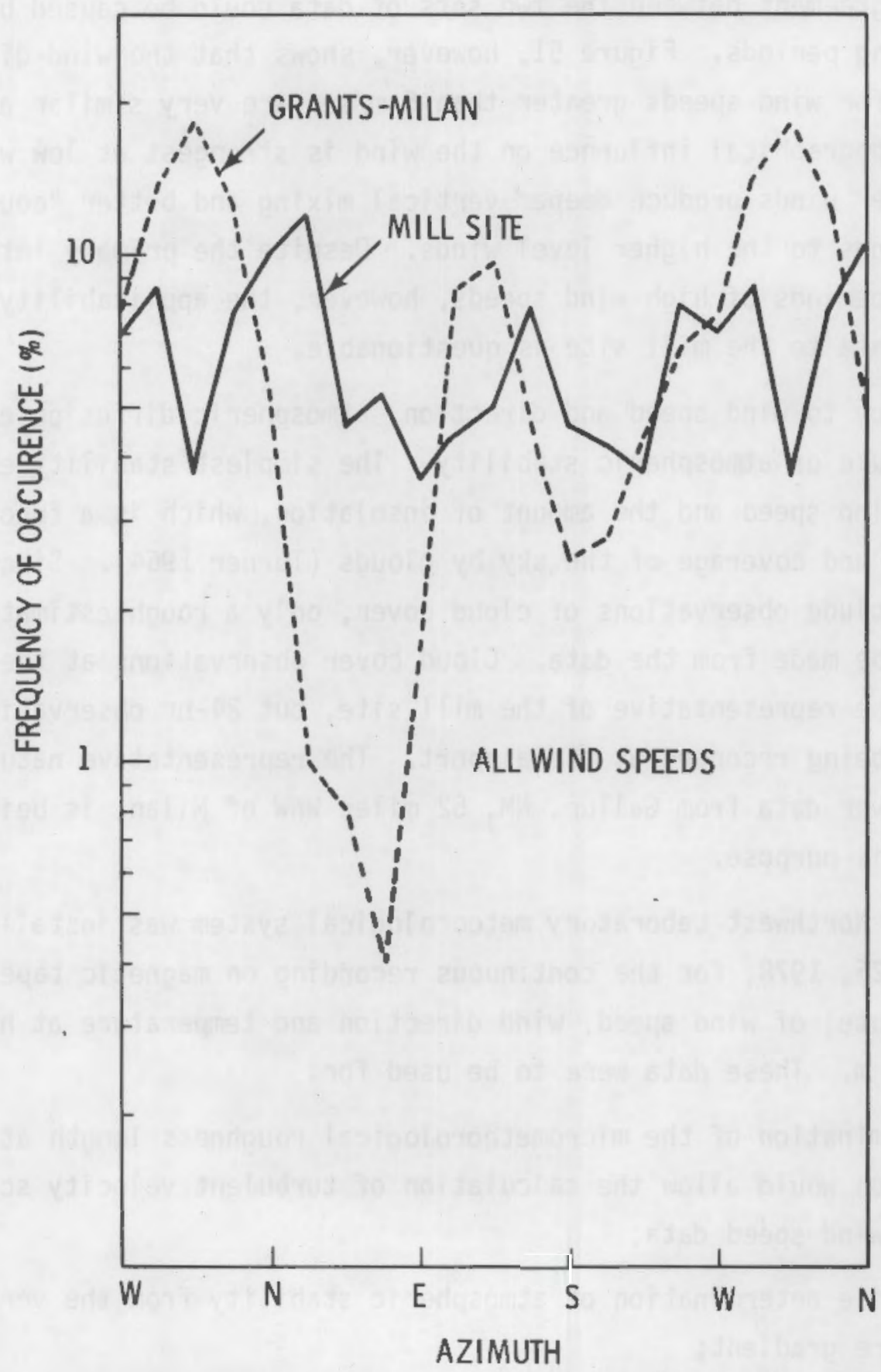

FIGURE 50. Annual Distribution of Wind Direction at Two Sites in New Mexico

A topographical influence would also be expected for most other locations in northwestern New Mexico, making National Weather Service wind data inapplicable to the mill site. 
This disagreement between the two sets of data could be caused by the different recording periods. Figure 51, however, shows that the wind-direction distributions for wind speeds greater than $6 \mathrm{~m} / \mathrm{sec}$ are very similar at the two sites. The topographical influence on the wind is strongest at low wind speeds; stronger winds produce deeper vertical mixing and better "coupling" of the surface winds to the higher level winds. Despite the primary interest of this study in periods of high wind speeds, however, the applicability of the airport wind data to the mill site is questionable.

In addition to wind speed and direction, atmospheric diffusion estimates require a measure of atmospheric stability. The simplest stability estimates are based on wind speed and the amount of insolation, which is a function of solar altitude and coverage of the sky by clouds (Turner 1964). Since the mill data do not include observations of cloud cover, only a rough estimate of stability may be made from the data. Cloud cover observations at the Milan airport would be representative of the mill site, but $24-\mathrm{hr}$ observations are not presently being recorded at the airport. The representative nature of 24-hr cloud cover data from Gallup, NM, 52 miles WNW of Milan, is being investigated for this purpose.

A Pacific Northwest Laboratory meteorological system was installed at Site A on May 25, 1978, for the continuous recording on magnetic tape (one sample per minute) of wind speed, wind direction and temperature at heights of $10 \mathrm{~m}$ and $2-1 / 2 \mathrm{~m}$. These data were to be used for:

- The determination of the micrometeorological roughness length at the mill site, which would allow the calculation of turbulent velocity scale $u_{*}$ from the wind speed data;

- more precise determination of atmospheric stability from the vertical temperature gradient;

- direct measurement of the lateral wind fluctuations that determine the crosswind atmospheric diffusion.

The system was in operation from May until September 1978, but data recovery has been unsatisfactory. Available data are currently being analyzed. 


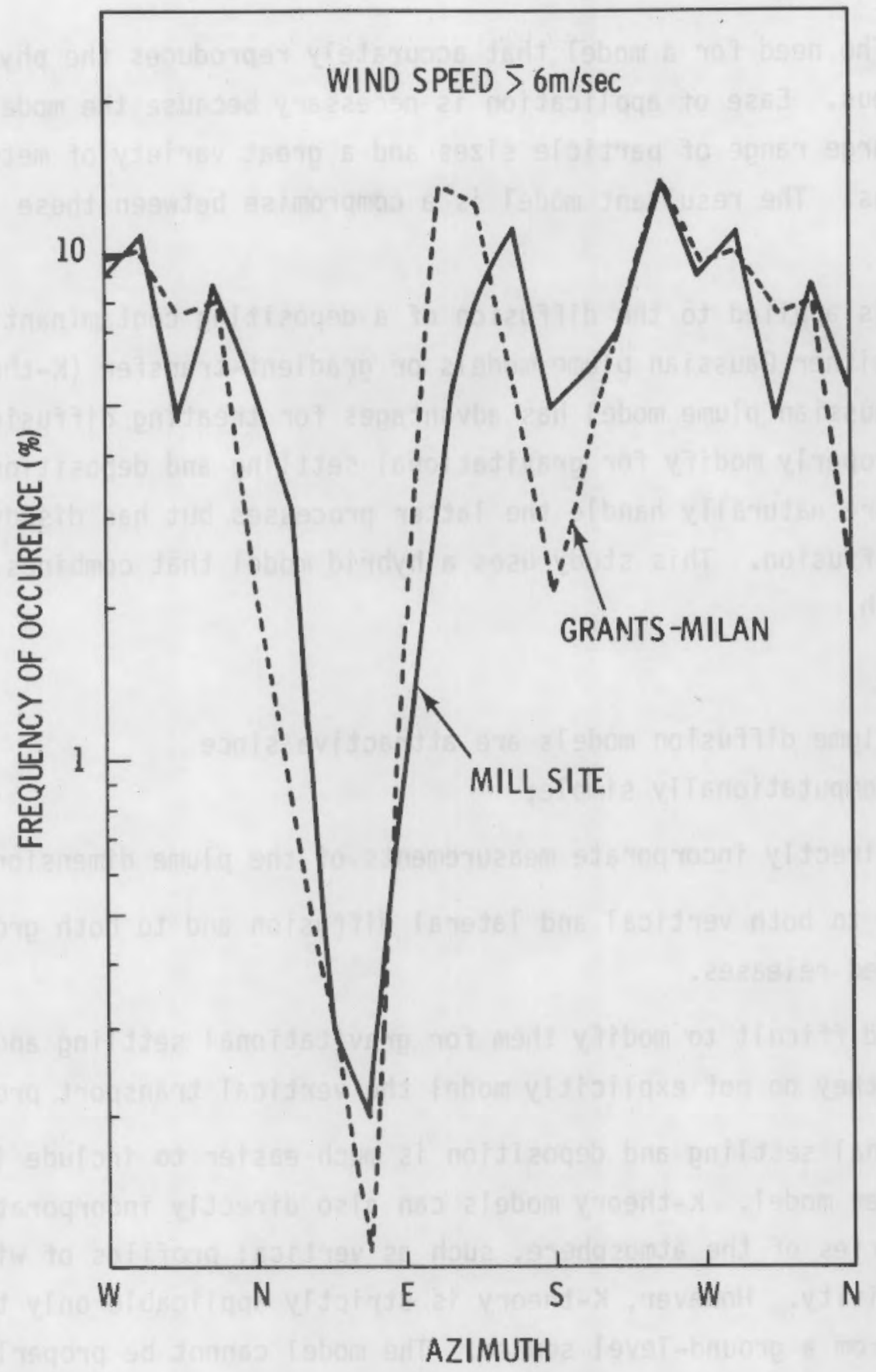

FIGURE 51. Annual Distribution of Wind Direction for High Wind Speeds at Two Sites in New Mexico

\section{DIFFUSION-DEPOSITION-RESUSPENSION MODELS}

Two considerations have influenced the choice of the atmospheric transport and deposition model to be used in this study: accuracy and ease of 
application. The need for a model that accurately reproduces the physical processes is obvious. Ease of application is necessary because the model must be applied to a large range of particle sizes and a great variety of meteorological situations. The resultant model is a compromise between these two requirements.

Most models applied to the diffusion of a depositing contaminant can be classified as either Gaussian plume models or gradient-transfer (K-theory) models. The Gaussian plume model has advantages for treating diffusion but is difficult to properly modify for gravitational settling and deposition. K-theory can more naturally handle the latter processes but has disadvantages for modeling diffusion. This study uses a hybrid model that combines the best features of both.

\section{Diffusion Model}

Gaussian plume diffusion models are attractive since

- they are computationally simple;

- they can directly incorporate measurements of the plume dimensions;

- they apply to both vertical and lateral diffusion and to both ground-level and elevated releases.

However, it is difficult to modify them for gravitational settling and deposition because they do not explicitly model the vertical transport process.

Gravitational settling and deposition is much easier to include in a gradient-transfer model. K-theory models can also directly incorporate physical properties of the atmosphere, such as vertical profiles of wind speed and eddy diffusivity. However, K-theory is strictly applicable only to vertical diffusion from a ground-level source. The model cannot be properly applied to lateral diffusion or to vertical diffusion in the vicinity of an elevated source. Further, a realistic vertical distribution of wind speed and eddy diffusivity usually requires a numerical solution of the equations.

The Gaussian plume diffusion model was chosen for this study. It is no less accurate than a $\mathrm{K}$-theory model and is computationally much simpler. Except for the largest particles, atmospheric transport is dominated by 
diffusion rather than settling and deposition. Thus, some approximation is permissible when including the latter processes in the Gaussian plume model.

The basic form of the diffusion model for a point source of contamination at height $h$ is

$C_{0}(x, y, z)=\frac{Q_{0} e^{-y^{2} / 2 \sigma_{y}^{2}}}{2 \pi u \sigma_{y} \sigma_{z}} \cdot\left\{\exp \left[-(h-z)^{2} / 2 \sigma z^{2}\right]+\exp \left[-(h+z)^{2} / 2 \sigma_{z}^{2}\right]\right\}$

$c_{0}$ is the airborne contamination (mass/volume) at a height $z$ and at a distance $x$ downwind and $y$ crosswind of the source, and $Q_{0}$ is the rate of contaminant emission (mass/time). The mean wind speed $u$ is determined at a height $h$ or $0.53 \sigma_{z}$, whichever is greater. The vertical spread of the plume $\sigma_{z}$ is a function of downwind distance and atmospheric stability and is either determined from empirical graphs, such as the Pasquill-Gifford curves, or may be calculated from Lagrangian similarity theory. The lateral spread of the plume $\sigma_{y}$ may also be determined from empirical curves or may be calculated from Taylor's statistical theory.

Equation (3) is appropriate for a short period during which the mean wind direction is relatively constant. However, mill tailings aerosol samples are collected over many hours during which the wind blows from different directions. When the range of possible directions $\Delta \theta$ is greater than $\sigma_{y} / x$, $C_{0}(x, \Delta \theta, z)$ is found by integrating (3) in the crosswind direction and assuming that the distribution of wind directions is uniform within the sector $\Delta \theta$ :

$C_{0}(x, \Delta \theta, z)=\sqrt{2 \pi} u \Delta \theta x \sigma_{z}^{Q_{0}}\left\{\exp \left[-(h-z)^{2} / 2 \sigma_{z}^{2}\right]+\exp \left[-(h+z)^{2} / 2 \sigma_{z}^{2}\right]\right\}$

Deposition Model For Nonsettling Particles

Aerosol particle sizes may be divided into two categories that depend on the relative contributions of gravitational settling and turbulent diffusion to vertical atmospheric transport. For nonsettling particles, those smaller 
than approximately $10-\mu m$ radius, settling may be neglected compared to diffusion. Respirable particles fall into this category.

For nonsettling particles the most accurate correction of the Gaussian plume model for deposition is the surface depletion model of Horst (1977). However, a hybrid source depletion model (Horst 1978) will be used here that compares quite well to the surface depletion model, but is computationally much less expensive. This latter model accounts for the loss of airborne contamination caused by deposition by reducing the source strength $Q$ as a function of downwind distance. A second correction is applied to account for the change in the vertical distribution caused by deposition.

If the reduction of $Q$ with $x$ is equated to the crosswind-integrated deposition loss, then:

$$
\frac{d Q(x)}{d x}=-v_{d}\left(z_{\star}\right) \bar{c}^{y}\left(x, z_{\star}\right)
$$

Here the vertical deposition flux is equal to the deposition velocity $v_{d}$ multiplied by the crosswind-integrated airborne contamination at the deposition reference height $z_{\star}$ and

$$
C^{-y}\left(x, z_{\star}\right)=Q(x) \bar{D}^{y}\left(x, z_{\star}\right) P\left(x, z_{\star}\right)
$$

where

$$
\bar{D}^{y}(x, z)=\sqrt{2 \pi u \sigma_{z}}\left\{\exp \left[-(h-z)^{2} / 2 \sigma_{z}^{2}\right]+\exp \left[-(h+z)^{2} / 2 \sigma_{z}^{2}\right]\right\} .
$$

An equation for $Q(x)$ is found by substituting (6) into (5),

$$
Q(x)=Q_{0} \exp \left\{-\int_{0}^{x} v_{d}\left(z_{\star}\right) \bar{D}^{y}\left(x^{\prime}, z_{\star}\right) P\left(x^{\prime}, z_{\star}\right) d x^{\prime}\right\}
$$


$P(x, z)$ accounts for the vertical gradient of airborne contamination caused by deposition. Without deposition the airborne contamination at ground level is independent of height. In order to approximate $P(x, z)$, it will be assumed that this is true at all heights, i.e., $\bar{D}^{y} \simeq(u \Delta z)^{-1}$ where $\Delta z$ is a mixing depth. For $\sigma_{z} / h \gg 1$ this approximation is exact at ground level if $\Delta z=\sqrt{\pi / 2} \dot{\sigma}_{z}$.

Thus

$$
\bar{C}^{y}(x, z) \simeq \frac{Q(x)}{u \Delta z} \quad P(x, z)
$$

and conservation of mass requires that

$$
\frac{1}{\Delta z} \int_{0}^{\Delta z} P(x, z) d z=1
$$

With $\bar{D}^{y}$ independent of height, gradient-transfer theory predicts that deposition produces a vertical distribution equal to

$$
\tau^{y}(x, z)=\tau^{y}\left(x, z_{\star}\right)\left\{1+v_{d} \quad \int_{z^{\star}}^{z} \frac{d z^{-}}{K\left(z^{\prime}\right)}\right\},
$$

where $K(z)$ is the vertical eddy diffusivity. Combining (9), (10) and (11) gives

$$
P\left(x, z_{\star}\right) \simeq\left\{\frac{1}{\Delta z} \int_{0}^{\Delta z}\left[1+v_{d} \int_{z^{\star}}^{z} \frac{d z^{-}}{K(z)}\right] d z\right\}^{-1} .
$$

Horst (1978) has compared the surface depletion model to the prediction of (6), (8) and (12) with $\Delta z=\sqrt{\pi / 2} \sigma_{z}$. For $\sigma_{z} / h \approx 1$, where most of the deposition occurs, the latter model compares very well with the surface depletion model and is a marked improvement on the uncorrected source depletion model $(P=1)$. 


\section{Deposition Model for Settling Particles}

A rigorous modification of the Gaussian plume diffusion model to account for gravitational settling has not been found. A common alteration, which will also be used in this study, is to replace the source height in (3) or (4) by:

$$
h^{\prime}=h-v_{s} x / u
$$

where $v_{s}$ is the particle settling velocity. This model conserves mass and is probably a reasonable approximation for:

$$
v_{s} x / \text { uh }<1
$$

The depletion of the plume caused by deposition is again modeled by (6) and (8). Equations (11) and (12) are modified to account for gravitational sett1ing by replacing the quantity $1+v_{d} I$ with:

$$
1-\frac{v_{d} v_{s}}{v_{s}}\left(1-e^{-v_{s} I}\right)
$$

where

$$
I=\int_{z^{\star}}^{z} \frac{d z^{\prime}}{K(z)}
$$

A model based completely on gradient-transfer theory would probably account more accurately for gravitational settling. However, this extension of the hybrid, nonsettling particle model will be used here for consistency and computational simplicity. The accuracy of this model is not known. A comparison with a gradient-transfer model would be worthwhile if large particles are important to this study.

Suspension/Resuspension Mode 1

The airborne contamination caused by the suspension of surface contaminants is calculated by simply integrating the point-source diffusion formulas over the source area. $Q$ is replaced by the vertical flux of contaminant at 
the surface multiplied by the differential area element, i.e., $F_{v} d x d y$. The vertical suspension flux is discussed in a previous section of this report, but one example of a suspension model is

$$
F_{v}=\Lambda G
$$

where $G$ is the amount of surface contamination per unit area and $\Lambda$ is a resuspension rate, the fraction of $G$ suspended per unit time.

If a model for the suspension flux is not available, the airborne contamination downwind of the tailings pile may be estimated from measurements of the horizontal flux of suspended contamination at the downwind edge of the pile. The downwind airborne contamination is then calculated by integrating the point source formulas over the area of the vertical plane containing the horizontal suspension flux. $Q$ is replaced by $F_{H}$ dydz, where $F_{H}$ is the horizontal flux in the downwind direction.

Suspension sources with a limited horizontal extent, such as the mill tailings pile, may be treated as point sources at downwind distances greater than several times their horizontal dimensions. Comparison of annual-averaged area source and point source calculations for the tailings pile $(500 \mathrm{~m} \times$ $1150 \mathrm{~m}$ ) show that a point source approximation is adequate at distances greater than $3000 \mathrm{~m}$ from the center of the pile. Closer to the pile, the actual spatial distribution of the source must be used for greatest accuracy.

\section{MODEL APPLICATIONS}

Since the suspension source term is still being developed from the aerosol data, model calculations to date have only been made for a unit source. These calculations show the dependence of the airborne contamination and deposition on particle size, wind speed, and source height, as well as the expected annual-average distribution based on the local diffusion climatology.

Figure 52 shows the crosswind-integrated ground-level airborne contamination as a function of downwind distance and particle radius. These calculations use the deposition velocities of Sehmel and Hodgson (1974) and $\sigma_{z}$ 


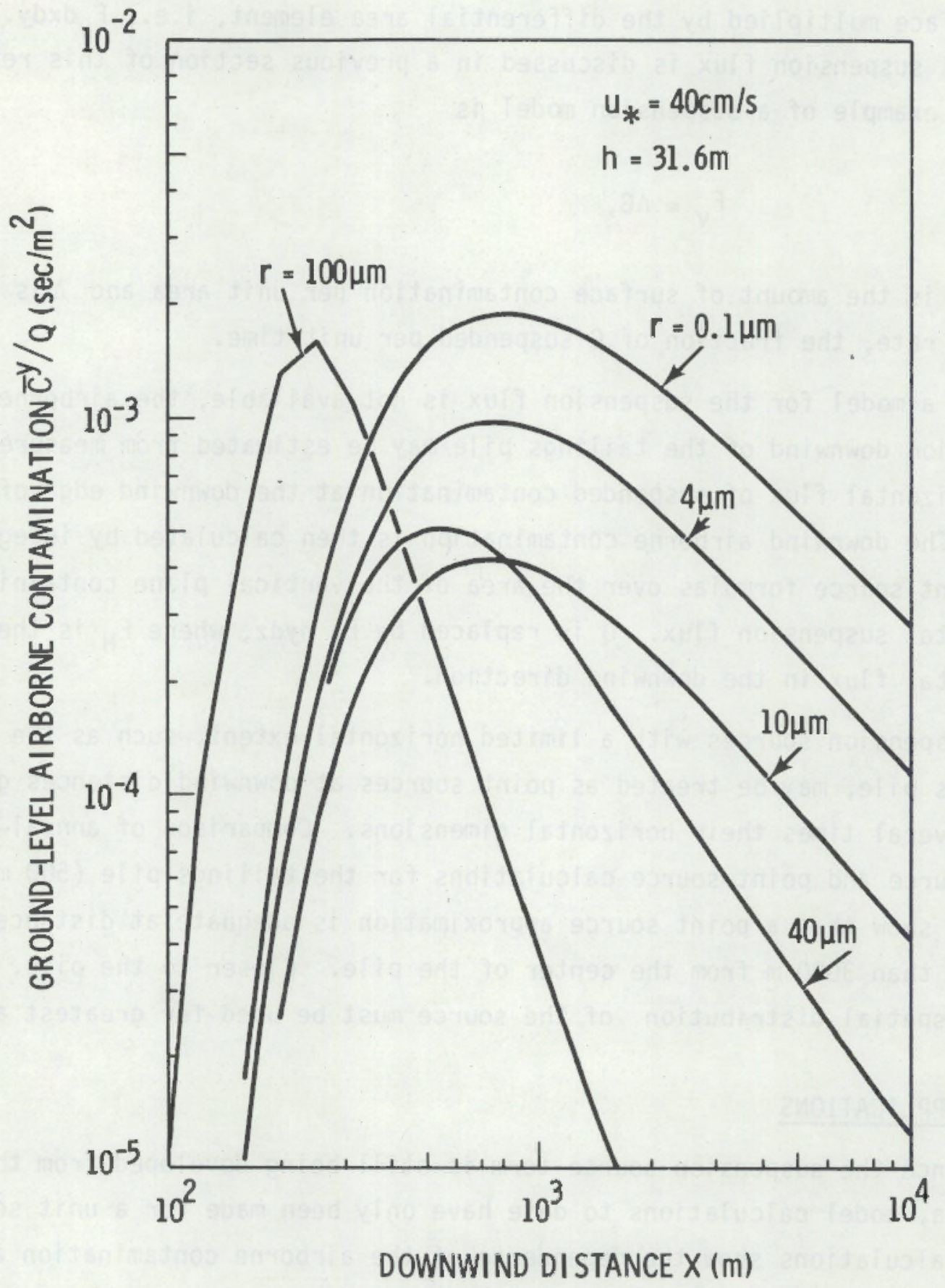

FIGURE 52. The Dependence of Airborne Contamination on Particle Size

values based on Lagrangian similarity theory (Chaudhry and Meroney 1973). For the nonsettling particles, $r<10 \mu \mathrm{m}, \bar{c}^{\mathrm{y}} / \mathrm{Q}$ generally decreases with increasing particle size and increasing deposition velocity as a result of 
depletion of the airborne plume $\left(\bar{C}^{y} / Q\right.$ for $r=0.01 \mu \mathrm{m}$ and $1 \mu \mathrm{m}$ are close to that for $r=0.1 \mu \mathrm{m}$.) The settling particles, $r>10 \mu \mathrm{m}$, order similarly at large distances, but the maximum concentration increases with particle size and occurs closer to the source as a result of settling of the plume.

Figure 53 shows the effect of source height on $\bar{c}^{y} / Q$. As source height increases, the peak values decrease and occur further from the source because the contaminant takes longer to diffuse or settle to ground level and hence is more dilute. Beyond their peak values, the curves for nondepositing particles would merge. At large downwind distances, the curves for $r=10 \mu \mathrm{m}$ decrease with decreasing source height, corresponding to greater deposition caused by larger ground-level concentrations and contact with the ground at shorter distances. Even greater separation occurs for the $r=100 \mu \mathrm{m}$ curves because of the dominance of gravitational settling.

Figure 54 shows the effect of friction velocity or wind speed on $u_{\star} \bar{c}^{y} / Q$. The friction velocity $u_{\star}$ is a measure of the turbulent mixing and is related to the wind speed by the drag coefficient,

$$
u_{\star}=c_{d}^{\frac{1}{2}} u
$$

For neutral atmospheric stability and for wind speed measured at $10 \mathrm{~m}, C_{d}^{\frac{1}{2}}=0.06$ and $u_{\star}=40 \mathrm{~cm} / \mathrm{sec}$ corresponds to $u=6.6 \mathrm{~m} / \mathrm{sec}$. For nondepositing particles, $u_{\star} \bar{c}^{y} / Q$ is independent of $u_{\star}$ and hence the separation of the curves in Figure 54 is caused by deposition. The deposition velocity of nonsettling particles, e.g. $r=10 \mu \mathrm{m}$, increases with $u_{\star}$ and the curves for $u_{\star} \bar{C}^{\mathrm{y}} / Q$ correspondingly decrease with increasing $u_{\star}$. The deposition velocity of settling particles, e.g. $r=100 \mu \mathrm{m}$, is insensitive to $u_{\star}$ but the downwind distance at which the plume centerline intersects the ground, $u h / v_{s}$, is directly proportional to $u_{*}$. Thus, for settling particles the peak concentration decreases and occurs at a greater downwind distance as $u_{\star}$ increases.

Figures 52,53 and 54 show the sensitivity of the diffusion-deposition model to changes in selected model parameters when the rest of the parameters 


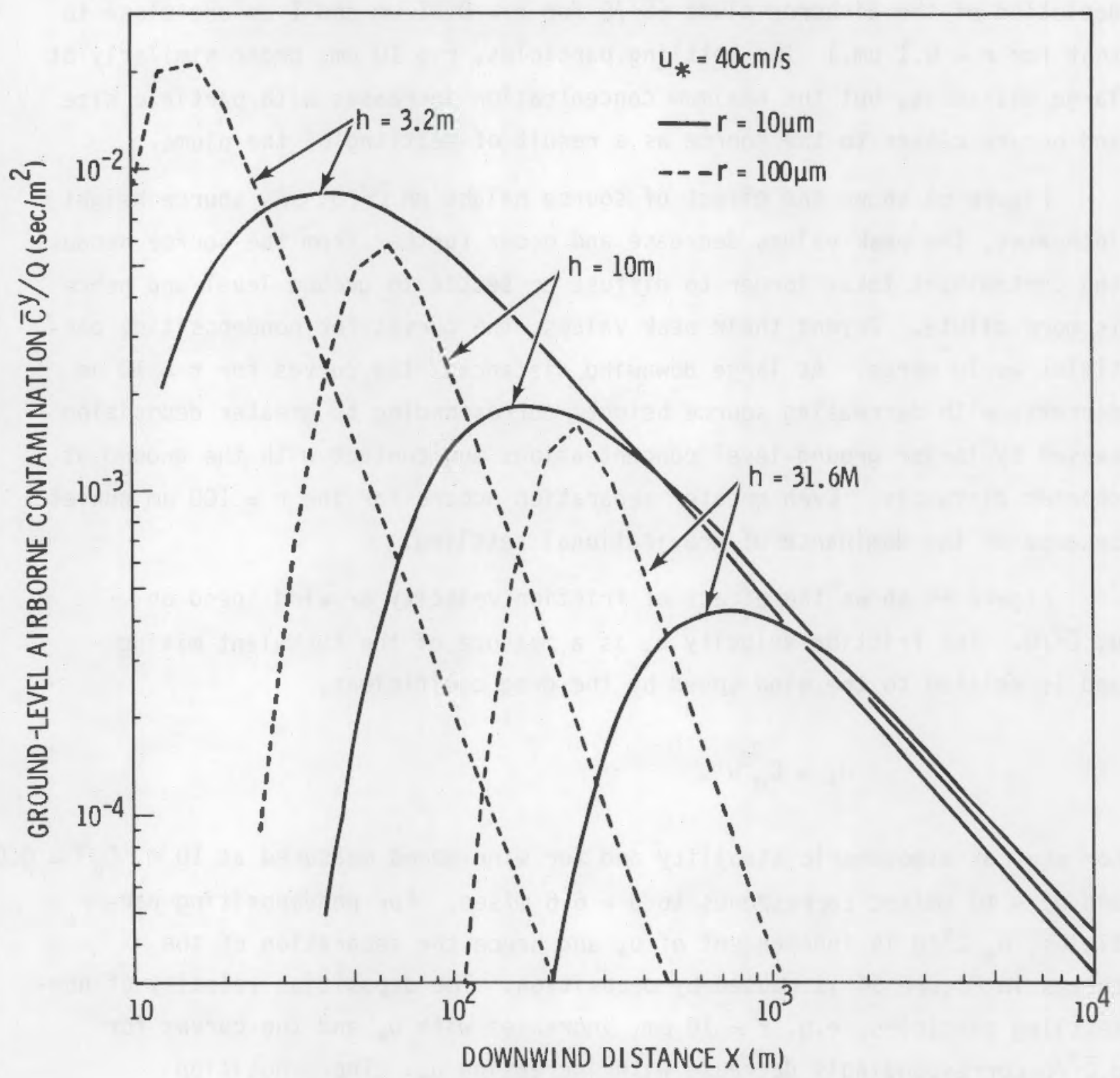

FIGURE 53. The Dependence of Airborne Contamination on Source Height

are held constant. Figure 55 shows the annual-average airborne contamination that results from summing over the distribution of wind speed, wind direction and atmospheric stability found at the mill site. The azimuthal distribution 


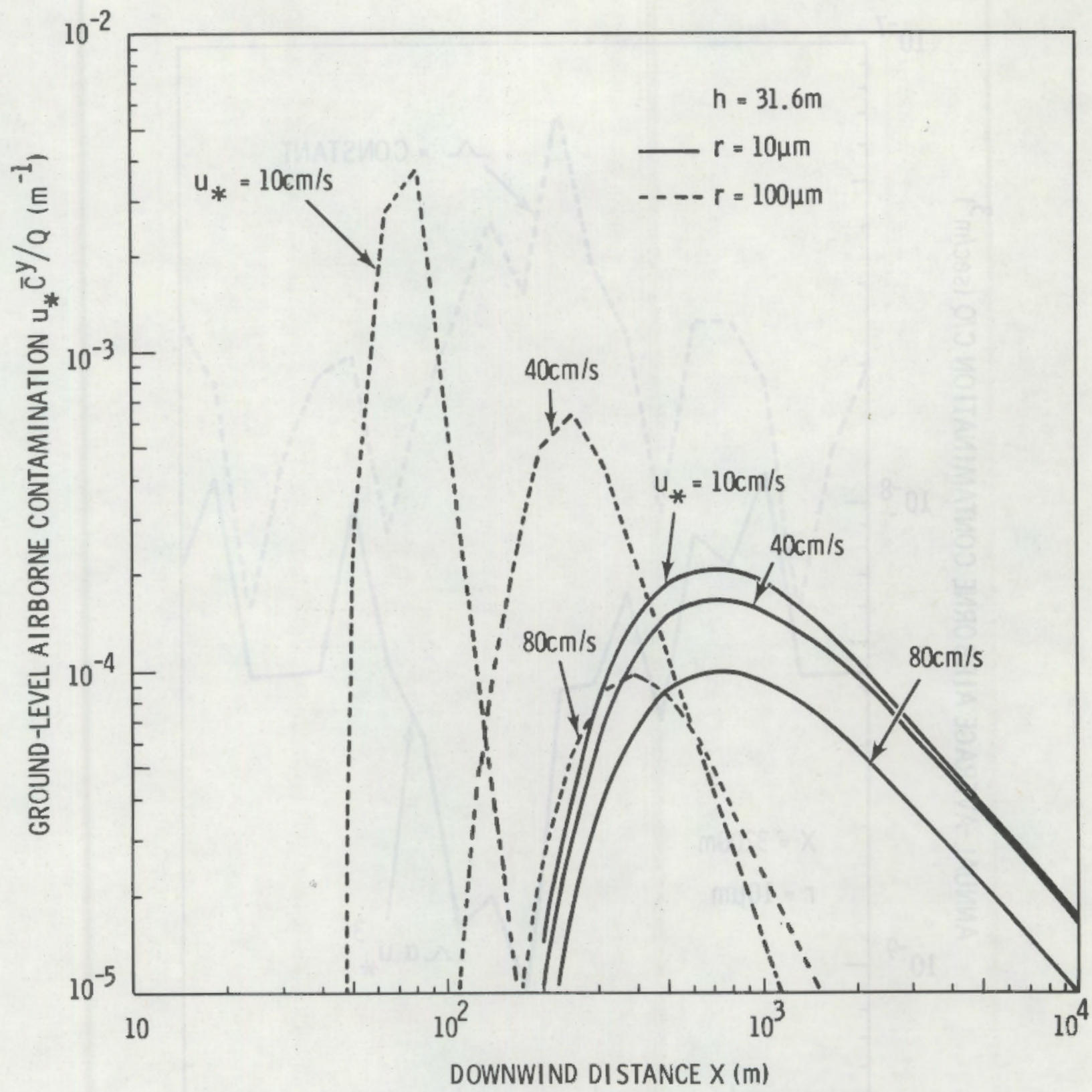

FIGURE 54. The Dependence of Airborne Contamination on Friction Velocity

of $\mathrm{C} / \mathrm{Q}$ for $10-\mu \mathrm{m}$ particles is shown at a distance of $3200 \mathrm{~m}$ from the tailings pile. The upper curve assumes that the source is independent of the wind speed and has a maximum value to the SSW. This corresponds to a high frequency of drainage winds from the NNE (see Figure 50) that are slow, occur at 


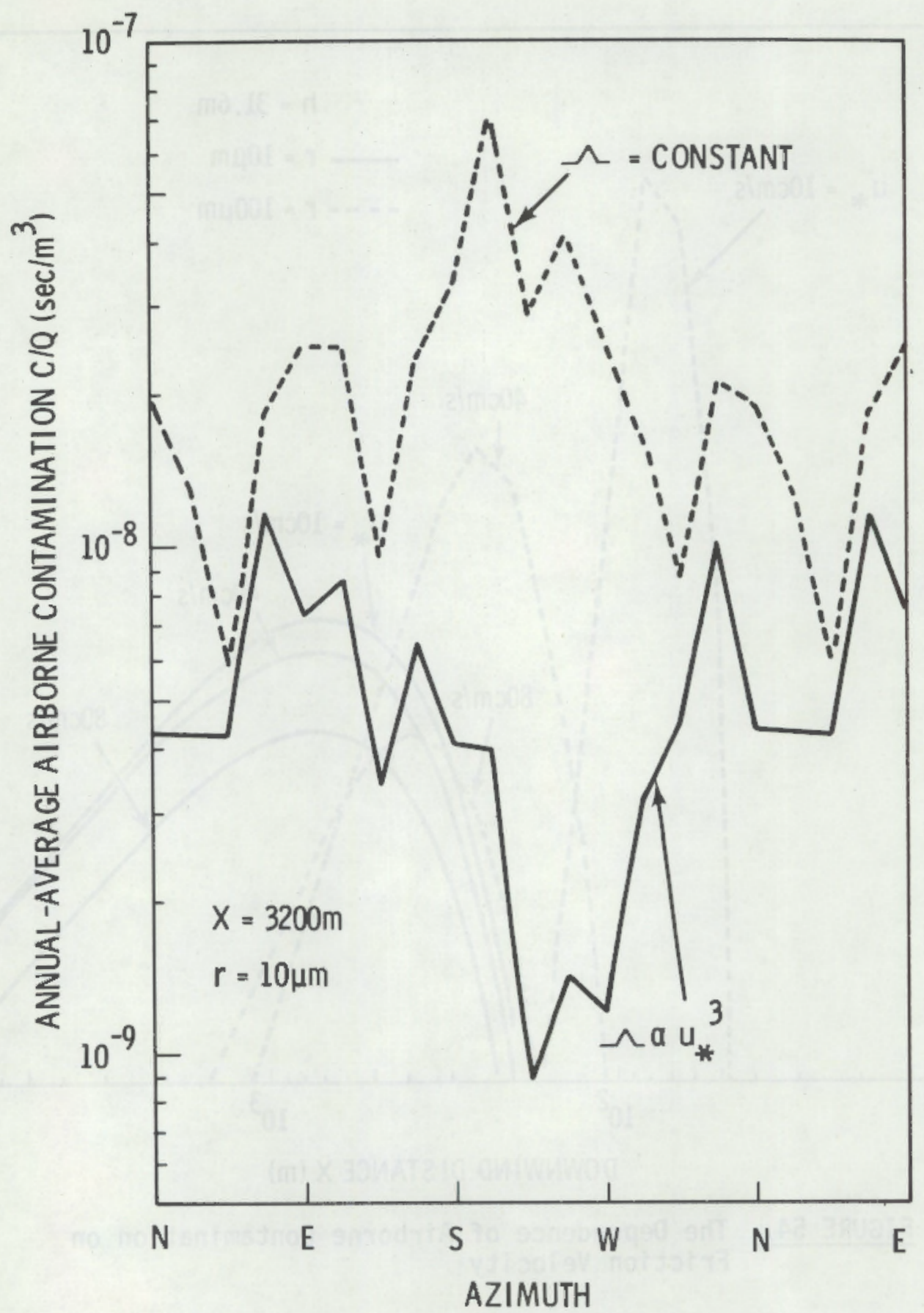

FIGURE 55. The Dependence of the Azimuthal Distribution of Airborne Contamination on Resuspension Rate.

night, and hence produce small dispersion. The lower curve assumes a suspension source proportional to $u_{*}^{3}$ and gives a radically different distribution. Peak concentrations to the NNW and ENE correspond to high winds that 
occur predominantly from SSE and WSW (Figure 51) and the entire curve is lower because the higher wind speeds produce greater contaminant dispersion.

These sample calculations have shown the capability of the diffusiondeposition model to reproduce the expected features of the atmospheric transport process. As the measurements on the tailings pile are used to develop a realistic source term as a function of location, particle size and meteorology, this model will be tested against the off-pile measurements of airborne and surface contamination. 



\section{REFERENCES}

Chaudhry, F.H., and R. N. Meroney. 1973. "Similarity Theory of Diffusion and the Observed Vertical Spread in the Diabatic Surface-Layer." Boundary Layer Met. $3,405-415$.

Code of Federal Regulations. 1977. 10 CFR 20, Appendix B, pp. 165-168. office of Federal Register, Washington, D.C. 20402.

Horst, T. W. 1977. "A Surface Depletion Model for Deposition from a Gaussian Plume." Atmospheric Environment. 11, 35-40.

Horst, T. W. 1979. "A Simple Correction to the Source Depletion Model." In Pacific Northwest Laboratory Annual Report for 1978 to the DOE Assistant Secretary for Environment, Part 3, Atmospheric Sciences. PNL-2850, Part 3, Pac ific Northwest Laboratory, Richland, WA 99352.

Mills, M. T., R. C. Dahlman, and J. S. 01son. 1974. Ground Level Concentrations of Dust Particles Downwind from a Tailings Area During a Typical Windstorm. ORNL-TM-4375, Oak Ridge National Laboratory, Oak Ridge, TN 37830.

Sears, M. B., R. E. Blanco, R. C. Dahlman, G. S. Hil1, D. D. Ryan and J. P. Witherspoon. 1975. Correlation of Radioactive Waste Treatment Costs and the Environmental Impact of Waste Effluents in the Nuclear Fuel Cycle for Use in Establishing "As Low as Practicable" Guides -- Milling of Uranium Ore. ORNL-TM-4903, Vol. 1, Oak Ridge National Laboratory, Oak Ridge, TN 37830.

Sehme1, G. A., and W. H. Hodgson. 1976. "Predicted Dry Deposition Velocities." In Proceedings of Atmosphere-Surface Exchange of Particulate and Gaseous Pollutants Symposium, Richland, WA, pp. 399-419. NTIS-CONF-740921.

Turner, D. B. 1964. "A Diffusion Model for an Urban Area." J. Appl. Met. $\underline{3}, 83-91$. 
APPENDIX A

METHODS OF SAMPLING AND INSTRUMENTAL TECHNIQUE FOR THE MEASUREMENT OF URANIUM AND URANIUM DAUGHTERS 


\section{METHODS OF SAMPLING AND INSTRUMENTAL TECHNIQUE FOR THE}

\section{MEASUREMENT OF URANIUM AND URANIUM DAUGHTERS}

The 5-cm core samples were taken by using a specially designed coring device. This device is constructed of stainless steel and contains four tracks positioned $1 / 2 \mathrm{~cm}, 1 \mathrm{~cm}, 2 \mathrm{~cm}$, and $5 \mathrm{~cm}$ from the top of the device (see Figure A.1). By driving the coring device into the ground and digging away at each end, a stainless stee 1 blade can be forced along each track to reach the desired sampling depth. The deeper cores were obtained by digging a trench and inserting a stainless steel flat scoop with $5-\mathrm{cm}$ high walls. The large area sample was obtained by scraping a $1 \mathrm{~m}^{2}$ section to a depth of $1 \mathrm{~cm}$.

The measurement of uranium and daughter radionuclides for each sample was obtained by first preparing a perfectly flat homogeneously mixed pellet. Fifteen grams of the sample matrix was homogenized with two grams of cellulose binder and formed under 30 tons of pressure into a 1/4-in. $\times 2$-in. pellet in a pressing chamber. The pellet was then placed in Saran wrap and analyzed with a high-resolution intrinsic germanium diode that measured the concentration of ${ }^{238} \mathrm{U},{ }^{235} \mathrm{U}$, and uranium daughters. (Uranium-238 is actually determined from analysis of its ${ }^{234}$ Th daughter; therefore, one must be certain that the parent-daughter equilibrium exists in making this measurement.)

The following table lists the radionuclides, photon energies, and the abundance of each of these photons.

TABLE A.1. Radionuclides, Photon Energies, and Abundance of Photons

$\begin{array}{lccc}\frac{\text { Radionuclide }}{226_{\mathrm{Ra}}} & & \text { Photon Energies (keV) } & \text { \% Abundance } \\ 214_{\mathrm{Pb}} & 186 & 4.0 \\ 235_{\mathrm{U}} & 295 & 18.9 \\ 210_{\mathrm{Pb}} & 205 & 5.0 \\ 230_{\mathrm{Th}} & 47 & 4.0 \\ { }^{227} \mathrm{Th} & 67 & 0.4 \\ { }^{234} \mathrm{Th}\left({ }^{238} \mathrm{U}\right) & 236 & 10.4 \\ & 63 & 5.7\end{array}$




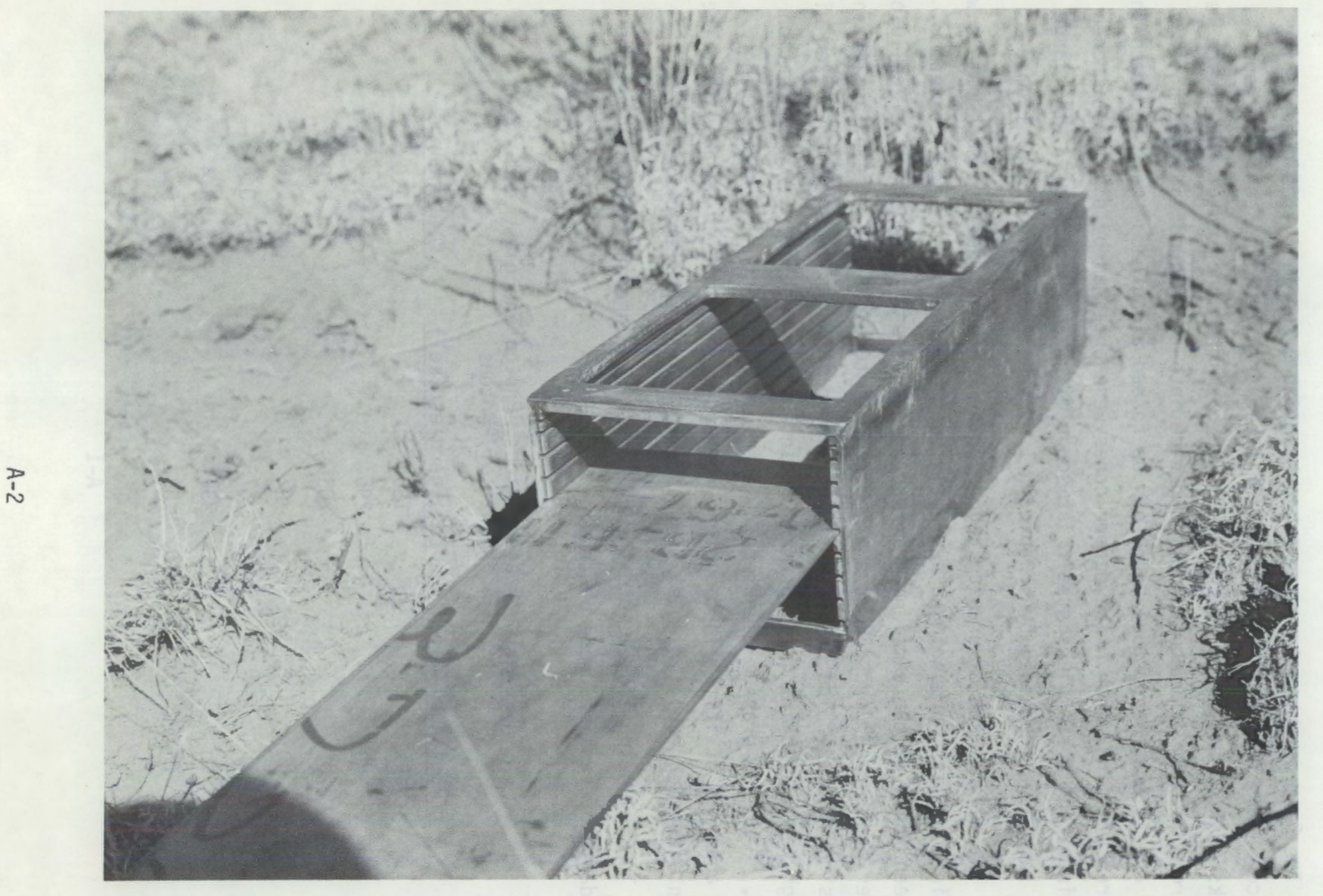

FIGURE A-1. Coring Device for Five-Centimeter Core Samples

NEG. $775832-27$ 
APPENDIX B

BRIEF CHRONOLOGY OF FIELD STUDY 


\section{BRIEF CHRONOLOGY OF FIELD STUDY}

October 24 to 26,1976

Visit to mills A, B and C near Milan, New Mexico. Tailings sand and seepage water collected for measurements. A few high-volume samples obtained at mi11 A site and at Grants.

July 27 to August 10,1977

Site preparation, erection of sampling arrays at mill A tailings pile. Site A controller determined to have sustained some damage requiring return to vendor. As an interim measure, first sampling was initiated with a wind direction only controller (all winds were sampled).

August 10 to September 8,1977

First sampling run carried out. Powered samplers were operated during the times when wind was blowing from the sector $181^{\circ}$ to $214^{\circ}$. During this period, samplers were not truly isokinetic due to sampling at all wind speeds. Sampler inlets remained open during the sampling run.

September 20 to October 4, 1977

Experiment 2 under conditions of Run 1 above. Run was initiated with double filters on high-volume samplers, but plugging permitted only a short run. Filters were replaced and third run started.

September 20 to October 24, 1977

Experiment 3 run. Conditions the same as in first run, but some samples were lost.

November 10 to December 8, 1977

Experiment 4. Solenoid-activated closures were installed on all electrically-powered samplers. The controller that activated selected samplers as a function of wind speed and direction was installed and used during this period. 
February 21 to March 27,1978

Experiment 5. Additional static impact samplers were installed on the north bank of the tailings pile and in the rangeland area. Sierra cascade impactors were located at four rangeland locations. Three additional static impactor samplers installed at Site $\mathrm{A}$ and two at tower B2.

March 30 to April 19, 1978

Experiment 6. The same sampling system was operated as in Experiment 5. Some north bank samplers were lost north of the tailings pile.

May 26 to June 16,1978

Experiment 7. Sierra cascade impactors and high-volume isokinetic samplers at sites A, B2 and in the rangeland.

May 26 to June 26,1978

Experiment 8. Static cascade impactors only at Site A, B2, north bank, north fence, and rangeland samplers.

June 13 to August 7,1978

Experiment 9, consisting of high-volume samplers at Sites A, B2, north fence, and rangeland locations. Sierra cascade impactors operated at Sites A, B2, rangeland Nos. 1, 2, 3, and 4, with static sampler at the north fence. August 9, 1978 to January 15, 1979

Improvements in design and reconstruction of samplers and control systems. New sampling array defined with emphasis on characterizing particle sizes and flux at a finite distance downwind of the tailings pile. 


\section{DISTR IBUTION}

No. of

Copies

DFFSITE

A. A. Churm

DOE Patent Division

9800 So. Cass Avenue

Argonne, IL 60439

225 U.S. Nuclear Regulatory Commiss ion

Division of Technical Information and Document Control

7920 Norfolk Avenue

Bethesda, MD 20014

\section{NTIS}

\section{DOE Technical Information Center}

6 Office of Nuclear Regulatory Research

Division of Safeguards, Fuel Cycle and Environmental Research

J. J. Davis

H. H. Landon (5)

Office of Nuclear Material Safety and Safeguards

Division of Fuel Cycle and Material Safety

Fuel Reprocessing and Recycle Branch

U.S. Nuclear Regulatory Commission

Washington, DC 20555

H. J. Miller

\section{ONSITE}

37 Pacific Northwest Laboratory
L. C. Schwendiman (20) 2-4227
R. W. Perkins
C. W. Thomas
G. A. Sehmel
R. K. Woodruff
F. D. Lloyd
G. B. Long
Technical Information
Publishing Coordination (2) 
